$$
\begin{aligned}
& \text { Fernando } \\
& \text { Peinado Miguel } \\
& \text { (Coordinador) }
\end{aligned}
$$

\title{
Formación, perfil profesional y consumo de medios de los alumnos en Comunicación
}

\author{
Prólogo de Bernardo Díaz Nosty
}

Cuadernos Artesanos de Comunicación / 77
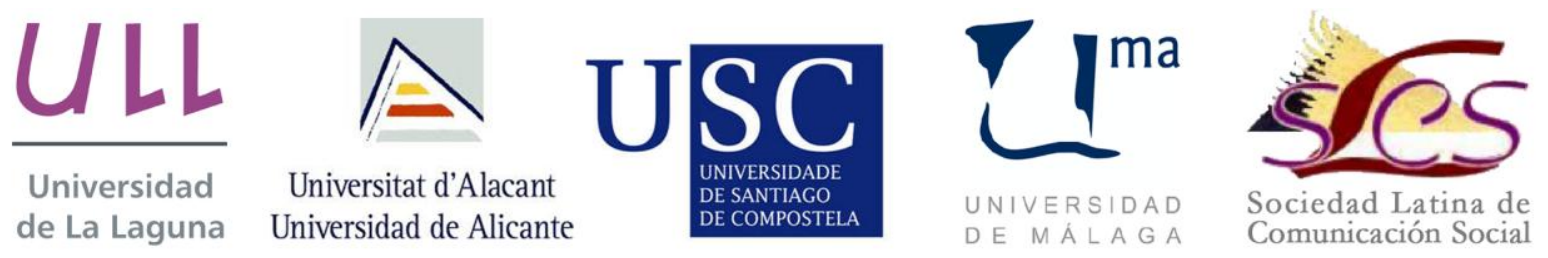
Cuadernos Artesanos de Comunicación - Comité Científico

Presidencia: José Luis Piñuel Raigada (UCM)

Secretaría: Concha Mateos (URJC)

- Bernardo Díaz Nosty (Universidad de Málaga, UMA)

- Carlos Elías (Universidad Carlos III de Madrid, UC3M)

- Javier Marzal (Universidad Jaume I, UJI)

- José Luis González Esteban (Universitas Miguel Hernández de

Elche, UMH)

- José Luis Terrón (Universidad Autónoma de Barcelona, UAB)

- José Miguel Túñez (Universidad de Santiago, USC)

- Juan José Igartua (Universidad de Salamanca, USAL)

- Julio Montero (Universidad Complutense de Madrid, UCM)

- Marisa Humanes (Universidad Rey Juan Carlos, URJC)

- Miguel Vicente (Universidad de Valladolid, UVA)

- Miquel Rodrigo Alsina (Universidad Pompeu Fabra, UPF)

- Núria Almiron (Universidad Pompeu Fabra, UPF)

- Ramón Reig (Universidad de Sevilla, US)

- Ramón Zallo (Universidad del País Vasco, UPV-EHU)

- Victoria Tur (Universidad de Alicante, UA)

* Queda expresamente autorizada la reproducción total o parcial de los textos publicados en este libro, en cualquier formato o soporte imaginables, salvo por explícita voluntad en contra del autor o autora o en caso de ediciones con ánimo de lucro. Las publicaciones donde se incluyan textos de esta publicación serán ediciones no comerciales y han de estar igualmente acogidas a Creative Commons. Harán constar esta licencia y el carácter no venal de la publicación.

* La responsabilidad de cada texto es de su autor o autora. 
Fernando Peinado Miguel (Coordinador)

Prólogo de Bernardo Díaz Nosty

\section{Formación, perfil profesional y consumo de medios de alumnos en Comunicación}

Cuadernos Artesanos de Comunicación / 77

ULL

Universidad de La Laguna

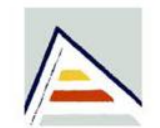

Universitat d'Alacant Universidad de Alicante
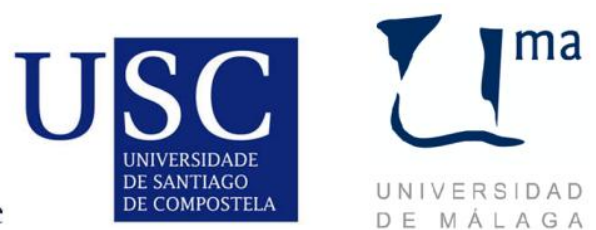

UNIVERSIDAD DE MÁLAGA

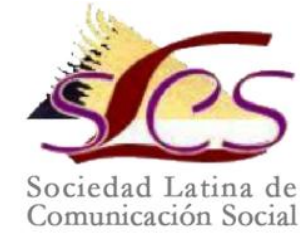


$\mathrm{CAC} 77^{\circ}$ - Formación, perfil profesional y consumo de medios de alumnos en Comunicación

\section{Coordinador: Fernando Peinado Miguel}

| Precio social: 7,95€ | Precio en librería: 10,35€ |

Editores: Javier Herrero y Alberto Ardèvol Abreu

Diseño: F. Drago

Ilustración de portada: Fragmento del cuadro Playa de Fuerteventura, de Guido Kolitscher (Austria - La Gomera).

Imprime y distribuye: F. Drago. Andocopias S. L.

c/ La Hornera, 41. La Laguna. Tenerife.

Teléfono: 922250554 | fotocopiasdrago@,telefonica.net

Edita: Sociedad Latina de Comunicación Social - edición no venal - La Laguna (Tenerife), 2015 - Creative Commons (http://www.revistalatinacs.org/09/Sociedad/estatutos.html)

Catálogo: http://www.cuadernosartesanos.org

Protocolo de envío de manuscritos con destino a CAC:

http://www.revistalatinacs.org/068/cuadernos/protocolo.html

Descargar $p d f$ :

http://www.cuadernosartesanos.org/\#77

ISBN - 13: 978-84-15698-94-4

DL: TF-78-2015

DOI: $\underline{10.4185 / \mathrm{cac} 77}$ 


\title{
Formación, perfil profesional y consumo de medios de alumnos en Comunicación
}

\begin{abstract}
El origen de este libro es la colaboración entre tres grupos de investigación: Research and Learning of Media and Communications Management (MediaCom UCM) http://www.ccinf.es/mediacom/; el GICID Grupo de Investigación en Comunicación e Información Digital (https://gestiona.unizar.es/webvrinv/datosgrupo.jsp?num grupo=1 45) y el Observatorio para el ocio y el entretenimiento digital, http://www.ocendi.com/ con líneas de investigación interesadas en la formación de los futuros profesionales de la Información y de la Comunicación; en la adecuación de las competencias adquiridas en los grados específicos al perfil de la demanda profesional en el mercado de la comunicación; y en el perfil como consumidores de productos de ocio y medios de los estudiantes en Comunicación.

Estas propuestas de mejora y conexión de la formación, la profesión y el dominio científico se tratan, en este Cuaderno Artesano de la Comunicación, desde perspectivas nacionales (con autores de siete universidades españolas) e internacionales, con las aportaciones de autores de dos universidades mexicanas, de Ecuador y de Suiza.
\end{abstract}

Keywords

Perfiles profesionales; Consumo de medios; Formación;

Comunicación; Radio.

\section{Forma de citar este libro}

Autor del capítulo (2015): "Título del capítulo", en Formación, perfil profesional y consumo de medios de alumnos en Comunicación, Fernando Peinado Miguel (Coord.). Cuadernos Artesanos de Comunicación, 77. La Laguna (Tenerife): Latina. 


\section{Índice}

Prólogo "Debilidades que debieran corregirse", por

Bernardo Díaz Nosty..........................................9

Formación

1. Cómo perciben los nuevos Grados en Comunicación los futuros periodistas de la UCM y de la UNIZAR. Carmen Marta Lazo; Miguel Á. Ortiz Sobrino y Fernando Peinado...................13

1. Consecuencia de una investigación conjunta

2. Manos a la obra: los objetivos, el método y el marco contextual.

3. Qué hemos sacado en claro. Los resultados

4 Conclusiones

2. Formación y vinculación académica de estudiantes en la radio universitaria de México. Marina Vázquez Guerrero.........23

1. Introducción

2. Los programas afines a la comunicación

3. Radios Universitarias

4. La radio que enseña

5. Estudiantil en la radio

6. Metodología

7. Resultados

8. Discusión

3. Indicadores para la evaluación de la alfabetización transmedia en los estudios universitarios de Comunicación.

María del Mar Grandío Pérez.....................................35

1. Introducción

2. Reflexión teórica: perspectivas sobre la transalfabetización

3. Propuesta de definición para alfabetización transmedia

4. Propuesta de dimensiones e indicadores

5. Conclusiones

4. Competencias mediáticas en el sur de Ecuador. Diana Rivera; Andrea Velásquez; Isidro Marín; Catalina Mier y Stephany Celly..............................................4

1. Introducción: Competencias y educomunicación

2. Materiales y métodos

3. Discusión y conclusiones

Perfiles profesionales

5. Qué requiere un estudiante de Periodismo para su mejor inserción en el mercado laboral. Miguel Ángel Ortiz Sobrino; Fernando Peinado Miguel y Lelia Zapata Palacios...................51 
1. Introducción

2. Estado de la cuestión

3. Metodología

4. Análisis y resultados

5. Conclusiones

6. Las radios universitarias en España: Equipos de trabajo, participación y función social. Daniel Martín Pena y Ana Segura

Anaya..............................................71

1. Introducción

2. Los colaboradores de las emisoras universitarias

2.1 Estudiantes y jóvenes que sí participan

2.2 El perfil de los colaboradores externos

3. Los alumnos de Ciencias de la Información

4. Colaboradores en las emisoras de la ARU

5. Conclusiones

7. Nuevos perfiles formativos del periodista multimedia

Pilar Sánchez-García

1. Introducción

2. El debate abierto de los nuevos roles profesionales

3. Del gatekeeper al curator, pasando por el periodista orquesta

4. Una propuesta revisionista de cuatro perfiles formativos

5. A modo de conclusión

8. El estudiante de Ciencias de la Comunicación de la UANL:

Consumo, perfil y aspiraciones. Laura Lizeth Campos Guido y

Juan Antonio Garza Sánchez..................................93

1. Introducción

2. Metodología y muestra

3. Resultados

3.1 Hábitos de consumo mediático

3.2 Educación y aspiraciones profesionales

3.3 La preferencia en la TV de Monterrey

4. Conclusiones

9. Perfil profesional que demandan las empresas periodísticas a la Universidad. María José Pérez Serrano, María Dolores Rodríguez Barba y Miriam Rodríguez Pallares..............................105

1. Introducción

2. Un escenario complejo. Esperanzador desde el emprendimiento

3. La Metodología y los límites de investigación para esta fase

4. Análisis y resultados en esta fase de la investigación

4.1 El mercado laboral

4.2 La distribución geográfica

4.3 Las condiciones de contratación 
5. A modo de conclusiones

\section{Consumo de medios}

10. La radio generalista española, ¿pensada para los jóvenes de hoy? Nereida López Vidales y Leire Gómez-Rubio................119

1. La radio generalista en España y el consumo juvenil el 2014

2. La programación de las grandes cadenas generalistas de radio

3. Los formatos programáticos de la radio, descripción y análisis

4. Radio generalista: una oferta acomodada y sin novedades

5. El Magazine: un híbrido convencional para adultos

6. Ideas para la reflexión

11. Jóvenes y ficción radiofónica. Terror y adaptaciones como apuesta segura para la ficción en Radio Nacional

Marta Hernando Lera.

1. Introducción

2. Metodología

3. La ficción radiofónica en España

4. Necesidades y preferencias de los jóvenes españoles

5. La ficción radiofónica en la actualidad

5.1 Primeros resultados del análisis comparativo

5.2 Estudio de caso: Ficción Sonora de RNE

5.3 Adaptaciones literarias. Análisis y características

$5.4 \mathrm{El}$ radioteatro

6. Conclusiones

12. ¿Cómo medir la intermetodología? Creación del

Cuestionario de Impacto Intermetodológico

Elisa Hergueta Covacho...

1. Introducción

2. Intermetodología

2.1 El Factor Relacional como eje intermetodológico

3. Educación 2.0. Elaboración del cuestionario

3.1 Dinámicas intermetodológicas

3.2 Elaboración del cuestionario

3.3 Aplicación del cuestionario. Resultados

4. Conclusiones

Bibliografía

Autores. 


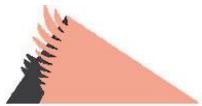 \\ Prólogo \\ Debilidades que debieran corregirse}

Bernardo Díaz Nosty, Catedrático de Periodismo de la Universidad de Málaga

$\mathrm{E}$ N EL ESCENARIO cultural iberoamericano se da, sin duda, la mayor concentración del mundo en centros académicos dedicados a la formación en Comunicación. Es lo que, en el ámbito específico de España, definimos como "burbuja académica", cuyos efectos sobre actividades como el periodismo, por ejemplo, han contribuido a la precarización profesional. Esta realidad, muy deficitaria respecto de los referentes que marcan las bases de la dignidad laboral, está asociada a la degradación de la imagen pública de los comunicadores, castigada además, en algunas naciones de habla hispana y portuguesa, por la facilidad con la que se mata al mensajero y la impunidad con la que se resuelven muchos de estos crímenes.

¿Por qué tantos jóvenes, sin embargo, se sienten atraídos por los estudios de comunicación? Probablemente, las encuestas convengan en expresar un argumento racionalizado de ese magnetismo, en el que primen los valores de la creatividad, pero no debiera descartarse, al menos como hipótesis, un efecto llamada durante los años previos a su ingreso en la Universidad. Efecto que estaría determinado por la experiencia personal en las gratificaciones propias del consumo de los viejos y nuevos medios, y, tal vez, en la percepción de que los estudios aparecen como un esfuerzo en el aprendizaje de un 
conocimiento que, en muchos casos, se pueden ver cercano al ocio. Es fácil entender que nuestros programas disten de la complejidad e, incluso, del rigor con el que se imparten otras disciplinas universitarias.

Es cierto que los estudios, especialmente cuando no alcanzan el nivel académico deseable, están salpicados de complementos y rellenos que no siempre contribuyen a darles el mejor sentido universitario. Factores de difícil corrección cuando los centros formativos se han multiplicado en las últimas décadas sin que previamente existiese un profesorado acreditado y competente. El problema no es estrictamente local. Hace muchos años, cuando la URSS se hallaba en fase de disolución, en una Universidad de Moscú escuché que los estudiantes de medicina y derecho llamaban a la Facultad de Comunicación la Tantsoushchitsy Fakul'tet, o la Facultad del Baile, con una sesgada percepción que no se diferenciaba mucho de otras algo más benévolas en entornos cercanos.

Una anécdota mucho más reciente, que solo debe entenderse como una anécdota, aunque literal en su descripción, nos sitúa ante un profesor joven, muy apreciable en su producción científica, con artículos en revistas JCR y acreditaciones, que, probablemente víctima de un sistema errático e injusto, demuestra su más absoluta ignorancia cuando en un examen hace, entre otras demandas del conocimiento impartido, preguntas como las que siguen:

«El Medievo a menudo se conoce como la "Edad Oscura"; ¿Cómo afectó a las Ciencias de la Comunicación? (Respuestas: 1.- Apenas se avanzó en las Ciencias de la Comunicación durante ese periodo de tiempo. 2.- La élite hizo un mal uso del conocimiento de las Ciencias de la Comunicación para mantener el poder sobre las masas. 3.- Las Ciencias de la Comunicación tuvieron que ser practicadas en secreto.)»

«Los periódicos renacentistas eran, en muchos sentidos, un medio de élite. La siguiente respuesta es falsa: 1.- La mayoría cubrían noticias extranjeras y políticas "a secas". 2.- Los ciudadanos de a pie tenían prohibido leer periódicos. 3.- El precio era alto.» 
Como se puede apreciar, parece que la escasa credibilidad del periodismo, por ejemplo, se corresponde también con una invención de las Ciencias de la Comunicación y de los periódicos muchos siglos antes de su propio tiempo histórico.

Otra de las aberraciones que impregnan el tiempo de formación consiste en la magnificación acrítica de lo tecnológico, anteponiendo la vertiente admirativa de las nuevas herramientas a su valor de uso, la matriz comercial de las mismas o su contribución al reforzamiento del discurso hegemónico. La ignorancia se suple con el manual de usuario...

La formación densa que debe atribuir el perfil de los comunicadores $y$, en general, de los universitarios, en un tiempo de especial complejidad, no se compadece con muchas de las opciones en presencia, cuyas debilidades no se deben tanto a malos planes de estudios o desconexión entre el mundo académico y la realidad, sino a formadores mal formados, que el sistema evalúa por el número de sus piruetas en congresos, publicaciones, proyectos, y no tanto por su capacidad real de producir y transmitir conocimiento...

La ausencia de estímulos de debate, de creación de juicio propio entre quienes van a proveer nutrientes a la sociedad, o de desarrollo de simples estímulos de mejora de la llamada cultura general, así como la ausencia generalizada de sustratos éticos, crean, con frecuencia, las condiciones de la tormenta perfecta.

La Universidad se aleja del objetivo de excelencia, un valor retórico que, sin embargo, hoy está más próximo en las potencialidades de aprendizaje que surgen de los propios mitos en los que se funda la sociedad de la información y el conocimiento.

La debilidad de nuestra estructura formativa se advierte en lo que podríamos llamar el relativismo de alta frecuencia. Es decir, la rapidez con la que introducimos términos de vida efímera en nuestro discurso académico o adaptamos los enunciados de nuestras disciplinas a los fenómenos de moda comercial o tecnológica. Esa debilidad estructural permite que sedimenten pensamientos mal estructurados y que la narración académica y la práctica investigadora aplique su 
esfuerzo, en muchas ocasiones, sobre soluciones de inutilidad creativa o propositiva.

Tal vez, si diferenciásemos entre la formación profesional de calidad y la dimensión académica que da amplitud argumental al pensamiento y justifica la investigación, saldríamos del tótum revolútum en el que se entremezclan esfuerzos y se destilan debilidades. Predominan en nuestro espacio de conocimiento, en ese contenedor que todo lo abarca de la comunicación, soluciones epistemológicas que rayan en el terreno de las ocurrencias, cuando no se amparan en pequeños guetos disciplinares donde se cultivan los minifundios del saber.

No se trata de hacer una crítica sin alternativa, condenando de modo generalizado lo que se ha hecho, sino de tomar conciencia del papel de las llamadas Ciencias de la Comunicación en la presente crisis de valores. ¿Han contribuido nuestra lectura acrítica del fenómeno central de la comunicación a desarmar a la sociedad frente a la prevalencia de soluciones intervenidas, ajenas a las que describe la cultura democrática y dan argumento institucional al Estado de derecho? Palabras graves, tal vez, para referir la responsabilidad de quienes hemos dejado la formación en valores, en nuestro caso estrechamente relacionados con las libertades públicas, en manos de aquellos que aportan retazos de discursos que solo son extensiones de las modas y de las propuestas del mercado, y por ello tienen un valor parcial y sesgado.

Magnificación de lo tecnológico, cultivo de la moda efímera, superficialidad, abandono de las raíces éticas y del entronque de la comunicación en la cultura democrática, son, entre otras, las debilidades más notables en la fase formativa de los comunicadores, en ese desdoblamiento ambiguo y contradictorio donde conviven periodistas y comunicadores, informadores y voceadores de bienes y servicios, compradores y vendedores. Curiosamente, con tan escaso compromiso, que hasta el atributo "ciudadano" aparece como un valor de innovación... 


\section{Cómo perciben los nuevos grados en Comunicación los futuros periodistas de la UCM y de la UNIZAR}

Carmen Marta Lazo (Universidad de Zaragoza) orcid.org/0000-0002-0004-1094 http://scholar.google.es/citations?user=vxisuH0AAAAJ\&hl=es

Miguel Ángel Ortiz Sobrino (Universidad Complutense Madrid) http:// orcid.org/0000-0003-0103-9524 http:// scholar.google.es/citations?user=3OCGQs4AAAAJ\&hl=es

Fernando Peinado Miguel (Universidad Complutense de Madrid) http://orcid.org/0000-0003-0048-4562

http://scholar.google.es/citations?user=wel7hwUAAAAJ\&hl=es

\section{Consecuencia de una investigación conjunta}

$\mathrm{D}$ URANTE EL CURSO 2014/2015 el Grupo de Investigación Research and Learning of Media and Communications Management/ Investigación y enseñanza de la Gestión de los Medios y de la Comunicación, de la Universidad Complutense de Madrid (MediaCom UCM) http://www.ccinf.es/mediacom/ y el Grupo de Investigación en Comunicación e Información Digital GICID, de la Universidad de Zaragoza, llevaron a cabo una investigación cuyo objetivo era determinar el nivel de satisfacción y expectativas de 
entrada y salida de los estudiantes de Periodismo en el momento de iniciar sus estudios y en el último año del Grado, justo en el periodo inmediatamente anterior a su titulación.

El trabajo de campo se realizó en la Facultad de Filosofía y Letras de la Universidad de Zaragoza, donde se imparte el Grado de Periodismo, y en la Facultad de Ciencias de la Información de la Universidad Complutense de Madrid, donde también se cursa esta titulación. El público objetivo sobre el que se hizo el trabajo de campo fueron los estudiantes de primer y cuarto curso del Grado de Periodismo de las dos universidades mencionadas. Entre las cuestiones planteadas en la investigación había algunos aspectos relacionados con su percepción de la Universidad y más específicamente del Grado en Periodismo en el escenario del Espacio Europeo de Educación Superior (EEES). A lo largo de esta contribución se pone de manifiesto la valoración y las impresiones de los estudiantes sobre la Universidad y el Grado de Periodismo desde la perspectiva del EEES.

A punto de cumplirse el primer lustro de la salida de los primeros egresados de los Grados de Periodismo en las Universidades españolas, estos dos grupos de investigación (Mediacom UCM y GICID) han abordado los niveles de satisfacción, motivación y expectativas de los estudiantes en relación con los estudios universitarios cursados.

Son muy recientes los trabajos efectuados que tratan de conocer la valoración de los alumnos sobre los Grados del Espacio Europeo de Educación Superior (EEES) y se apoyan en los estudios que se vienen realizando en el ámbito de la Comunicación (Peinado y Fernández Sande, 2010 y 2011; Ortiz Sobrino, 2012; Vadillo, Marta Lazo y Cabrera, 2010) cuyos esfuerzos han provocado sinergias que han dado como resultado análisis territoriales que comportan escenarios y perspectivas diferentes aunque con fines similares.

\section{Manos a la obra}

\subsection{Los Objetivos}

El objetivo principal de la investigación era detectar las expectativas de los alumnos de Periodismo, tanto al inicio de los estudios de 
Grado como inmediatamente antes de su titulación y salida al mercado de trabajo. En paralelo, se pretendía conocer también cual era la impresión de la formación recibida en el Grado de Periodismo y su percepción de la implantación de estos estudios en el EEES.

De forma complementaria, interesaba igualmente conocer otros aspectos, como los referentes profesionales de los estudiantes, su nivel de conciencia en cuanto a la posible influencia políticoeconómica y social en los medios de comunicación, así como la incidencia de la información en los hábitos de consumo de la población.

\subsection{El método}

La metodología de investigación utilizada se ha basado en las respuestas de un cuestionario de veintisiete preguntas para los alumnos de primeros cursos del Grado de Periodismo y otro de veintiocho preguntas para los alumnos de cuarto curso de la misma titulación. El cuestionario fue cumplimentado por alumnos de la Universidad pública de Zaragoza y de la Universidad Complutense de Madrid.

Aunque se pretendía obtener información sobre diferentes aspectos relacionados con las expectativas de los estudiantes y sus referentes profesionales e informativos, a efectos de la presente contribución se han tomado en consideración sólo las partes del cuestionario relativas a la imagen y percepción del EEES de los estudiantes de título de Periodismo. En este sentido, los resultados de esta contribución se centrarán en las respuestas emitidas en torno a los siguientes aspectos:

- Percepción del nivel de calidad de las enseñanzas recibidas.

- Opinión sobre el tipo de formación que debe primar en los estudios de Periodismo.

- Valoración de la adaptación de los estudios de Periodismo al EEES

- Valoración de las posibilidades de inserción laboral en relación con las competencias recibidas en el Grado.

- Perspectiva de futuro en relación con su formación. 


\subsection{El marco contextual}

El contexto geográfico y académico de la presente investigación se circunscribe a la Facultad de Ciencias de la Información de la Universidad Complutense de Madrid y al Grado de Periodismo de la Facultad de Filosofía y Letras de la Universidad pública de Zaragoza. En estos dos centros educativos es donde se ha desarrollado el trabajo de campo.

La Facultad de Ciencias de la Información de la Universidad Complutense de Madrid es el centro más antiguo de España -junto a la Facultad de Comunicación de la Universidad Autónoma de Barcelona- donde se imparte el Grado de Periodismo y, antes de la implantación del EEES, la Licenciatura. Su primera promoción comenzó los estudios en el año 1971-1972.

El Grado de Periodismo de la Universidad de Zaragoza es una de las últimas ofertas que se han incorporado a la universidad pública española. Los primeros estudiantes de esta titulación en aquella Universidad se incorporaron en el curso 2009/2010.

Desde el punto de vista de la literatura científica, se puede construir un marco teórico para esta investigación a partir de los resultados de otros estudios realizados por los dos grupos de investigación responsables del trabajo cuyos resultados ahora se presentan (Vadillo, Marta Lazo, y Cabrera, 2010; Marta Lazo y Vadillo Bengoa,2013; Ortiz Sobrino, Rodríguez Barba 2011; Ortiz Sobrino , Rodríguez Barba y Pérez Serrano, 2011; Peinado y Fernández Sande, 2010 y 2011; Ortiz Sobrino, 2012; Humanes y Roses, 2014; Pérez Serrano, Marta Lazo y Ortiz Sobrino, 2014). El marco puede completarse con otras investigaciones que se han adentrado en la percepción de los estudiantes en relación a las competencias adquiridas en los Grados de Comunicación (Gómez-Puertas, Roca-Cuberes, Guerrero-Solé, 2014) o referidos al concepto Bolonia- EEES (Font-Mayolas y Masferrer, 2010; Sierra Sánchez, 2010). En esta misma línea, también han sido objeto de reflexión la respuesta de los alumnos al reto de las TIC y la innovación educativa en el EEES (Murillo y Vizuete, 2009; Peinado et alt., 2013). 
Tampoco hay que perder de vista la abundante literatura científica protagonizada por el EEES y la Comunicación (Humanes y Roses, 2014; Murciano, 2010; Marta Lazo, 2009). Ni por supuesto, las primeras experiencias sobre expectativas estudiantiles llevadas a cabo en disciplinas similares, como los estudios de Biblioteconomía y Documentación (Tejada, 2003).

\section{Qué hemos sacado en claro}

Analizadas las respuestas de los alumnos en relación a su percepción de la formación recibida y del Grado implantado en el EEES, los resultados más relevantes fueron los siguientes:

\subsection{Los alumnos de la Universidad de Zaragoza y Madrid tienen una percepción negativa de la adaptación de los estudios de Periodismo al EEES}

En el caso de los alumnos de la Universidad de Zaragoza, su valoración media de la adaptación de estos estudios al espacio de Bolonia no llega al aprobado, situándose en un 2,43 puntos sobre 5 . El grueso de sus respuestas se concentra en valoraciones claramente negativas (Poco o Nada) o bien sobre valoraciones normales.

En el caso de los estudiantes de Madrid, la percepción es todavía peor. Con una valoración media de 1,99 sobre 5 puntos, también sus respuestas se inclinan hacia las opiniones más negativas (Poco o $\mathrm{Nada}$, incluso de manera más rotunda que sus colegas de Zaragoza.

3.2. Como resultado de la investigación, destaca el hecho de que para los encuestados los pilares de su formación deberían estar en "la combinación de una buena teoría con la práctica" y "tener profesionales en activo entre sus profesores". Se trata de una apreciación compartida tanto por los alumnos de la Universidad de Zaragoza como por los de Madrid. Sin embargo, los resultados porcentuales varían entre los estudiantes aragoneses y madrileños.

A la pregunta “¿Qué debería primar en la enseñanza del Periodismo en la Universidad?" algo más del $28 \%$ de los estudiantes encuestados de Zaragoza pensaban que combinar la teoría y la práctica era esencial para estos estudios, tal y como se observa en el gráfico I 


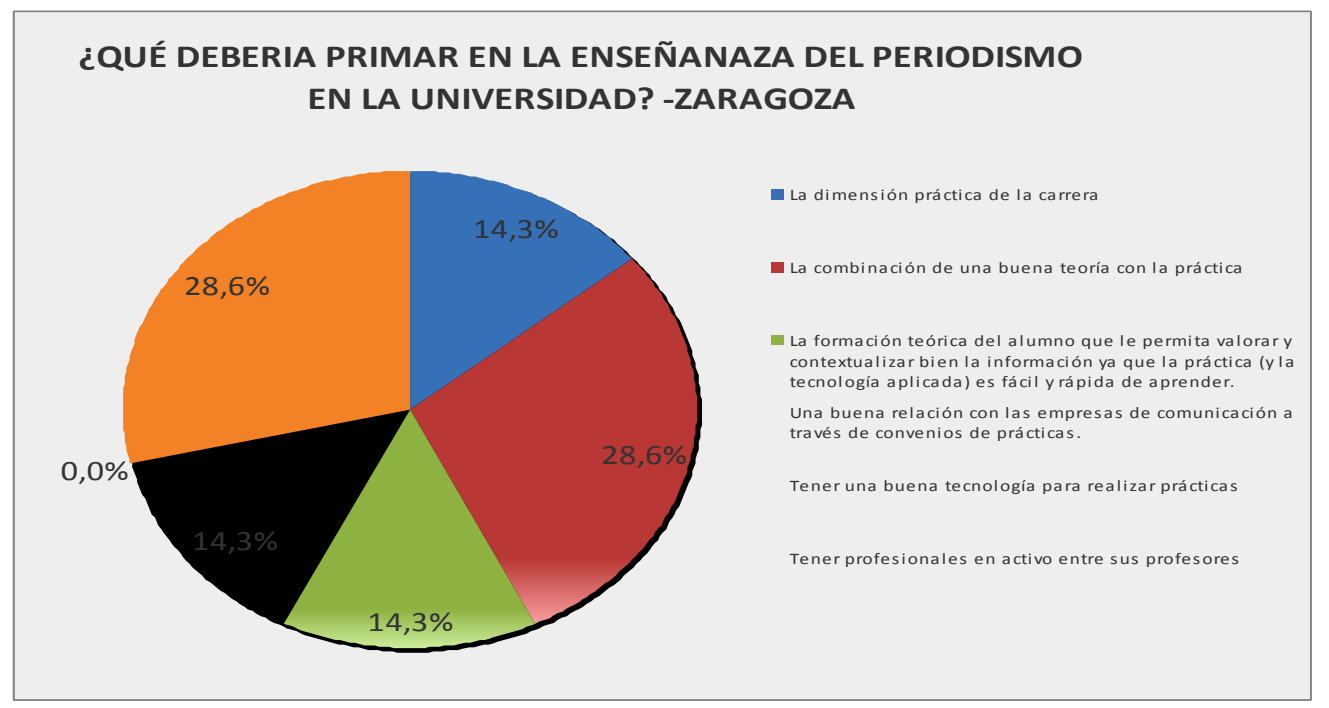

Gráfico I: Elaboración propia.

Por su parte, los estudiantes del último curso de Periodismo de la Universidad Complutense opinaban, igualmente, que la dimensión teoría-práctica era la mejor manera de formar a los nuevos periodistas, pero en este caso el porcentaje superaba el 31\% de los encuestados (Gráfico II).

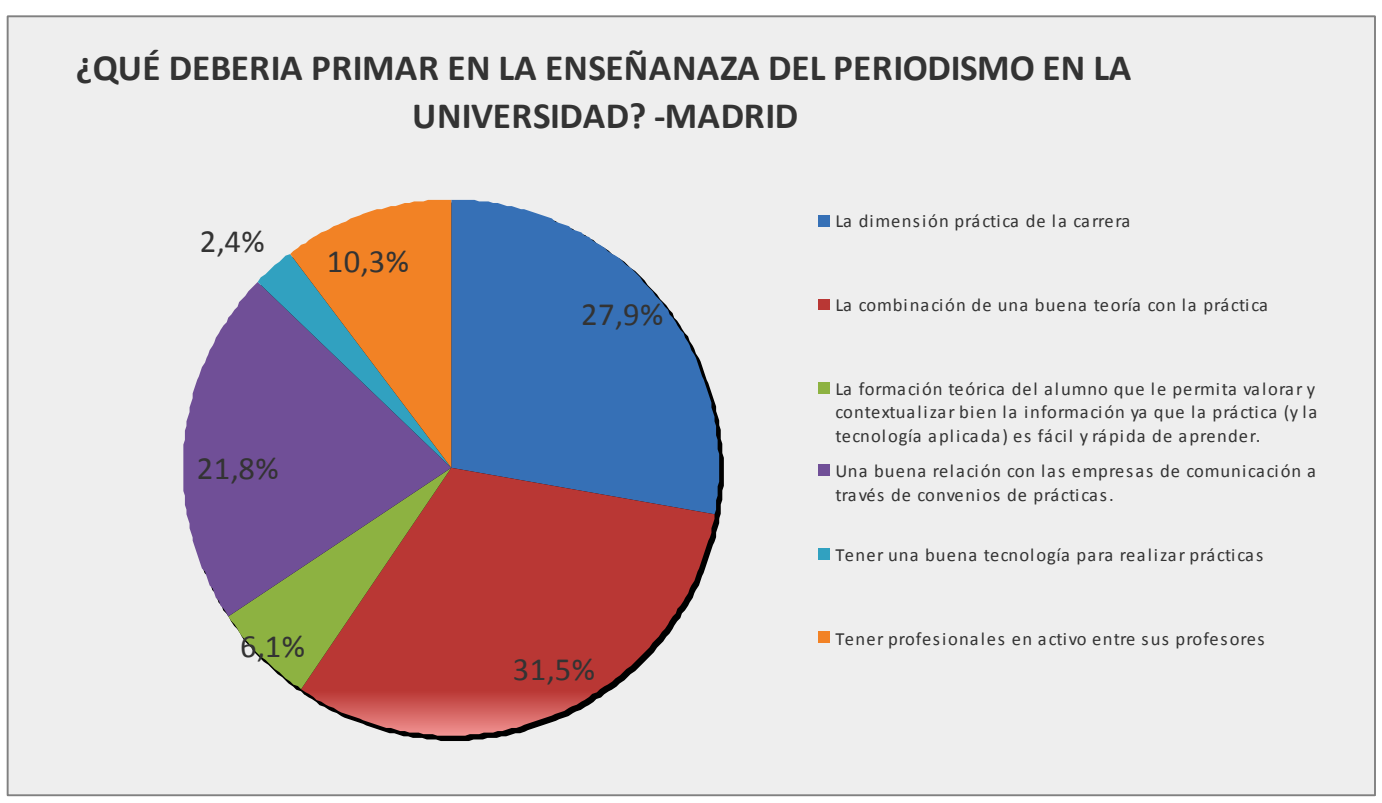

Gráfico II: Elaboración propia.

\subsection{No tienen una imagen positiva de su formación}

Otra de las conclusiones del estudio apunta a que los estudiantes de Periodismo no tienen una imagen excesivamente positiva sobre la formación recibida. De hecho, en el caso de los alumnos de 
Zaragoza, al preguntarles si pensaban que la Universidad les había formado bien como periodistas, el $60 \%$ de ellos respondían que "nada" o "poco", con una valoración media de los estudios de 2,9 puntos sobre 5 .

Entre los encuestados en la Facultad de Ciencias de la Información de Madrid, los resultados no difieren mucho. Con una valoración media de sus estudios de 2,3 puntos sobre 5 , los estudiantes se sitúan en la opción intermedia-negativa de la valoración.

\subsection{Aunque, la formación es diferente según el tipo de Universidad}

Tanto en el caso de los alumnos de Zaragoza como en los de Madrid hay una percepción clara de que los resultados formativos dependen y varían según los Centros educativos y las zonas geográficas.

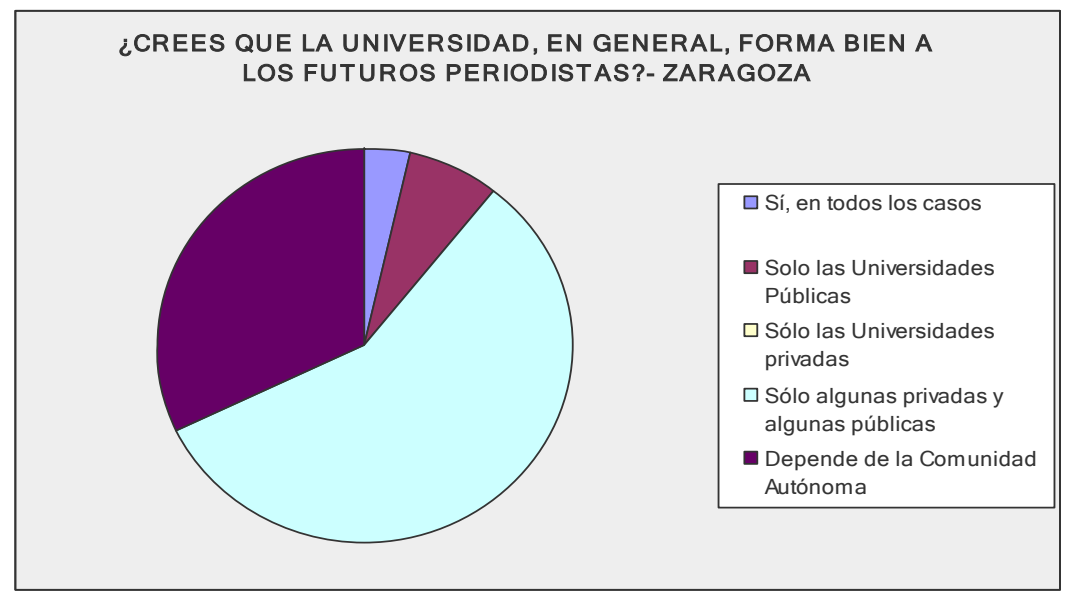

Gráfico III: Elaboración propia

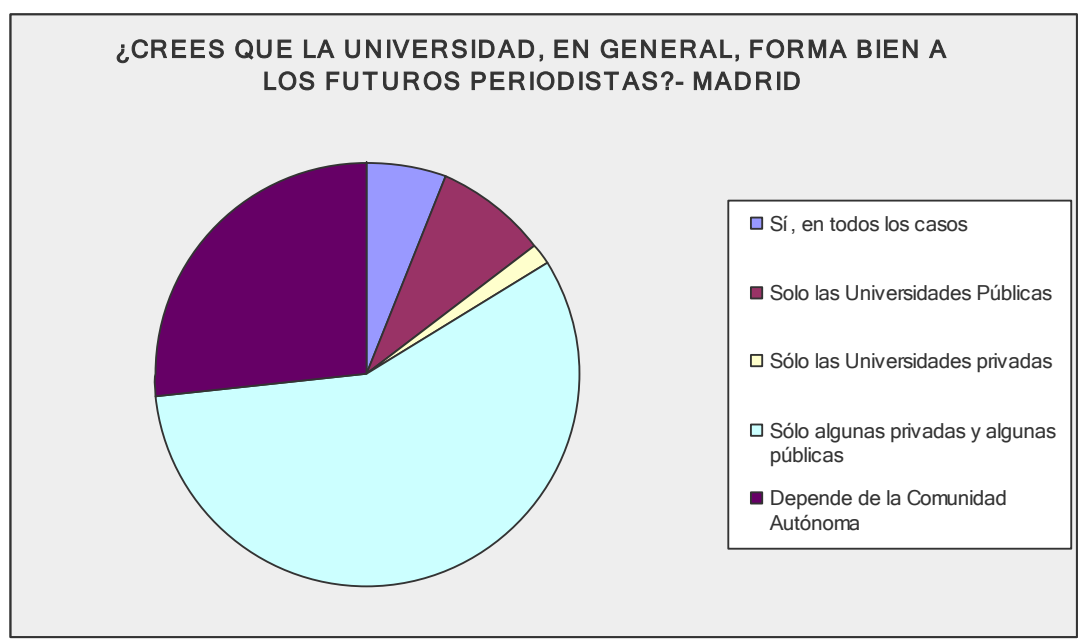

Gráfico IV: Elaboración propia. 
Algo más del 57,1 \% de los alumnos de Zaragoza creen que sólo se forma bien a los nuevos periodistas en algunas universidades públicas o privadas y en determinadas Comunidades Autónomas (Gráfico III).

Casi en idéntica proporción (57\%) los estudiantes de la universidad madrileña consultados piensan igualmente que la formación periodística varía dependiendo de los Centros y las Comunidades Autónomas donde se imparte (Gráfico IV).

\subsection{Son poco optimistas con su futuro profesional}

Cuando se le preguntó a los estudiantes de Periodismo de la Universidad de Zaragoza "en qué medida pensaban que sería fácil su acceso al mercado laboral tras su graduación", la respuesta fue rotunda: el 96\% consideró que no iba a ser fácil incorporarse a un trabajo.

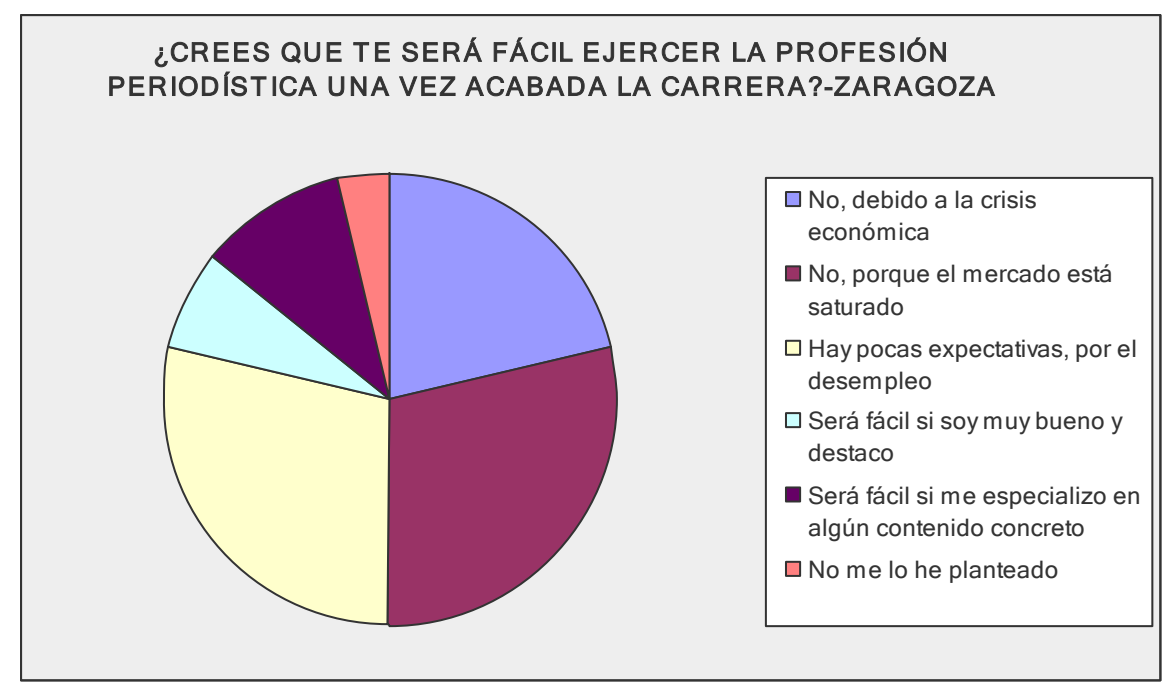

Gráfico V: Elaboración propia.

Las razones esgrimidas eran diversas, aunque para más del $57 \%$ de los encuestados las causa principales señaladas eran la saturación del mercado laboral en los medios y la situación de paro general en el país (Gráfico V). Curiosamente, la situación de crisis económica solo aparecía como causa de la falta de expectativas laborales para un 21,4\% de los encuestados. En relación con su formación, el 10,7\% de los encuestados pensaba que si se especializaba encontraría un trabajo, frente a un $7,1 \%$ que confiaba en encontrar un trabajo si era muy bueno y destacaba. 
Consultados sobre la misma cuestión, los estudiantes madrileños achacaban la falta de expectativas laborales a la situación general de desempleo en España. El 32,6\% de los encuestados pensaban que la principal causa del bajo nivel de empleo de los egresados en el Grado de Periodismo estaba en la situación desempleo sistémico de todo el país. En cambio, ni la saturación del mercado laboral en los medios $(13 \%)$, ni la crisis económica $(10,9 \%)$ aparecía como las principales causas (Gráfico VI).

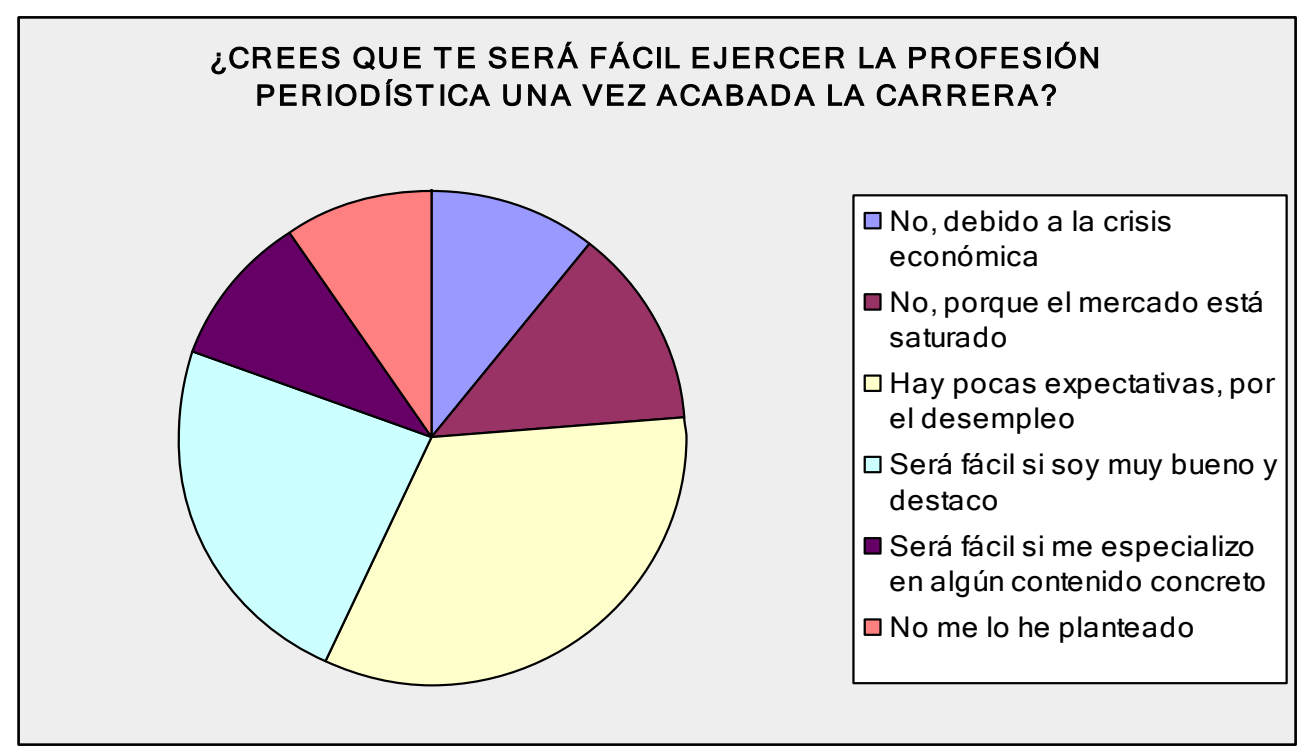

Gráfico VI: Elaboración propia

Solo el 10,1 \% creía que si se especializaba encontraría un trabajo. En cambio, era muy alto el porcentaje de los que opinaban que encontrarían trabajo si eran muy buenos y destacaban $(23,9 \%)$.

\subsection{Piensan en continuar los estudios}

Tanto en el caso de los alumnos de Zaragoza como los de Madrid, el futuro pasaba por continuar su formación para gran parte de los encuestados.

En el caso de Zaragoza más del 32\% pensaba en continuar estudios de postgrado, de idiomas $(14,3 \%)$ o bien otra carrera $(14,3 \%)$.

La situación de los estudiantes de Madrid era parecida, aunque con algunas matizaciones. El 30\% pensaba seguir formándose, pero en torno al $25 \%$ se inclinaba por seguir haciendo prácticas en algún medio. Estudiar idiomas era una opción para menos del 20\% de los 
encuestados y estudiar otra carrera sólo era una alternativa para algo más del 10\%.

\section{Conclusiones}

Aunque todavía son pocas las promociones salidas de los nuevos Grados de Periodismo de las diferentes universidades españolas, la conclusión principal que se saca del análisis de los resultados de la investigación es que hay una percepción bastante negativa de estos estudios entre sus estudiantes encuestados.

Probablemente, la situación generalizada de desempleo y en particular la crisis tan importante que atraviesan los medios de comunicación, están influyendo en la imagen y expectativas que los estudiantes de Periodismo tienen sobre sus propios estudios.

No obstante, el hecho de que en sus respuestas reconozcan que la calidad de la formación recibida depende bastante del tipo de centro y de la Comunidad Autónoma donde se imparte, significa que dejan entreabierta una puerta a la mejora de la formación de los nuevos periodistas, a sus expectativas de empleo, e invitan a establecer áreas de mejoras y replanteamientos de los estudios de Comunicación en España.

Además, a título de discusión de los resultados y a la luz de las expectativas poco optimistas de los alumnos que están a punto de titularse en el Grado de Periodismo, habrá que esperar a completar estos resultados con otros extraídos de un trabajo de campo realizado entre los alumnos ya titulados para ver su nivel de inserción laboral y en qué medida las expectativas se mantienen o cambian de sentido. 


\section{Formación y vinculación académica de estudiantes en la radio universitaria de México}

Marina Vázquez Guerrero (Universidad de Colima, México) http://orcid.org/0000-0001-9875-4211

http://scholar.google.com.mx/citations?user=O4f8uB8AAAAJ\&hl=es

\section{Introducción}

Q I BIEN las radios comerciales son las más importantes y la $\checkmark$ mayoría en México, en el país es posible sintonizar toda una gama de opciones sin fines de lucro, que forman parte de un grupo denominado hasta hace poco tiempo como medios permisionados o la otra radio. En esta categoría encontramos las indigenistas, públicas (de los gobiernos federal y estatales); culturales, sociales, y las universitarias, que hasta los primeros meses de 2014 se contabilizaban en por lo menos 75 universidades haciendo radio por antena e Internet (Vázquez Guerrero, 2014), lo que convierte a México en el país de habla hispana con el mayor número de radios universitarias. Sus objetivos son contrarios al desarrollo comercial y los servicios empresariales; en términos muy generales buscan apoyar la difusión de la cultura y ofrecer contenidos de tipo social, institucional y cultural. De ella nos ocuparemos en esta investigación, que busca conocer el tipo de formación que ofrecen las radios universitarias a los estudiantes de planteles vinculados y relacionados de la comunicación. 


\section{Los programas afines a la comunicación}

En cuanto al número de programas educativos relacionados a la comunicación, por el gran crecimiento que se dio en los años ochenta, no se conocen cifras precisas. A través de un estudio promovido por la UNESCO en 2009, se contabilizó la existencia de 1,006 centros de enseñanza universitaria, lo que convierte a México en un país con una saturación de escuelas y programas tan solo de comunicación, de las cuales es imposible tener un control ni registro (FELAFACS, 2009). La mayoría de estas instituciones son particulares, sin una estructura adecuada y sin una "planta académica estable, suficiente y calificada" (Fuentes 2011). Por ello, no es extraño encontrar que solamente un $6.75 \%$ de estas licenciaturas, tenga certificado de acreditación por organismos de calidad. Esto lleva a que no se responda adecuadamente a las necesidades de la sociedad y el mercado laboral, a pesar de que la mayoría de estos programas enfoque su formación en las áreas profesionales y técnicas, haciendo uso de tecnologías y conocimientos muy prácticos.

Sobre la oferta educativa, en licenciaturas de programas afines a la comunicación, donde incluimos para este estudio al periodismo, comunicación, relaciones públicas, mercadotecnia y publicidad, siguiendo el registro de ANUIES, encontramos una diversidad donde predominan las carreras de comunicación con 20 diferentes programas que ofertan 43 universidades, principalmente de particulares, en 100 diferentes ciudades. En el país se ofertan también 16 programas de mercadotecnia en 37 universidades de 210 ciudades. La mayoría también está en manos de instituciones particulares. Después le sigue publicidad, con cinco programas diferentes que ofrecen ocho universidades en doce ciudades.

En cuanto a los estudios de periodismo, se ha ido a la baja y actualmente solo se ofrece en ocho instituciones en once ciudades, con un número igualitario de instituciones públicas y particulares. Por último está el programa de relaciones públicas que está concentrado en nueve sedes de la Universidad del Valle de México, institución particular (ANUIES, 2012). El panorama entonces, de la oferta del área relacionada a la comunicación, en las universidades más 
importantes de México de acuerdo con la ANUIES, es de 40 instituciones, donde el 57\% son privadas.

\section{Radios universitarias}

Por otra parte tenemos que en México se hace radio universitaria desde mucho antes de la aparición de las licenciaturas afines a la comunicación. Radio UNAM se inauguró en 1937 y la primera licenciatura en periodismo en 1951 (Islas, Gutiérrez y Campo Garrido, 2002). Al igual que las instituciones de educación superior, es difícil registrar cuáles de las más de 2 mil tienen una emisora, porque a partir de la llegada de Internet, muchos centros educativos han optado por abrir una y realizar transmisiones regulares, con incluso mayor penetración que las radios por antena.

Siguiendo las cifras oficiales a través de la red SINPRIES ${ }^{1}$, en su último recuento de radios afiliadas, registra 65 instituciones (SINPRIES, 2014). Por su parte, el Instituto Federal de Telecomunicaciones (IFETEL, 2014) registra alrededor de 50 universidades con permiso para emitir por antena.

Haciendo un cruce con los datos encontramos que un $22 \%$ (40) de todas las universidades afiliadas a la ANUIES, oferta programas de licenciaturas en carreras afines a la comunicación y un 36\% (65) hace radio. El dato numérico nos dice que existen pocas experiencias radiofónicas vinculadas a centros educativos, para un país tan grande, con tanta competencia educativa y necesidades de desarrollo social y profesional.

\section{La radio que enseña}

En el contexto iberoamericano, las experiencias formativas en la radio provienen de la radio escolar que comenzó con la apertura de emisoras de baja potencia en España, después de la dictadura franquista. Se dio esta práctica desde finales de los años ochenta en los niveles de Primaria y ESO I para contribuir en la formación de los

\footnotetext{
${ }^{1}$ Sistema Nacional de Productoras y Radiodifusoras de las Instituciones de Educación Superior, Organismo perteneciente a la ANUIES que agrupa la mayoría de radios universitarias.
} 
alumnos (Rodero, Vázquez, Larrea y Mas, 2014), con la realización de contenidos propios a partir del programa de estudios.

Modelos similares se han ido replicando en diferentes partes del mundo, por las aportaciones que dejan en los niños y adolescentes, que consiguen en ellos desde el trabajo en equipo; la estimulación de la creatividad e imaginación, conocimiento del entorno y realidades más o menos ajenas o lejanas; responsabilidad, actitudes críticas, entre otras (Torregrosa: 174).

Por otra parte Rodero (2008) afirma que la radio dota de competencias que potencian la formación integral de los estudiantes a través del progreso personal, la creatividad, la visión crítica, la comunicación y el uso de tecnologías.

Finalmente, a través del estudio realizado en seis casos de radios universitarias de México y España (Vázquez Guerrero, 2012), se puede comprobar que en este contexto precisamente, se da un aprendizaje importante de las competencias mencionadas anteriormente, pero también de otras más específicas que tienen que ver con competencias instrumentales, interpersonales y sistémicas entre las que destacan la capacidad de organizar información, la comunicación oral y escrita; el trabajo en equipos interdisciplinarios y/o multidisciplinario; capacidad para formular y gestionar proyectos, entre otras. Las competencias profesionales como la realización de guiones, entrevistas, la musicalización, edición y operación de equipo técnico también se dan en gran medida.

La radio universitaria dota al participante de habilidades para uso de tecnologías, verbales, entre otras, lo que comprueba que es "una formadora nata de personas que colaboran o participan dentro de sus actividades comunicativas" porque se adquieren competencias suficientes y los jóvenes valoran positivamente su paso por la radio, "aún en aquellas que no tienen un objetivo primordial de hacerlo" (Vázquez Guerrero, 2012: 331).

La tesis manifiesta que es necesaria una forma de trabajo específica para lograr una participación y formación estudiantil efectiva como tener reglamentos tanto institucionales como internos; hacer convocatorias para motivar la participación y visibilizar la radio; dar a conocer a los jóvenes las características del medio y sus ventajas sobre 
todo sociales; ofrecerles capacitación; una constante comunicación y retroalimentación así como la oportunidad proponer proyectos y seguir aprendiendo.

Dado que el estudio de ese año demostró que tanto en las radios escolares como en las radios de corte social o institucional se aprenden competencias y que es necesaria una revisión más a fondo de otras experiencias que nos permitan encontrar los elementos necesarios para desarrollar una propuesta viable de vinculación y formación integral, por lo menos del sector estudiantil de los programas académicos afines como la publicidad, relaciones públicas, comunicación, mercadotecnia y periodismo, que como hemos visto líneas arriba requiere de mayor calidad y profesionalismo, que es posible adquirir por esta vía, precisamente porque se tiene el instrumento necesario que es una emisora de radio con equipamiento y programación, acordes.

Partiendo de la premisa de que el paso de los estudiantes por una radio universitaria les enriquece en aspectos sociales, personales, culturales, pero principalmente profesionales, se comenzó en 2014 este proyecto que busca conocer el panorama de México en particular.

\section{Estudiantil en la radio}

Adentrándonos en la situación actual de las emisoras mexicanas, encontramos que en los últimos años, varias de ellas han incluido al estudiante como colaborador, lo que refleja mayor presencia e interés por darles un espacio. A través de un estudio cuantitativo reciente realizado para esta investigación (Vázquez Guerrero, 2014) encontramos que de 31 universidades participantes, 30 suelen tener estudiantes como colaboradores que inscritos en 33 diferentes disciplinas, que van desde las relacionadas con el arte, la música y la educación, hasta las ingenierías, ciencias químicas, económicas, políticas, idiomas o finanzas. La mayoría son estudiantes de comunicación (25) y en menor medida de otras carreras del área como Periodismo (en 11); Mercadotecnia e ingeniería (10); Letras (6) Publicidad, Psicología y Educación (4) Relaciones públicas (1 caso), reflejo de la oferta en el país. La participación es muy variable en 
cuanto a número, pues se encuentran casos desde 130 por semestre hasta tres.

Hay alta presencia por diferentes razones, pero en pocos casos hay vinculación directa con materias. Lo manifestaron solamente 14 radios, de las cuales la mayoría son particulares (nueve). Aquí se comienza a observar que son en su mayoría las universidades particulares y por Internet quienes han replanteado sus talleres y estrategias, para contribuir en la formación integral de sus alumnos a través de su participación en la radio, con respuesta positiva. Los resultados del estudio cualitativo que aquí se presenta, así lo refleja, con algunas reservas respecto a la vinculación académica obligatoria.

\section{Metodología}

A través de un diseño etnográfico, en este estudio se recurrió a la técnica cualitativa de la entrevista semiestructurada por internet, aplicada a través de la plataforma Skype. De un universo de 14 radios que cumplían con el perfil necesario, la muestra está conformada por ocho radios universitarias, de las cuales dieron testimonio sus directores/coordinadores o responsables de la vinculación estudiantil.

\section{Tabla 1. Emisoras e informantes en el estudio}

\begin{tabular}{|l|l|l|}
\hline \multicolumn{2}{|l|}{ RADIOS PARTICULARES } \\
$\begin{array}{l}\text { NOMBRE Y AÑO DE } \\
\text { CREACIÓN }\end{array}$ & FRECUENCIA & UNIVERSIDAD Y CIUDAD \\
\hline Radio Anáhuac & AM & $\begin{array}{l}\text { Universidad Anáhuac } \\
\text { Huixquilucan, Edomex }\end{array}$ \\
\hline $\begin{array}{l}\text { Azul83 } \\
2012\end{array}$ & Internet & $\begin{array}{l}\text { ITESM Campus Sonora Norte } \\
\text { Hermosillo }\end{array}$ \\
\hline Frecuencia CEM & Internet & ITESM Campus estado de México \\
Atizapan, Edomex
\end{tabular}




\begin{tabular}{|l|l|l|}
$\begin{array}{l}\text { Radio } \\
\text { Aguascalientes } \\
1978\end{array}$ & FM & $\begin{array}{l}\text { Universidad Autónoma de Aguascalientes } \\
\text { Aguascalientes }\end{array}$ \\
\hline Frecuencia UAL 2006 & FM & $\begin{array}{l}\text { Universidad de la Laguna } \\
\text { Torreón, Coahuila }\end{array}$ \\
\hline UABC Radio & AM y FM & $\begin{array}{l}\text { Universidad Autónoma de Baja California } \\
\text { Mexicali, Tijuana y Ensenada }\end{array}$ \\
\hline 2007 & FM & $\begin{array}{l}\text { Universidad Autónoma del estado de } \\
\text { México/ Toluca }\end{array}$ \\
\hline
\end{tabular}

Elaboración propia.

Las características de la muestra son la diversidad y pertinencia al tipo de estudio: existe representatividad por áreas geográficas ${ }^{2}$, tamaño de radio; tipo de emisión, tipo de oferta académica - incluyen por lo menos una de las carreras afines a la comunicación- y tipo de universidad. De este grupo, cuatro son pertenecientes a universidades particulares: tres del sistema ITESM (Instituto Tecnológico y de Estudios Superiores de Monterrey) en diferentes ciudades y una de la Universidad Anáhuac. Otras cuatro emisoras son parte de universidades públicas de diferentes regiones del país: Autónoma de Aguascalientes, Universidad de la Laguna; Autónoma de Baja California y de la Universidad Autónoma del Estado de México (tabla $1)$.

\section{Resultados}

Las emisoras públicas tienen en común que la mayoría de ellas no hace convocatoria para invitar a los estudiantes a participar, pues suelen tener una solicitud alta. Ninguna tiene presencia masiva de alumnos y se trabaja en general con las vacantes de Servicio Social y Prácticas profesionales ${ }^{3}$. En cuanto al tipo de participación que tienen durante su estancia en la emisora, en todas las radios públicas intervienen directamente en el proceso de producción que va desde la

\footnotetext{
${ }^{2}$ La muestra incluye representantes de 5 de las 6 regiones geográficas clasificadas por ANUIES

${ }^{3}$ Obligatorio para instituciones educativas del país.
} 
investigación, entrevistas, guionismo, locución, conducción y edición de secciones, cápsulas, promocionales o programas.

En todas existe un acompañamiento profesional, donde se les va orientando sobre la forma de trabajar. En radio UABC la dinámica es a través de células de producción radiofónica a cargo de un productor de la institución. De acuerdo a su perfil de estudios, se les asignan producciones diversas. En Radio UAA el proceso es similar, la mayoría de prestadores de servicio y prácticas provienen de las licenciaturas de comunicación organizacional o de comunicación e información por lo que varios programas cuentan con estudiantes de manera permanente. Sin embargo, hay presencia de alumnos de otras carreras como filosofía.

Por su parte, en las instituciones particulares la radio forma parte de los laboratorios a los que tienen acceso todo tipo de carreras. El alumno llega libre y colabora de manera voluntaria. Una vez allí, se les puede acreditar su servicio, que se puede prolongar el tiempo que ellos decidan.

En Radio Anáhuac los interesados deben comenzar por tomar un curso de capacitación especializado en locución. Al igual que en las radios públicas, las particulares los instruyen para intervenir en todo el proceso de producción, solamente en el caso de Concepto Radial y Frecuencia CEM, se ha restringido el uso de redes sociales oficiales.

En cuanto a la dinámica de inducción al medio y la formación durante su estancia en ella, se observa que en las radios públicas no hay capacitación formal para los estudiantes. La dinámica de ingreso consiste en una entrevista para conocer a la persona y sus intereses, para posteriormente comenzar su colaboración con el seguimiento de un productor o jefe asignado.

Por su parte en las radios particulares se da una entrevista inicial, con el seguimiento del coordinador y la retroalimentación posterior a las emisiones. Concepto radial y Radio Anáhuac, a pesar del poco personal tienen diseñados cursos y otras dinámicas para el control de la calidad. En la primera, además de la entrevista de ingreso, se les pide una lectura del reglamento y se les da una capacitación semi 
formal a través de cursos de producción, locución, redes sociales y operación técnica, con evaluaciones a mitad y final de semestre.

Radio Anáhuac, es quien tiene más avanzada esta parte pues además de lo general, se les ofrece un taller de 21 horas donde se les enseña la estructura de un programa de radio, el lenguaje radiofónico y el ritmo y tono de la voz. Tienen un seguimiento puntual durante su participación pues deben mandar a revisión y autorización la escaleta de su programa, 24 horas antes de la emisión.

Respecto a la vinculación con materias encontramos en las radios particulares, que los cambios en los planes de estudio, han provocado el cierre de materias relacionadas a la radio.

Como se observa en la tabla 2, hay algunas radios donde el número de materias vinculadas es bajo e inexistente en otras. En Azul 83 ha habido vinculación de materias de bachillerato y licenciatura, que han optado por realizar cápsulas con contenidos afines a las materias.

\section{Tabla 2. Vinculación con materias en las radios universitarias}

\begin{tabular}{|c|c|c|}
\hline EMISORA & $\begin{array}{l}\text { MATERIAS QUE } \\
\text { ESTUVIERON VINCULADAS }\end{array}$ & MATERIAS VIGENTES \\
\hline $\begin{array}{l}\text { Concepto } \\
\text { radial }\end{array}$ & $\begin{array}{l}\text { Periodismo radiofónico } \\
\text { Producción radiofónica }\end{array}$ & Audio para multiplataformas \\
\hline Radio Anáhuac & Radio en vivo & $\begin{array}{l}\text { Estrategias de programación para } \\
\text { radio musical } \\
\text { Practicum de periodismo } \\
\text { Lenguaje periodístico para medios } \\
\text { electrónicos digitales y } \\
\text { convergentes }\end{array}$ \\
\hline $\begin{array}{l}\text { Frecuencia } \\
\text { CEM }\end{array}$ & $\begin{array}{l}\text { Hubo varias materias } \\
\text { obligatorias que } \\
\text { desaparecieron del plan de } \\
\text { estudios }\end{array}$ & Ninguna \\
\hline Azul 83 & Varias temporales & Expresión verbal y literatura \\
\hline $\begin{array}{l}\text { Frecuencia } \\
\text { UAL }\end{array}$ & & $\begin{array}{l}\text { Producción radiofónica; Locución } \\
\text { aplicada o doblaje } \\
\text { Edición de audio }\end{array}$ \\
\hline
\end{tabular}




\begin{tabular}{|lll|}
\hline Radio UAA & $\begin{array}{l}\text { Comunicación } \\
\text { organizacional } \\
\end{array}$ & $\begin{array}{l}\text { Comunicación e } \\
\text { información }\end{array}$ \\
\hline Radio UABC & Radio & Ninguna \\
\hline UNIRadio & $\begin{array}{l}\text { Hubo un intento pero no } \\
\text { funcionó }\end{array}$ & Ninguna \\
\hline
\end{tabular}

Elaboración propia.

En las radios públicas se tiene un panorama diferente. Tres de las cuatro emisoras han tenido vinculación de materias, pero el hecho de que las carreras de comunicación cuenten con sus propios talleres, lejos de la emisora, ha afectado para que se lleve a cabo esta labor, que en algunos casos se dio inicialmente.

La radio que sí tiene una vinculación con materias es Frecuencia UAL que reporta actividad de las tres materias de la licenciatura en comunicación y periodismo. Ellos utilizan las instalaciones y el profesor se encarga de la calificación.

Esta forma poco sistematizada de formar en la radio, ha tenido sin embargo buenos frutos y el reconocimiento de que se da un aprendizaje significativo en los estudiantes.

Tanto en las radios particulares como en las públicas, si bien no existen evaluaciones para probar sus aprendizajes, se tiene la certeza de que por lo menos salen capacitados para bablar bien. Los informantes de las radios afirman que obtienen competencias muy básicas de dicción, de guionización, de edición, de producción y que tienen la posibilidad de hacer un programa, si se los pidiera una empresa. También que se aprende "el trabajo en equipo, la responsabilidad, el saber seguir reglas, ser creativos, hacerse responsable de un proyecto que muchas veces nace de ellos". (Castelazo, 2014).

Las radios más jóvenes como Frecuencia UAL y Azul 83 afirman que la apertura de la radio ha traído grandes beneficios a la universidad y a las carreras que participan. En las radios con más tiempo, hay casos 
de éxito de personas que ahora ocupan cargos importantes en los medios y que reconocen la aportación de la radio universitaria. Las radios con mayor incidencia son la Radio UAA, por la antigüedad y por el espíritu formativo que ha tenido en varios periodos y Radio Anáhuac por el perfil de sus estudiantes. En esta radio son muchos los egresados colocados en puestos importantes y se tiene la convicción y objetivo de ser "un semillero de talento para la industria radiofónica (...) tanto en el ámbito de la locución, la producción, de la locución, el diseño de contenidos y la administración” (King, 2014).

\section{Discusión}

Si bien se observa que en todas las radios hay presencia de estudiantes, en la mayoría solo se da una inducción a través de la entrevista y sesiones de sensibilización y en dos radios particulares, cursos mejor estructurados.

Todas las radios han tenido casos de éxito profesional de ex colaboradores y se tiene la convicción de que el estudiante hace buen papel en la radio y debe continuar presente, sin embargo no consideran necesario motivar la presencia directa de estudiantes de las áreas afines a la comunicación.

Los hallazgos más importantes de esta investigación se encuentran en la vinculación, pues contrario a la hipótesis que se venía planteando, las radios universitarias de México tienen una limitada vinculación con materias y en algunos casos se han venido eliminando, por la complejidad que conlleva y por situaciones académicas que van más allá de sus posibilidades como el cambio de plan de estudios.

Es notorio como cada vez son menos las materias vinculadas a la radio y en los pocos casos donde hay, la radio no tiene una injerencia directa en la formación, ya que solo facilitan el espacio y el profesor es quien evalúa de acuerdo a sus criterios.

La formación integral de estudiantes a través de la radio no es considerada una opción por quienes dirigen estas emisoras pues la mayoría encuentran poco viable la posibilidad de formalizar la vinculación con materias o la capacitación por diferentes motivos 
como el exceso de trabajo, escasez de personal, falta de visión o políticas que lo propicien y los objetivos de la radio.

Aun así y de acuerdo a los requerimientos básicos para lograr una participación y formación estudiantil efectiva (Vázquez Guerrero, 2012), algunas se estas radios están muy cerca de conseguirlo si formalizaran sus reglamentos institucionales e internos, su método de capacitar y si enfatizan en las ventajas sociales y formativas del medio a los estudiantes, quienes a fin de cuentas saldrán al mercado a demostrar competencias y valores que hablarán de la profesionalización y calidad de la universidad que les entrega un título profesional. 


\section{Indicadores para la evaluación de la alfabetización transmedia en los estudios universitarios de Comunicación}

María del Mar Grandío-Pérez (Universidad de Murcia)

orcid.org/0000-0002-2577-4059

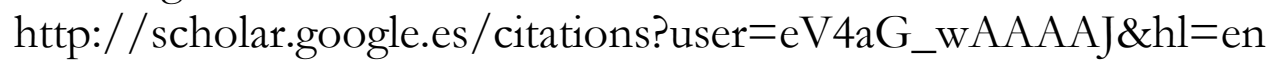

\section{Introducción}

— L TÉRMINO alfabetización o "literacy" fue acuñado en el siglo XIX para describir la capacidad de los ciudadanos para leer y escribir (Williams, 1976). Dos siglos después, el concepto sobre qué es hoy en día "saber leer y escribir" ha mutado enormemente. La alfabetización se ha ampliado para centrarse ahora en aspectos más profundos: cómo las audiencias interpretan, critican y responden a los medios de comunicación u otras plataformas tecnológicas, así como las actividades e interacciones que desarrollan en estos contextos propios de la Era Móvil y Digital.

Actualmente, la investigación sobre alfabetización mediática es claramente multidisciplinar, aunando perspectivas provenientes de los estudios sociales de la Tecnología, Ciencias de la Información y Documentación, la Educación, la Lingüística o el ámbito de la Comunicación y Estudios de Audiencias, principalmente. Estas disciplinas han examinado los conocimientos y capacidades que la audiencia necesita en el ecosistema mediático actual, a menudo desarrollando ideas paralelas (Livingstone, Van Couvering and Thumim, 2008) o presentando, por el contrario, tensiones 
conceptuales divergentes (Livinstone, Papaioannou, Grandío y Wijmen, 2012, p. 3).

La transalfabetización o transliteracy se presenta como un horizonte integrador en la alfabetización mediática e informacional actual (FrauMeigs, 2012). Este capítulo pretende potenciar este concepto en el ámbito hispano-hablante desde una perspectiva global y poniendo el énfasis en el principal actor del proceso comunicativo: la audiencia y en el uso y las razones que la llevan utilizar unos medios para informarse, entretenerse o participar en una sociedad en continuo cambio. Además, se desea ofrecer unas dimensiones e indicadores que permitan evaluar e implementar la alfabetización transmedia en el contexto universitario actual, especialmente en los ámbitos relacionados con la Comunicación y la Educación, por ser profesiones estrechamente relacionadas con el ámbito de la educación mediática y transmedia.

\section{Reflexión teórica: perspectivas sobre la transalfabetización}

Sin hablar directamente de la transalfabetización, Henry Jenkins, uno de los principales investigadores sobre narrativas transmedia actuales, señalaba ya en el 2006 en el informe para la Fundación MacArthur Confronting the challenges of Participatory Culture: Media Education for the 21 st Century la necesidad de que los estudiantes aprenden a navegar a través de relatos transmedia, entendida la "navegación transmedia " como la habilidad de seguir flujos de historias e información a través de múltiples modalidades, moviéndose constantemente en planos de recepción y creación (Jenkins, 2006: 48).

Señala además retos que es necesario trabajar desde instancias educativas y políticas como la capacidad de participación en estos nuevos escenarios, algo que se presenta como desequilibrado dependiendo de los dispares accesos a la educación según el autor. El término concreto de "transliteracy" o transalfabetización se acuñó desde el ámbito de la Comunicación y Estudios Culturales. Sue Thomas fue quien definió el concepto de transalfabetización o "transliteracy" en 2007 para señalar cómo "leer y escribir" ya no era suficiente para catalogar a un alfabetizado en el contexto mediático coetáneo. Hacía hincapié en una doble perspectiva: el uso y recepción de material proveniente de diferentes plataformas, junto con la 
capacidad de poder interactuar a través de estas plataformas utilizando diferentes lenguajes a través de dichas plataformas (televisión, radio, redes sociales...) (Thomas et al., 2007).

Desde el ámbito de la alfabetización informacional y siguiendo el concepto propuesto por Thomas, Susie Andretta aplica este término al ámbito de la práctica de la biblioteconomía para analizar la necesidad de "moverse a través" e incorporar múltiples alfabetizaciones (Andretta, 2009: 1). Divina Frau-Meigs utiliza el concepto de "transliteracy" para aprovechar también las ventajas potenciales y mitigar los riesgos de la llamada Sociedad de la Información. Partiendo de la base de la necesidad de alfabetizaciones múltiples en el ecosistema mediático actual, propone un horizonte de la transalfabetización que se centre menos en aspectos tecnológicos para virar la mirada más hacia los actores y el uso contextual y con objetivos que hacen de los medios y tecnologías. Para ello, presenta el término como un concepto global que incluye las alfabetizaciones informacional, mediática e informática (Frau-Meigs, 2012).

\section{Propuesta de definición para alfabetización transmedia}

A efectos de esta comunicación se sugiere una definición para la alfabetización transmedia que contempla simultáneamente el plano de recepción crítica y expresión-creación. Bajo este enfoque, la alfabetización transmedia sería:

La capacidad para evaluar y crear contenido a través de múltiples plataformas con un sentido unitario y complementario, teniendo en cuenta diversos lenguajes y experimentaciones creativas, presentando además una actitud ética hacia su propio contenido y el de los demás y con el objetivo de fomentar la participación plena en contextos interculturales.

\section{Propuesta de dimensiones e indicadores}

Siguiendo la definición propuesta, ¿qué indicadores relacionados con el transmedia deberían reflejarse en un alumno alfabetizado mediáticamente? La búsqueda de indicadores para la medición de las alfabetizaciones mediáticas ha sido trabajado desde diferentes ámbitos de la educomunicación (Marta y Grandío, 2013). Las capacidades relacionadas directamente con el transmedia las encontramos ya de manera transversal en las seis dimensiones propuestas por Ferrés y Piscitelli para la medición de competencias mediáticas: el lenguaje, la 
tecnología, los procesos de producción y programación, ideología, recepción e interacción, y estética (Ferrés i Prats y Piscitelli, 2012). Estos autores contemplan interesantes indicadores como la capacidad de compartir y diseminar información a través de diferentes entornos comunicativos, así como evaluar la fiabilidad de las fuentes de información, o relacionar las producciones mediáticas con otras manifestaciones artísticas.

La propuesta que se hace en esta comunicación se centra específicamente en aspectos relacionados directamente con el transmedia. Todas las dimensiones se presentan en dos niveles imprescindibles y simultáneos para la alfabetización transmedia: 1) plano de recepción crítica 2) plano de expresión-creación. Además, estas dimensiones no se evalúan de manera lineal, sino que son convergentes.

Las seis dimensiones propuestas son las siguientes:

1. Contenido: La principal características de las narrativas transmedia es la creación de mundos unitarios que albergarán diferentes relatos multimodales complementarios. Es por ello que el alumno deberá, en primer lugar, ser capaz de evaluar material transmitido a través de diferentes plataformas (desde medios convencionales como la televisión o el cine hasta las redes sociales) y comprender su sentido unitario. Además, tendrá que mostrar la capacidad para crear la misma estrategia transmedia.

2. Lenguaje: Las narrativas transmedia albergan múltiples lenguajes que van desde el icónico o escrito hasta el audiovisual. El alumno deberá comprender el contenido que provenga de cualquier lenguaje y, además, ser capaz de utilizarlos de manera estratégica para crear una historia unitaria a través de diferentes plataformas.

Tabla 1: Dimensiones e indicadores para valorar la alfabetización transmedia

\begin{tabular}{|l|l|}
\hline DIMENSIÓN & INDICADORES \\
\hline CONTENIDO & $\begin{array}{l}\text { 1. Capacidad para comprender relatos multimodales y } \\
\text { aprehender su significado unitario } \\
\text { 2. Capacidad para crear universos narrativos compuestos } \\
\text { por relatos multimodales }\end{array}$ \\
\hline LENGUAJE & 1. Capacidad para entender diferentes lenguajes como el \\
\hline
\end{tabular}




\begin{tabular}{|c|c|}
\hline & $\begin{array}{l}\text { icónico, sonoro, audiovisual y escrito, así como las } \\
\text { particularidades expresivas de las plataformas propias de } \\
\text { la web móvil } 2.0 \\
\text { 2. Capacidad para comprender un lenguaje hipertextual } \\
\text { (saltar de un texto a otro del mismo código) e } \\
\text { hipermedial (conectar códigos diferentes). } \\
\text { 3. Capacidad para utilizar de manera combinada lenguajes } \\
\text { como el icónico, sonoro, audiovisual y escrito, así como } \\
\text { las plataformas propias de la web móvil } 2.0 \\
\text { 4. Construir relatos a través un lenguaje hipertextual e } \\
\text { hipermedial }\end{array}$ \\
\hline PLATAFORMAS & $\begin{array}{l}\text { 1. Consumo complementario de contenido a través de } \\
\text { medios tradicionales (televisión, prensa, cine, libros...) y } \\
\text { de medios sociales (redes sociales, móviles) } \\
\text { 2. Selección idónea y complementaria de diversas } \\
\text { plataformas tradicionales y propias de la web } 2.0 \text { para la } \\
\text { construcción de relatos multimodales }\end{array}$ \\
\hline CREATIVIDAD & $\begin{array}{l}\text { 1. Relacionar las producciones mediáticas con otras } \\
\text { manifestaciones artísticas } \\
\text { 2. Apropiarse y transformar producciones artísticas, } \\
\text { potenciando la, innovación, la experimentación y la } \\
\text { sensibilización estética. }\end{array}$ \\
\hline ÉTICA & $\begin{array}{l}\text { 1. Actitud responsable ante la propia identidad } \\
\text { online/offline y de los demás } \\
\text { 2. Respeto a determinadas normas tácitas de los nuevos } \\
\text { entornos (no apropiación indebida de material de autor) }\end{array}$ \\
\hline PARTICIPACIÓN & $\begin{array}{l}\text { 1. Capacidad de compartir material u opiniones del } \\
\text { contenido consumido a través de los diferentes medios } \\
\text { (fenómeno televisión } 2.0 \text { ) } \\
\text { 2. Colaboración en la autoría o difusión de contenido } \\
\text { propio o ajeno }\end{array}$ \\
\hline
\end{tabular}

3. Plataformas: El alumno deberá ser capaz de realizar un consumo crítico y complementario de contenido a través de medios tradicionales (televisión, prensa, cine, libros...) y de medios sociales (redes sociales, móviles). Además, ofrecer una selección idónea y complementaria de diversas plataformas tradicionales y propias de la web 2.0 para la construcción de sus relatos multimodales 
4. Creatividad: Es la capacidad de crear universos y relatos originales. En esta dimensiones, se incluyen aspectos relacionados con la apropiarse y transformar producciones artísticas, potenciando la, innovación, la experimentación y la sensibilización estética.

5. Ética: Mostrar una actitud responsable hacia uno mismo y hacia los demás es connatural del proceso creativo y comunicativo. Aspectos como la privacidad de la identidad online o las apropiaciones indebidas de material (plagio o piratería) se incluirían dentro de esta dimensión.

6. Participación: Para poder generar una verdadera cultura de la participación es necesario que la población tenga acceso a las nuevas tecnologías y más allá del mero acceso, sobre todo que haga un uso crítico y creativo de dichas plataformas. Esta dimensión incluye compartir material u opiniones del contenido consumido a través de los diferentes medios (fenómeno televisión 2.0) así como la colaboración en la autoría o difusión de contenido propio o ajeno

\section{Conclusiones}

La alfabetización transmedia se presenta como uno de los grandes retos de las instituciones educativas y culturales de la sociedad actual. Enmarcada dentro de una verdadera cultura de la participación, los ciudadanos, especialmente aquellos que vayan a liderar los procesos educativos y comunicativos en el futuro, deberán incorporar en sus destrezas profesiones las capacidades para evaluar y crear contenidos a través de múltiples plataformas, utilizando diversos lenguajes y mostrando una actitud ética y responsable ante su propia dieta mediática y producciones. Es por ello, que principalmente es importante la alfabetización transmedia en los Grados y Titulaciones relacionadas con la Educación y Comunicación. La propuesta de dimensiones e indicadores realizada en esta comunicación pretende ser una herramienta flexible para la evaluación de las capacidades de los alumnos en relación al transmedia, así como para diseñar programas y actividades que permitan incorporar estas cuestiones en el aula. 


\section{4 \\ Competencias mediáticas en el sur de Ecuador}

Diana Rivera (Universidad Técnica Particular de Loja, Ecuador) orcid.org/0000-0003-0534-290X\#sthash.z6tggdA4.dpuf http://scholar.google.es/ citations?user=lCG0DloAAAAJ\&hl=es\&oi=ao

Andrea Velásquez (Universidad Técnica Particular de Loja, Ecuador) orcid.org/0000-0003-0534-290X\#sthash.z6tggdA4.dpuf http://scholar.google.es/citations?user=-HcRFe8AAAAJ\&hl=es

Isidro Marín (Universidad Técnica Particular de Loja, Ecuador) orcid.org/0000-0002-6858-0983

http://scholar.google.com.ec/citations?user=Jvs80KEAAAAJ\&hl=es

Catalina Mier (Universidad Técnica Particular de Loja, Ecuador) orcid.org/0000-0002-4868-7142

http://scholar.google.com.ec/citations?user=xr4bvDwAAAAJ\&hl=en

Stephany Celly (Universidad Técnica Particular de Loja, Ecuador) orcid.org/0000-0003-4771-947X

http://bit.ly/14BokOA

\section{Introducción}

— STA INVESTIGACIÓN nace con el afán de determinar y - establecer el nivel de competencia mediática en los jóvenes de 14 a 18 años de las instituciones educativas de las ciudades de Loja y Zamora - Ecuador, edades comprendidas en estudiantes de décimo año de educación básica y tercer año de bachillerato; de la misma manera el nivel que tienen los profesores que imparten clases en estos años y los padres de familia de los alumnos.

En la presente investigación se destaca una relación directa con las seis dimensiones: lenguaje, tecnología, procesos de interacción, 
procesos de producción y difusión, ideología y valores, y estética propuestas por Ferrés y Piscitelli (2012); que a su vez mediante una serie de indicadores permiten medir la competencia en dos ámbitos: análisis y expresión.

Este tema en la actualidad debe ser abordado con atención, por el hecho de vivir en un medio que demanda a cada persona a estar informada, considerando los distintos medios de comunicación como la fuente más directa. Para que de esta manera los adolescentes tomen conciencia del uso que le dan a las tecnologías (lugar en el que generan contenido) como una herramienta de aprendizaje, más no como una herramienta de ocio.

¿Cuál es el estado de las competencias mediáticas en jóvenes, profesores y padres de familia pertenecientes a instituciones de educación públicas y privadas de Loja y Zamora? La respuesta a la anterior pregunta invita a la reflexión sobre asuntos como la alfabetización digital, la capacidad analítica de los sujetos, para procesar información y el diseño de metodologías para un mejor aprovechamiento de las potencialidades de las Tecnologías de la Información y Comunicación y los medios de comunicación en la perspectiva de formar mejores ciudadanos.

Las instituciones educativas deben encargarse de que los estudiantes se conviertan en sujetos que desarrollen nuevas competencias, adaptadas a la era digital en la que nos encontramos. Las autores Villanueva y Casas (2010), las denominan e-competencias o competencias electrónicas, las cuales pueden definirse como un subproducto.

\subsection{Competencias mediáticas y comunicación}

Las competencias mediáticas, es un término que en un principio se aplicó en el ámbito laboral, y con el tiempo se introdujo en la comunicación, en la Declaración de Grünwal, documento que se redactó durante el Congreso Internacional de Educación en Medios de la UNESCO (Alemania, enero de 1982). Para de esta manera reforzar el vínculo entre la comunicación y la educación, aumentando la posibilidad de una mejora en la educación (Sánchez y Contreras, 2012). También existe un documento oficial del Parlamento Europeo 
(2006), en que se encuentran algunas enmiendas en el marco de las competencias de clave para el aprendizaje permanente (Pérez y Martínez, 2011).

En la sociedad actual "las competencias mediáticas comportan el dominio de conocimientos, destrezas y actitudes relacionados con seis dimensiones básicas, de las que se ofrecen los indicadores principales. Estos indicadores tienen que ver, según los casos, con el ámbito de participación como personas que reciben mensajes e interaccionan con ellos (ámbito del análisis) y como personas que producen mensajes (ámbito de la expresión) (Ferrés y Pscitelli, 2012).

\subsection{Educomunicación y medios.}

Educomunicación tiene como fin preparar a las personas para que puedan interpretar y dar su opinión crítica frente a los contenidos que brindan los diversos medios de comunicación, haciendo que no solo se reciba la información (consumidores), sino, que también sepan de qué medios, y cómo acceder a la información, de esta manera se puedan utilizar estos contenidos y convertirse en prosumidores con bases previamente analizadas-valoradas.

Se rescata la importancia de este tema ante el mundo mediatizado y digitalizado al que nos enfrentamos, en el que desde el hogar y las instituciones educativas se debe preparar a cada estudiante; de esta manera, obtener una educación en medios y ciudadanos capaces de abrirse paso en esta nueva era de manera eficiente.

Por lo descrito anteriormente, y hablando netamente de la educación, es necesario contar con docentes que sean una guía para los estudiantes, por lo tanto, necesitan estar inmersos en un proceso denominando "alfabetización mediática", y que sin duda, y en palabras de Aguaded (2011), se logrará gracias a la "Educomunicación", que comprende una educación crítica, activa y plural ante los medios de comunicación, que ha de estar dotada de docentes capaces de desarrollar propuestas didácticas coherentes, que integren el potencial de las tecnologías que facilitan el alcance del conocimiento, y de la competencia digital y mediática, para lograr un uso adecuado de los medios, y de las nuevas formas de comunicación.

De esta manera y siguiendo a Pérez Tornero (2003) cuando habla de 
los retos de la educación en la sociedad audiovisual, considera ciertos puntos principales para su buen desarrollo, entre estos: apertura de la escuela a otras fuentes del saber, utilización de una didáctica de la exploración, el descubrimiento y la invención; la participación de la comunidad entera en la educación; alfabetización audiovisual; educación multicultural que transcienda espacios y limitaciones; superación del modelo educativo fabril y existencial; renovación tecnológica; redefinición del papel del profesorado y del papel del estado; consideración el principio de educación continua; y la implicación de la escuela en la sociedad y en el entorno al que ha de dar respuestas.

Tomando en cuenta lo que menciona Pérez Tornero, se puede decir que hay que considerar al realizar una planificación de educación: el enfoque en medios de comunicación, cuidando de no caer solamente en utilizar mecánicamente las tecnologías, sino, en la que los jóvenes conozcan estos nuevos lenguajes, aprovechen la información que llega a sus manos; y de esta manera reflexionar sobre el impacto que la educación puede tener en cada uno de los ellos.

\section{Materiales y Métodos}

Los primeros resultados de esta investigación aplican lineamientos metodológicos de tipo cuantitativo y cualitativo, desarrollados en un ámbito exploratorio enfocándose al nivel de competencia mediática que poseen los jóvenes, profesores y padres de familia. Se utilizó, en una primera fase un proceso de en cuestación. A partir del proceso de investigación bibliográfica se hizo el diseño de dos encuestas, una dirigida a los estudiantes y otra dirigida a los docentes para medir el nivel de cada grupo. El objetivo de este artículo es analizar el grado de formación recibida en comunicación audiovisual y digital, determinar los puntos principales en los que se debe prestar mayor atención dentro de la educación en medios, específicamente en la dimensión de Recepción e Interacción; tanto de profesores como alumnos en las dos ciudades analizadas (Loja y Zamora).

Las encuestas fueron aplicadas on-line (previamente se realizó encuestas piloto y su respectiva valoración) a una población específica de estudiantes de 14 a 18 años, edades comprendidas entre décimo a tercer año de bachillerato de 23 colegios de la ciudad de Loja y 6 
colegios de la ciudad de Zamora, y a los docentes que componen estas instituciones educativas, para determinar cómo utilizan las herramientas tecnológicas, adquieren e imparten sus conocimientos educativos.

En el proceso también se empleó la técnica del focus group, grupos de discusión, orientado a los padres de familia en una muestra mínima de 8 y máxima de 10 personas, con este técnica se logró contrastar la información proporcionada por los estudiantes y profesores. Se contó con un banco de preguntas que respondían a las seis dimensiones.

Para el análisis de los resultados se utilizó la herramienta estadística SPSS, y los criterios de valoración de cada cuestionario en base al artículo de Ferrés y Piscitelli (2012) quienes dirigieron esta investigación desde su inicio en España.

\subsection{Muestra}

La población o universo de estudio fue de 13.922 de estudiantes de ambas ciudades, finalmente en función del cálculo muestral para el análisis de los datos se tomó en cuenta 1.150 encuestas aplicadas a los alumnos y 160 encuestas aplicadas a profesores en la ciudad de Loja. De igual forma, para la ciudad de Zamora se tomó en cuenta 253 encuestas de alumnos y 53 de profesores con las que se analizaron los datos.

Con el objetivo de conseguir una población homogénea se seleccionó en un principio 29 colegios de la ciudad de Loja (de los cuales aceptaron participar 23 colegios), y 5 colegios de la ciudad de Zamora con una población estudiantil en similares condiciones. Las instituciones seleccionadas fueron Colegio Experimental "Beatriz Cueva de Ayora", Colegio Dr. Antonio Peña Celi, Colegio Experimental "Bernardo Valdiviezo", Colegio Experimental "Pío Jaramillo Alvarado", Colegio Nacional Adolfo Valarezo, Colegio Particular Juan Montalvo, Colegio Particular Eugenio Espejo, Colegio Particular José María Vivar Castro, Colegio Hernán Gallardo Moscoso, Colegio Iberoamericano San Agustín, Instituto Tecnológico Superior "Daniel Álvarez Burneo", Unidad Educativa José Antonio Eguiguren "La Salle", Centro Educacional Liceo de Loja, Tagesschule y colegio "San Gerardo", Unidad Educativa 
Ateneo, Unidad Educativa San José de Calasanz, Unidad Educativa "Fernando Suárez Palacio", Unidad Educativa "Vicente Anda Aguirre", Unidad Educativa "La Porciúncula", Unidad Educativa "La Inmaculada", Unida Educativa "San Francisco de Asís" y Colegio Militar "Tcrn. Lauro Guerrero".

En la ciudad de Zamora fueron seleccionados los colegios: Colegio 12 de Febrero, Colegio Amazonas, Unidad Educativa Madre Bernarda, Colegio Luis Felipe Borja de Alcázar y Colegio San Francisco.

\subsection{Análisis y resultados}

Los resultados de los cuestionarios distribuyen la muestra por estudios de manera desigual. Se obtuvieron 53 respuestas de profesores de Zamora (3,2\%), 187 de profesores de Loja (11,4\%), 1,150 estudiantes de Loja $(70 \%)$ y 253 estudiantes de Zamora $(15,4 \%)$.

$\mathrm{Al}$ analizar los datos que corresponden al grado de formación recibida en comunicación audiovisual y digital, se concluye que los profesores de Loja son los que han tenido mayor formación $(21,9 \%$ tienen una alta competencia); seguido de los estudiantes de la ciudad de Loja $(19,5 \%$ poseen una alta competencia). Posteriormente, le siguen los profesores de la ciudad de Zamora $(18,9 \%$ ha recibido formación audiovisual) y por último están los estudiantes de la ciudad de Zamora $(16,6 \%)$.

De esta manera se destaca que tanto los alumnos como los docentes de las diferentes instituciones de educación de la ciudad de Loja han recibido formación en comunicación audiovisual y digital.

Partiendo de estos conocimientos previos, se han determinado puntos principales en los que se debe prestar mayor atención dentro de la educación en medios, específicamente en la dimensión de Recepción e Interacción; tanto por profesores como alumnos en las dos ciudades analizadas (Loja y Zamora). 
Tabla1. Participación en los últimos 5 años en algún proyecto de investigación, sobre competencias en medios de comunicación

\begin{tabular}{|c|c|c|c|c|}
\hline & \multicolumn{2}{|c|}{$\begin{array}{l}\text { ¿Ha participado en los últimos cinco años en } \\
\text { algún proyecto de investigación, innovación o } \\
\text { elaboración de materiales didácticos sobre } \\
\text { competencias en medios de comunicación? }\end{array}$} & \multirow[t]{2}{*}{ Total } \\
\hline \multirow{5}{*}{ Tipo } & & $\begin{array}{l}\text { 0. No ha participado } \\
\text { o no conoce si la } \\
\text { elaboración de algún } \\
\text { producto suyo está } \\
\text { dentro de estos } \\
\text { parámetros. }\end{array}$ & $\begin{array}{l}\text { 2. Capacidad de aportar } \\
\text { al desarrollo de } \\
\text { competencias en medios } \\
\text { de comunicación. }\end{array}$ & \\
\hline & \multirow{2}{*}{$\begin{array}{l}\text { Profesores } \\
\text { ciudad de } \\
\text { Loja }\end{array}$} & 142 & 45 & 187 \\
\hline & & $75,90 \%$ & $24,10 \%$ & $100,00 \%$ \\
\hline & \multirow{2}{*}{$\begin{array}{l}\text { Profesores } \\
\text { ciudad de } \\
\text { Zamora }\end{array}$} & 39 & 14 & 53 \\
\hline & & $73,60 \%$ & $26,40 \%$ & $100,00 \%$ \\
\hline \multirow{2}{*}{ Total } & & 181 & 59 & 240 \\
\hline & & $75,40 \%$ & $24,60 \%$ & $100,00 \%$ \\
\hline
\end{tabular}

Fuente: Profesores de los colegios públicos, privados y fiscomisionales de Loja y Zamora. Elaboración: Los autores

Un punto importante en el que debe existir mayor atención en los docentes se encuentra en la falta de investigación, innovación de materiales didácticos sobre competencias mediáticas. Tal como se puede observar en la Tabla $1 . e l$ 75,9\% de alumnos de la ciudad de Loja no ha participado en los últimos cinco años en algún proyecto de investigación, innovación o elaboración de materiales didácticos sobre competencias en medios de comunicación, al igual que los docentes de la ciudad de Zamora que tampoco han realizado esta actividad en un $73,60 \%$

Con los resultados obtenidos que muestra la Tabla 1, se determina una "baja competencia en el ámbito del análisis", en los profesores de Loja y Zamora al no haber participado o no conocer si la elaboración de algún producto académico se encuentra dentro del tema de 
competencias mediáticas por parte de los docentes; no cuentan con la "capacidad de llevar a cabo un trabajo colaborativo mediante la conectividad y la creación de plataformas que facilitan las redes sociales".

Esta realidad que muestran los profesores de las ciudades de Loja y Zamora se ve reflejada en sus alumnos; si los docentes no participan en este tipo de proyectos, tampoco se encuentran relacionados con las diferentes herramientas o formas de participar en esta era digital, lo mencionado se resalta en los siguientes resultados.

Los datos de uno de los puntos que necesitan atención es la participación de los estudiantes en temas sociales y/o políticos a través de los medios. Los alumnos de Loja en su mayoría $75 \%$ no participan en la sociedad con los medios; seguido de los estudiantes de la ciudad de Zamora (74,3 \% que tampoco realizan esta actividad).

\section{Tabla 2. Participación en temas sociales y/o políticos}

\begin{tabular}{|c|c|c|c|c|}
\hline & & \multicolumn{2}{|c|}{$\begin{array}{l}\text { ¿Crees que tienes una participación } \\
\text { activa en los temas sociales y/o políticos } \\
\text { (colaboración con ONG’s, debatiendo } \\
\text { sobre temas de interés político o social, } \\
\text { participando en concentraciones } \\
\text { solidarias a través de las redes...) a través } \\
\text { de las tecnologías o }\end{array}$} & \multirow[t]{2}{*}{ Total } \\
\hline & & $\begin{array}{l}0 . \text { El alumno no } \\
\text { participa en la } \\
\text { sociedad a través } \\
\text { de los medios. }\end{array}$ & $\begin{array}{l}\text { 2. El alumno } \\
\text { participa activamente } \\
\text { en la sociedad a } \\
\text { través de los medios }\end{array}$ & \\
\hline \multirow{4}{*}{ Tipo } & \multirow{2}{*}{$\begin{array}{l}\text { Alumnos } \\
\text { de Loja }\end{array}$} & 863 & 287 & 1150 \\
\hline & & $75,00 \%$ & $25,00 \%$ & $100,00 \%$ \\
\hline & \multirow{2}{*}{$\begin{array}{l}\text { Alumnos } \\
\text { de } \\
\text { Zamora }\end{array}$} & 188 & 65 & 253 \\
\hline & & $74,30 \%$ & $25,70 \%$ & $100,00 \%$ \\
\hline \multirow{2}{*}{ Total } & & 1051 & 352 & 1403 \\
\hline & & $74,90 \%$ & $25,10 \%$ & $100,00 \%$ \\
\hline
\end{tabular}

Fuente: Estudiantes de los colegios públicos, privados y fiscomisionales de Loja y Zamora. Elaboración: Los autores 
Los alumnos demostraron tener una "baja competencia mediática" en la dimensión Recepción e interacción, al no tener una actitud activa en la interacción con las pantallas, entendidas como oportunidad para construir una ciudadanía más plena, un desarrollo integral, para transformarse y transformar el entorno.

Dejando en evidencia la falta de educación en este aspecto; y de cierta manera incumpliendo hasta ahora con lo propuesto por la Constitución de la República del Ecuador (2008), en el apartado del "Buen Vivir", artículo 347, numeral 8, que indica que es responsabilidad del Estado: "incorporar las tecnologías de la información y comunicación en el proceso educativo y propiciar el enlace de la enseñanza con las actividades productivas o sociales" (Constitución Política de Ecuador, 2008).

\section{Discusión y Conclusiones}

Los resultados indican que las Tecnologías de la Información y Comunicación han modificado las estructuras de los centros escolares a un nivel organizativo. También el uso de las TIC fomenta en el alumnado una alta motivación para aprender. Pero no basta con poner equipos en las escuelas y tampoco con enseñar a los profesores a usarlo; es necesario pero no suficiente. El alumnado tiene que construir su mundo; los ordenadores son solo una innovación educativa (Mcclintock, 2000).

Se tiene que dar mayor importancia al componente pedagógico que al tecnológico. Hay que insertar las tecnologías en los colegios con miras a generar conocimiento. La tecnología formará parte de nuestra cotidianeidad pero aún no ha logrado entrar pedagógicamente en las escuelas ecuatorianas, por el escaso juicio que se ha dado a este proceso, así como el inadecuado o nulo uso en prácticas educativas.

Las TIC son un importante recurso en la sociedad del conocimiento y un apoyo docente, pero la solución no está en las pantallas sino en la motivación del profesorado, en la formulación de políticas educativas integrales que atiendan a las necesidades educativas venideras. Eso parece que es mayor en la ciudad de Loja que en la de Zamora. Se tiene que devolver al profesor el orgullo de serlo y a las aulas su 
capacidad de formar a ciudadanos. Esto es hoy uno de los desafíos más importantes que tiene la democracia en nuestras sociedades (Bacher, 2009).

Durante la investigación hemos podido constar que el gobierno ha incluido políticas públicas de educación dirigido a maestros, es así que aparte de evaluar sus conocimientos realiza capacitación en cuanto al uso y aprendizaje de las nuevas tecnologías, además dota de recursos necesarios para llevar a cabo el proceso de enseñanza. ${ }^{4}$

\footnotetext{
${ }^{4}$ El capítulo es resultado del estudio desarrollado en el marco de la Convocatoria de Proyectos I+D del Ministerio de Economía y Competitividad con clave: EDU2010-21395-C03-03, titulado «La enseñanza obligatoria, ante la competencia en comunicación audiovisual en un entorno digital». Y Pertenece a la V Convocatoria Anual de Proyectos de Investigación con Fondos Internos (2014) al proyecto de investigación interna de la UTPL "Competencias mediáticas en jóvenes, profesores y padres de familia de instituciones educativas públicas y privadas de Ecuador" cuya directora es Diana Rivera Rogel y participan como investigadores: Isidro Marín, Catalina Mier, Andrea Velásquez, Juan Carlos Torres, Margoth Iriarte, Lucy Andrade y, como becaria de investigación, Stephany Celly.
} 


\section{Qué requiere un estudiante de Periodismo para su mejor inserción en el mercado laboral.}

Miguel Ángel Ortiz Sobrino (Universidad Complutense Madrid) http:// orcid.org/0000-0003-0103-9524

http://scholar.google.es/citations?user=3OCGQs4AAAAJ\&hl=es

http://orcid.org/0000-0003-0103-9524

Fernando Peinado Miguel (Universidad Complutense de Madrid) orcid.org/0000-0003-0048-4562

http://scholar.google.es/citations?user=wel7hwUAAAAJ\&hl=es

Lelia Zapata Palacios (Universidad Complutense de Madrid) http://orcid.org/0000-0002-6543-7348

https://scholar.google.es/ citations?user=bKsNu4MAAAAJ\&hl=es

\section{Introducción}

— L PRESIDENTE de la Comisión Europea decía que las investigación científica, la cualificación profesional, la integración en un proyecto para toda la vida y la cooperación internacional (Delors, 1996). Es propósito de este trabajo respetar, desde la investigación científica desarrollada por un grupo de profesores universitarios que dedican su vida a la docencia y a la investigación, la capacidad que les otorga la Sociedad para cualificar conductas discentes y establecer su adecuación a la realidad laboral de nuestros días. 
Una investigación posible gracias a los datos que el Centro de Orientación e Información de Empleo (COIE) de la UCM ofrece de los alumnos de la Facultad de Ciencias de la Información que realizan prácticas tuteladas en empresas que mantienen acuerdos de colaboración con la UCM. Y a pesar de la mala imagen que se desea ofrecer de la enseñanza pública, la universidad pública les acoge, año tras año, por una serie de razones objetivas que ellos mismos eligen para matricularse y estudiar.

En esta ocasión, en la UCM, durante el curso 2013- 2014 han sido la excelencia académica (32,8\%) en primer lugar y como segundo elemento motivador la oferta de títulos $(28,5 \%)$ según se aprecia en el Barómetro Universidad - Sociedad 2014, informe en el que los alumnos de Ciencias de la Información han participado en un 9,2\% sobre la muestra total. Una Universidad cuyo alumnado de nuevo ingreso es de fuera de la Comunidad de Madrid en un 45 por ciento (EMES, 2012)

Una vez se tienen "datadas" las empresas en las que los estudiantes han desarrollado prácticas, se crean indicadores y se establecen una serie de parámetros para analizar el estado de la cuestión y lograr respuestas a las preguntas objeto de esta investigación. Siempre respetando, tal y como establece la Memoria anual de seguimiento del Grado de Periodismo desde el curso académico 2011/2012, que las prácticas externas solo se realizaban por parte de los alumnos matriculados en Licenciatura, mientras que en el curso 2012-2013 si podían acceder lo que cursaban $3^{\circ}$ de Grado, al estar ya en el segundo ciclo. Durante el curso 2013-2014 el ciclo completo permitía la realización de prácticas al total de alumnos de $3^{\circ}$ y de $4^{\circ}$ de Grado además de los alumnos del segundo ciclo de la Licenciatura.

A partir de los datos oficiales fuente de la investigación se buscan qué estrategias son las más adecuadas para lograr el mejor impacto de los estudiantes en prácticas en las empresas; qué iniciativas pueden favorecer su inserción laboral, incluso desde el emprendimiento, a partir de una favorable gestión del conocimiento y sus entornos colaborativos que les permita integrarse en las nuevas organizaciones empresariales para realizar labores informativas y de comunicación. 
Un estudio de estas características permite alcanzar un conocimiento de la realidad objetivada, si bien entre los fines más directos están:

1. La cuantificación de la oferta que desde el mercado (canalizado por el COIE/UCM) se ofrece a los estudiantes de Periodismo de Ciencias de la Información para realizar prácticas periodísticas y en comunicación.

2. La tipología de esas prácticas para conocer qué demandan las empresas y qué espacios laborales pueden encontrar los estudiantes una vez egresados.

3. Qué conocimientos básicos reclaman las empresas del sector a los futuros licenciados y graduados, para

4. Conocer, analizar y presentar qué nuevos perfiles profesionales demanda el mercado informativo y de la comunicación. Qué nuevas modalidades laborales se presentan para los futuros profesionales.

Una vez contemplados los objetivos, se plantea la hipótesis en relación a la demanda de empleo por parte de las empresas:

H1. Si realmente las funciones que demandan mayoritariamente las empresas han cambiado a consecuencia de una evolución de los medios y el alcance de esa nueva demanda como afecta a los futuros profesionales.

\section{Estado de la cuestión}

Con un mercado en regeneración, consecuencia de la crisis financiera y de los avances de las nuevas tecnologías como Internet, las dificultades para los que participan en el sector de la comunicación e información, tanto empresas como futuros titulados que desean acceder a un puesto de trabajo, requieren de fases de adaptación, entre las que ya se han consolidado las prácticas formativas. Es evidente que aún existe masificación en las aulas de las universidades públicas, como es el caso de la Universidad Complutense de Madrid objeto de este artículo, y se mantienen los mismos problemas que hace dos décadas (Ortega y Humanes, 2000) como son los recursos económicos y los problemas pedagógicos. 
Ahora bien, este estudio trata de averiguar qué necesidades tienen los estudiantes y cómo compaginarlas sobre las cualidades y capacidades que el mercado demanda. Y cómo apoyar desde los procesos formativos con más y/o mejores prácticas, bien en el aula, como en platós, estudios y laboratorios. No es fácil trabajar en grupos muy numerosos desarrollos prácticos $\mathrm{y}$, sin embargo, esta dinámica de trabajo se la encuentran después en los espacios laborales en los que se les pide más cantidad que calidad en el desempeño. Cómo compaginar lo que se requiere en y desde las empresas y lo que los estudiantes aportan con sus prácticas durante el tiempo de realización de su beca. Es básico establecer un diseño de procesos activos de adquisición de competencias y capacidades para el desempeño profesional. Algo que pasa obligatoriamente por mejorar los mecanismos y las actividades de coordinación docente. $\mathrm{Y}$ las prácticas en empresas se han considerado como una estrategia laboral en el marco de la creciente importancia de la empleabilidad (Brunner, 2002) al ser reconocida la práctica como algo fundamental en el aprendizaje del desempeño profesional (Marhuenda Fluixá, Bernard i García y Navas Saurin, 2010)

La oferta de formación especialmente diseñada para periodistas como complemento a su etapa universitaria está enfocada al conocimiento profesional. El objetivo es la adquisición de experiencia a partir de actividades basadas en el día a día de la mano de expertos de primer nivel. Este es el principal reclamo de másteres profesionales de universidades públicas y privadas, sobre todo los que tienen una relación dependiente de los grandes grupos empresariales. Por lo tanto, parece que una de las necesidades evidentes, en el caso de los estudios de Periodismo, pasa por mejorar la práctica profesional mediante los posgrados que ofrecen una relación directa, como por ejemplo El País/UAM; ABC/UCM; RNE/UCM; Cope/CEU San Pablo; TVE/URJC. (233grados, 2013) que permite el seguimiento de prácticas por parte de profesionales y que cuentan con el prestigio de los centros universitarios.

Los propios centros universitarios iniciaron ya hace años la praxis universidad - empresa para ayudar a incorporar a los estudiantes al mercado laboral (López-García, 2010; Montoro-Sánchez, 2012), Y en este recorrido hemos alcanzado incluso una figura reconocida 
socialmente como la del "becario en prácticas", consecuencia de esta realidad, muy criticada (Lamuedra, 2007; APM, 2012).

$\mathrm{Y}$ es difícil entender las razones por las que el sector se ha precarizado. Un mercado en el que un $22 \%$ de los universitarios trabajan sin contrato alguno, porcentaje que se eleva en el interanual respecto a 2013 en ocho puntos (GAD3 Consultores, 2014) cuando las prácticas reguladas hacen posible su incorporación con unos costes muy bajos para las empresas. En una situación en la que la vocación se convierte en el mejor aliado de quienes desean incorporarse a las rutinas sociales con opciones retributivas a cambio de una práctica laboral que tenga relación con sus estudios, bien para pagárselos o para ayudar a sus familias.

En los últimos años se vienen realizando estudios para conocer cómo es el nuevo alumno de Grado en Periodismo en la CAM (Ortiz Sobrino, Rodríguez Barba y Pérez Serrano, 2011), cuáles son sus motivaciones e incluso sus percepciones de los nuevos Grados en el espacio Bolonia (Peinado y Fernández Sande, 2011 y Ortiz Sobrino, 2012). Conocimientos que ayudan a perfilar cómo será el profesional en el momento de su inserción laboral, si bien faltaba el análisis posterior a la práctica formativa en su primer contacto con el mercado de trabajo.

Un perfil que motiva la creación de nuevos espacios y de responsabilidades con tareas adaptadas según imponen los nuevos medios (Esteban, 2012; Yuste y Cabrera, 2014) o que abre posibilidades de emprendimiento desde el autoempleo (Paniagua Rojano y Gómez Aguilar, 2014; Casero Ripollés y Cullel-March, 2013)

\begin{tabular}{|l|l|l|l|}
\hline \multicolumn{4}{|c|}{ Tabla 1. Curso 2011-2012 - Matriculados en Periodismo en la CAM } \\
\hline U. Públicas & Licenciatura & Grado & Total \\
\hline C. Propios & 3.310 & 2.977 & 6.287 \\
\hline C. Adscritos & 107 & 98 & 205 \\
\hline U. Privadas & 442 & 784 & 1.226 \\
\hline UDIMA & & 246 & 246 \\
\hline Totales & 3.859 & 4.105 & $\mathbf{7 . 9 6 4}$ \\
\hline
\end{tabular}

Fuente: EMES, 2013 
La Comunidad de Madrid es un excelente laboratorio de estudio por acoger al mayor número de periodistas en paro, un total de 7.891 que representan el 28,7 por ciento del total del estado español, por encima de Andalucía (14,5\%) y de Cataluña (12,3\%) que entre las tres comunidades superar el 55,5 por ciento del paro nacional en el sector (APM, 2012) y la mayor demanda de empleo (SEPE, septiembre de 2012) con el $28,3 \%$.

En los últimos años el número de Titulados en Periodismo en España ha pasado de los 3.268 licenciados del año 2000 a los 2.909 licenciados y graduados en 2012 (APM, 2013, 45) Mientras se produce este descenso en los egresados, el número de matrículas continua al alza y sólo en la Comunidad de Madrid alcanzó en el curso 2011-2012 los 7.964 alumnos matriculados sólo en Periodismo (no se incluyen el resto de las titulaciones en comunicación y dobles titulaciones) de los que considerados como nuevas matrículas fueron 924 (729 pertenecen a la UCM)

\section{Metodología}

La actividad académica e investigadora es la base que motiva el estudio que se presenta, coaligado con la realidad que se ofrece para los futuros profesionales desde el mercado laboral. El grupo de investigación Research and Learning of Media and Communications Management (MediaCom UCM) ha tenido desde su formación el interés por conocer cuál era el perfil de entrada de los estudiantes en el Grado de Periodismo (Peinado, 2011; Peinado y Fernández Sande, 2011; Ortiz Sobrino, Rodríguez Barba y Pérez Serrano, 2011) así como por el desarrollo de estos para afrontar la etapa de posgrado.

Con la inmersión de los aconteceres universitarios en el Espacio Europeo de Educación Superior, para esta investigación se ha utilizado una metodología acorde con los progresos metodológicos propios del "Plan Bolonia" y que se viene aplicando desde inicios de este siglo XXI. Se trata de la metodología Tuning (Valle, 2006; López Sarmiento 2011; Deusto, 2014) que permite identificar puntos de referencia comunes desde la perspectiva universitaria, y con la que se pretende desarrollar perfiles profesionales y resultados de aprendizaje comparables y compatibles. Además, facilita el empleo promoviendo 
la transparencia en las estructuras educativas y favorece un lenguaje común tanto para el sector educativo como para el empresarial.

Conocer las necesidades de los estudiantes de Periodismo para su mejor inserción en el mercado laboral tiene su marco objeto de estudio en la Comunidad de Madrid, sobre una población universitaria que se aloja en la Facultad de Ciencias de la Información de la UCM, centro en el que un 45 por ciento de los alumnos proceden de otras comunidades autónomas y regiones internacionales.

El estudio se fundamenta en los datos que contempla el Centro de Orientación e Información de Empleo de la Universidad Complutense de Madrid. La base son las fichas de contratación que este organismo tiene para el seguimiento de las prácticas de los alumnos de Periodismo de Ciencias de la Información de la UCM y que se han generado entre el 10 de enero de 2012 y el 22 de diciembre de 2013. Se corresponden con periodos de prácticas que alcanzan desde el 10 de enero de 2012 al 1 de octubre de 2013 (de partida) y del 27 de julio de 2012 al 14 de julio de 2014 (a término)

El trabajo de campo se ha llevado a cabo durante los meses de mayo a julio de 2014 sobre un total de 1.386 fichas válidas que representan un $44,7 \%$ sobre el total de alumnos matriculados durante los cursos 2012-2013 y 2013-2014 y que cursan el segundo ciclo tanto del Grado como de Licenciatura, con un porcentaje mayoritario de mujeres $(60,60 \%)$ y una media de edad de 21 años.

Los rasgos académicos del alumnado de Periodismo de Ciencias de la Información que hace prácticas corresponde al segundo ciclo del Grado $\left(3^{\circ}\right.$ y $4^{\circ}$ curso y siempre que se hayan superado el $25 \%$ de los créditos); segundo ciclo de Licenciatura $\left(4^{\circ}\right.$ y $5^{\circ}$, si bien en el curso 2013-2014 solo se mantiene $5^{\circ}$ y los grupos "R" de cursos anteriores); alumnos de Máster y de Doctorado.

Destaca la mayoría de alumnos de Licenciatura, 1.031 de los que 872 están matriculados en Periodismo. La diferencia procede de alumnos que están matriculados en las otras titulaciones como Comunicación Audiovisual, Publicidad y Relaciones Públicas e incluso Biblioteconomía y Documentación, cuyos estudios afines hacen posible 
también la realización de prácticas en empresas informativas. Y se aprecia el superior números de alumnos de máster que hacen prácticas por encima de los doctorandos, lo que evidencia que mientras el máster puede tener una deriva más profesional, los estudios de doctorado se perfilan hacia la carrera docente e investigadora.

\section{Figura 1. Rasgos académicos del alumnado que realiza prácticas}

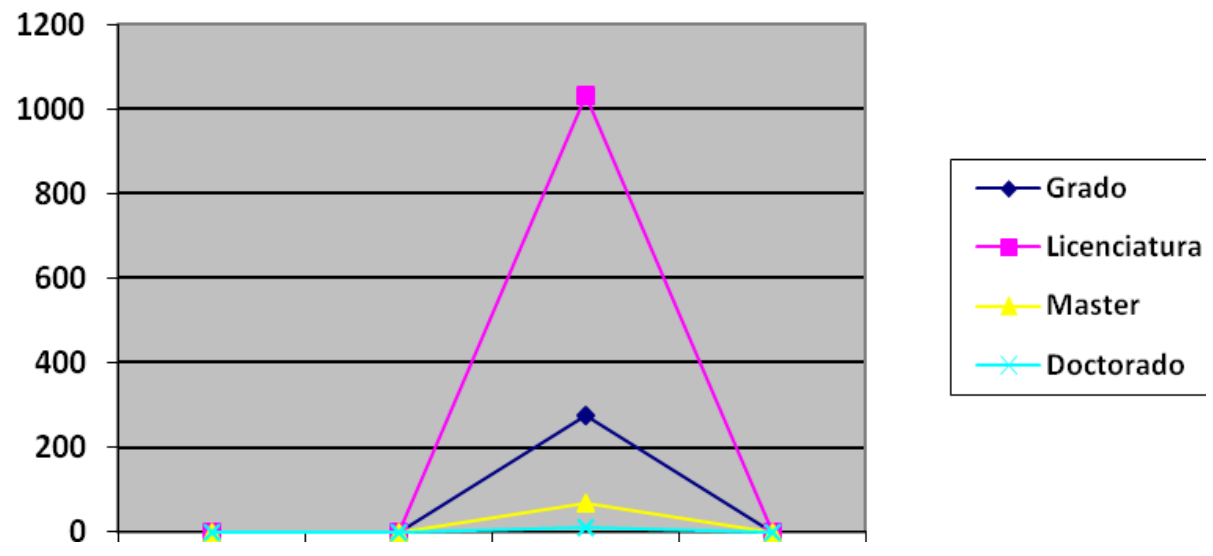

Fuente: Elaboración propia.

La información se obtiene a partir de las 442 empresas con las que la Universidad mantiene acuerdos de colaboración para la realización de prácticas tuteladas por docentes. Representan a 87 destinos y un total de 2.219 funciones profesionales.

Los resultados se elaboran como consecuencia del método hipotético - deductivo y fundamentado en planteamientos cuantitativos. Se configura una base de datos multivariable dividida en cinco bloques:

D1. Número de ficha

D2. Contrato e intervinientes

D3. Requisitos académicos

D4. Características del puesto

D5. Perfiles profesionales demandados 
Para afrontar esta investigación se preparó un Tesauro a partir de una tipología de empresas informativas y de comunicación para el control y seguimiento de cada una de las fichas, uno de los grupos "diana" que se señala en la metodología Tuning: las empresas por un lado y en el otro los estudiantes y docentes.

\section{Tabla 2. Tipología de empresas de comunicación (nacional e internacional)}

\begin{tabular}{|c|c|c|c|c|}
\hline \multicolumn{3}{|c|}{ Clasificación en esta investigación } & \multicolumn{2}{|c|}{ Clasificación nacional e internacional } \\
\hline Conjunto & Sector & $\begin{array}{l}\text { Tipo de empresa de } \\
\text { comunicación }\end{array}$ & $\begin{array}{l}\text { CNAE } 2009 . \\
\text { (Real Decreto } \\
475 / 2007 \text {, } \\
\text { de } 13 \text { de abril, } \\
\text { por el } \\
\text { que se aprueba la } \\
\text { Clasificación } \\
\text { Nacional de } \\
\text { Actividades } \\
\text { Económicas } \\
\text { 2009) }\end{array}$ & $\begin{array}{l}\text { Standard Industrial } \\
\text { Classification (SIC). } \\
\text { Desplazado, en parte, } \\
\text { por el Código NAICS } \\
\text { (North American } \\
\text { Industry } \\
\text { Classification System) } \\
\text { más moderno }\end{array}$ \\
\hline \multirow{6}{*}{$\begin{array}{l}\text { Medios } \\
\text { tradicionales } \\
\text { (información y } \\
\text { Periodismo) }\end{array}$} & \multirow{3}{*}{1} & Prensa & 58.1 & 22 \\
\hline & & Periódicos & 58.13 & 2212 \\
\hline & & Revistas & 58.14 & 2213 \\
\hline & 2 & Radio & 60.10 & 4832 \\
\hline & 3 & Televisión & 60.20 & 4833 \\
\hline & 4 & Agencias de información & 63.91 & 7351 \\
\hline \multirow{6}{*}{$\begin{array}{l}\text { Sector de la } \\
\text { comunicación } \\
\text { y Publicidad }\end{array}$} & 5 & $\begin{array}{l}\text { Agencias de } \\
\text { comunicación }\end{array}$ & 70.21 & 4899 \\
\hline & 6 & Agencias de publicidad & 73.11 & 7311 \\
\hline & 7 & $\begin{array}{l}\text { Empresas del sector } \\
\text { publicitario }\end{array}$ & 73 & 7319 \\
\hline & \multirow{3}{*}{8} & $\begin{array}{l}\text { Instituciones públicas y } \\
\text { privadas }\end{array}$ & & \\
\hline & & $\begin{array}{l}\text { Administración } \\
\text { Pública (local) }\end{array}$ & 84 & 9121 \\
\hline & & $\begin{array}{l}\text { Actividades } \\
\text { asociativas }\end{array}$ & 94 & 99 \\
\hline
\end{tabular}

Fuente: Tesauro PIMCD nº 176 y elaboración propia 
En la tabla 3 se aprecian la clasificación utilizada en este trabajo a partir de la teoría y planteamientos conceptuales de la Empresa Informativa así como de las codificaciones CNAI y SIC, que ayudan a ver y comprender las relaciones entre la Universidad y el mercado de la comunicación.

Los límites del análisis se establecen en los dos cursos académicos en los que se fundamenta el estudio y en la necesidad de completarlo con un cualitativo mediante entrevistas en profundidad tanto a empresarios - empleadores como a los estudiantes en prácticas y una encuesta de satisfacción para ambos colectivos. Esta sería la manera de encontrar resultados cuyas conclusiones se podrían extrapolar, si bien la base de datos en la que reposa la investigación permite una representatividad muy alta.

\section{Análisis y resultados}

Una de las razones de la investigación es conocer y comprobar si hay diferencias en la demanda que las empresas realizan, en este caso a la UCM, para que los alumnos desempeñen sus prácticas.

En los medios audiovisuales, radio y televisión, los perfiles que se han demandado históricamente han sido: Redactores, locutores, productores.

En el caso de los medios impresos y agencias de información, el perfil del alumno que realizaba prácticas era también para la redacción, bien como auxiliar, colaborador $\mathrm{o}$ incluso en tareas gráficas.

En los medios digitales el perfil de alumno de prácticas más demandado es el de redactor, responsable de contenidos, webmáster y Community manager.

Esta investigación establece una serie de ocupaciones según las demandas de las empresas a partir de la única función o desde la multifunción.

4.1 Desde la demanda de una única función se aprecia que la tarea principal no difiere de la ya tradicional que corresponde a las labores periodísticas habituales, como son la Redacción, ya sea en medios 
impresos diarios como en los audiovisuales, agencias de información y en medios electrónicos.

Figura 2. Las quince primeras funciones demandadas cuando se oferta sólo una función por contrato de prácticas

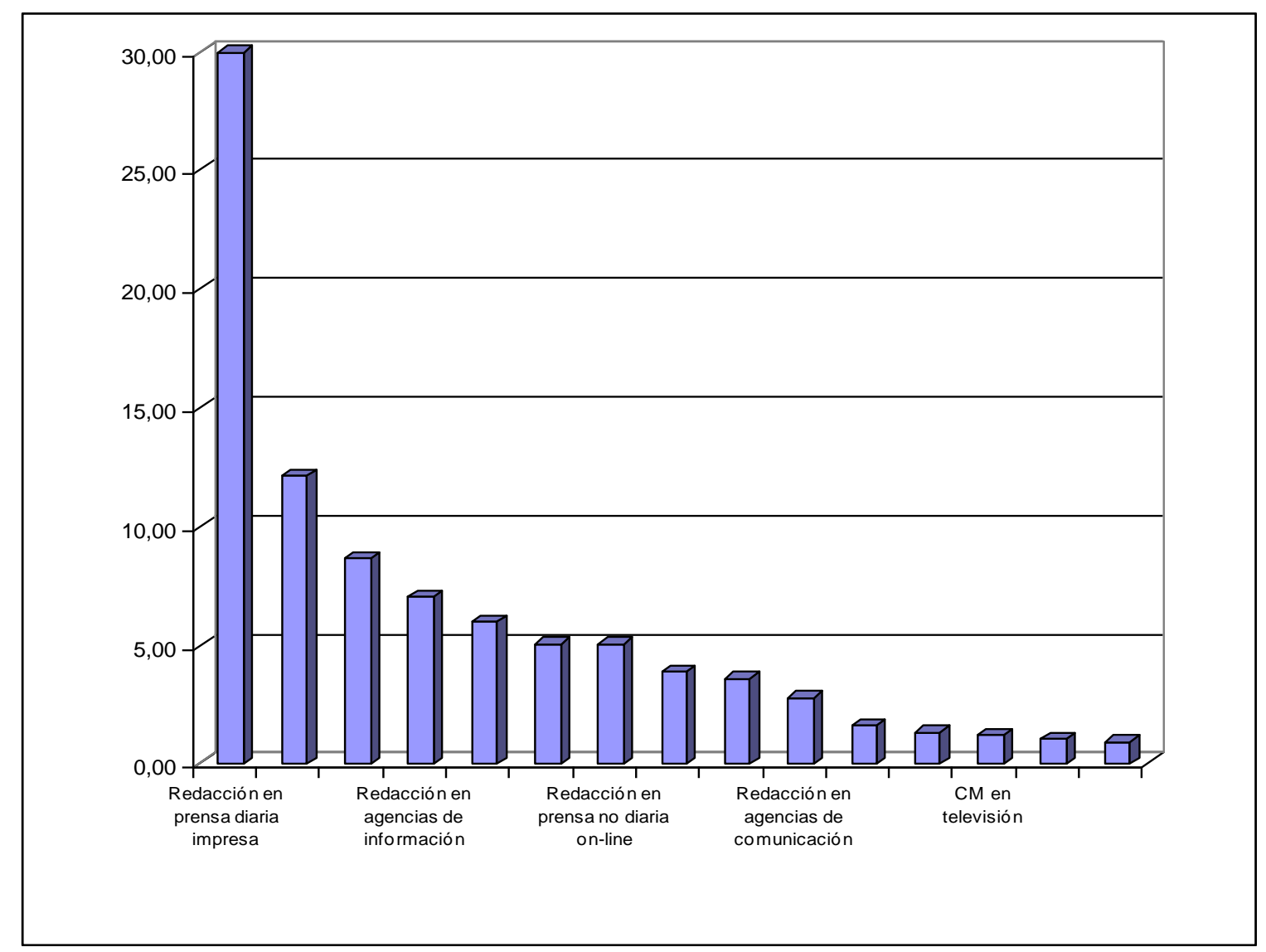

Fuente: Tesauro PIMCD nº 176 y elaboración propia

Y se puede destacar también la escasa demanda de nuevos puestos como el de Community Manager, tan aclamados, y que sin embargo en esta clasificación no resalta por una porcentualidad si acaso mediana (muy por debajo del 5\%).

Entre las menos demandadas están las prácticas de documentación en diarios impresos y en prensa diaria on line así como en agencias de información y de comunicación con un $0,27 \%$, mismo porcentaje que la demanda para realizar prácticas en Comunicación interna en diarios de papel y prensa no diaria, en agencias de publicidad y en las instituciones públicas y privadas labores de diseño y análisis de investigación de mercados. 
Con un $0,13 \%$, la menor demanda se refleja en comunicación externa de medios impresos diarios y en internet, comunicación interna en prensa no diario on-line; la documentación en empresas del sector publicitario así como en instituciones públicas y privadas; para realizar análisis e investigación de mercados en agencias de publicidad; No se requieren demasiados puestos para diseño en prensa diaria y no diaria impresa ni para agencias de comunicación (incluido el entorno on-line); ha caído la demanda de la prensa no diaria on-line; no se requieren becarios para Community Manager en agencias de información y de comunicación.

\subsection{Cuando se trata de la demanda para la realización de} prácticas mediante "multifunciones", se observa un incremento en Comunicación y aquí ya si aparece el Community Manager en quinto lugar, si bien en instituciones públicas y privadas (con un $4,5 \%)$. $Y$ es precisamente en estas organizaciones en donde la fenomenología desprende una multitarea para los redactores $(7,7 \%)$ y en labores de comunicación (5,5\%) Entre las quince primeras funciones el diseño y la documentación en las instituciones públicas y privadas también se encuentran como demandadas cuando la oferta es de "multifunción".

La radio y la televisión también requieren de becarios para prácticas de multitareas, algo comprensible debido a la prolongación de estos medios hacia soportes digitales. Y la demanda de redactores para medios impresos, en cualquiera de sus categorías avanza el cambio multifuncional que se ha producido en estos medios.

También las empresas del sector publicitario y de la comunicación reconocen la convergencia tecnológica en función de la demanda de prácticas multifuncional sobre todo para la redacción.

Cuando se trata de multifunción, hay menos demanda en Comunicación, bien sea interna o externa, de los diarios de papel, que tampoco solicitan Community Manager $(0,07)$, ni en la prensa digital $(0,14 \%)$. La demanda para Recursos Humanos en televisión y prensa digital son del 0,07\% sobre el total. Un 0,27\% alcanza la demanda de alumnos para realizar prácticas en análisis e investigación de mercados en agencias de publicidad, mismo porcentaje en la demanda de Community Manager y Documentación para Radio. Este medio 
audiovisual tampoco supera el 0,34 de demanda para Comunicación interna, al igual que ocurre con la prensa no diaria impresa y la documentación en agencias de publicidad.

\section{Tabla 3. Principales ocupaciones según demanda empresarial (para una única función) en \%}

\begin{tabular}{|l|l|}
\hline Redacción en prensa diaria impresa & 29,96 \\
\hline Redacción y locución en radio & 12,12 \\
\hline Redacción y locución en televisión & 8,66 \\
\hline Redacción (también on-line) en agencias de información & 7,06 \\
\hline Redacción en prensa diaria on-line & 5,99 \\
\hline Redacción en prensa no diaria impresa & 5,06 \\
\hline Redacción en prensa no diaria on-line & 5,06 \\
\hline $\begin{array}{l}\text { Comunicación (interna y publicidad) en instituciones públicas } \\
\text { privadas }\end{array}$ & 3,86 \\
\hline Redacción en instituciones públicas y privadas & 3,60 \\
\hline Redacción en agencias de comunicación & 2,80 \\
\hline Redacción en empresas del sector publicitario & 1,60 \\
\hline Documentación en televisión & 1,07 \\
\hline CM en televisión & 1,20 \\
\hline CM en empresas del sector publicitario & 1,33 \\
\hline Comunicación (interna y publicidad) en agencias de comunicación & 0,93 \\
\hline CM en instituciones públicas y privadas & 0,93 \\
\hline Diseño y postproducción en televisión & 0,93 \\
\hline $\begin{array}{l}\text { Comunicación (interna y publicidad) en el empresas sector } \\
\text { publicitario }\end{array}$ & 0,80 \\
\hline Comunicación (interna y publicidad) en televisión & 0,67 \\
\hline Diseño y gestión de contenidos digitales en prensa no diaria on-line & 0,53 \\
\hline Redacción en agencias de publicidad & 0,53 \\
\hline Diseño (también on-line) en empresas del sector publicitario & 0,53 \\
\hline CM (Community manager) en prensa no diaria on-line & 0,40 \\
\hline CM en agencias de publicidad & 0,40 \\
\hline
\end{tabular}

Fuente: Tesauro PIMCD no 176 y elaboración propia 
Tabla 4. Las 15 primeras funciones que demandan las empresas (según se oferta “multifunción” por contrato de prácticas y \%)

\begin{tabular}{|l|l|l|}
\hline $\begin{array}{l}\mathrm{N}^{\circ} \\
\cdot\end{array}$ & Descripción de la multifunción & $\begin{array}{l}\text { Frecuencia de aparición } \\
\text { en contratos \% }\end{array}$ \\
\hline 1 & Redacción en instituciones públicas y privadas & 7,77 \\
\hline 2 & Redacción y locución en televisión & 5,66 \\
\hline 3 & $\begin{array}{l}\text { Comunicación (interna y publicidad) en } \\
\text { instituciones públicas y privadas }\end{array}$ & 5,52 \\
\hline 4 & Redacción en prensa diaria impresa & 5,11 \\
\hline 5 & CM en instituciones públicas y privadas & 4,50 \\
\hline 6 & Redacción en prensa diaria on-line & 4,29 \\
\hline 7 & Diseño y postproducción en televisión & 4,09 \\
\hline 8 & Redacción empresas del sector publicitario & 3,89 \\
\hline 9 & Redacción y locución en radio & 3,27 \\
\hline 10 & Redacción en prensa no diaria on-line & 3,20 \\
\hline 11 & Redacción en agencias de comunicación & 3,07 \\
\hline 12 & Redacción en prensa no diaria impresa & 2,79 \\
\hline 13 & $\begin{array}{l}\text { Comunicación (interna y publicidad) en agencias } \\
\text { de comunicación }\end{array}$ & 2,79 \\
\hline 14 & $\begin{array}{l}\text { Diseño (también en el entorno on-line) } \\
\text { instituciones públicas y privadas }\end{array}$ & 2,73 \\
\hline 15 & $\begin{array}{l}\text { Documentación en instituciones públicas y y } \\
\text { privadas }\end{array}$ & 2,59 \\
\hline
\end{tabular}

Fuente: Tesauro PIMCD nº 176 y elaboración propia

4.3 las funciones con más frecuencia en la demanda, según se observa en el estudio, son la de redactor para medios diarios en papel 
$(13,52 \%)$ seguida del redactor y locutor en televisión (6,67\%); redactores demandados por instituciones públicas y privadas $(6,35 \%)$ y para la redacción y locución en radio $(6,26 \%)$ Las instituciones públicas y privadas estén en un 4,96\%en frecuencia de Comunicación interna y publicidad. Son las empresas del sector publicitario y las agencias de comunicación las que mantienen una frecuencia menor a lo largo de la muestra objeto de esta investigación.

Figura 3. Gráfico de las quince primeras funciones demandadas cuando se oferta "multifunción" por contrato de prácticas y porcentajes

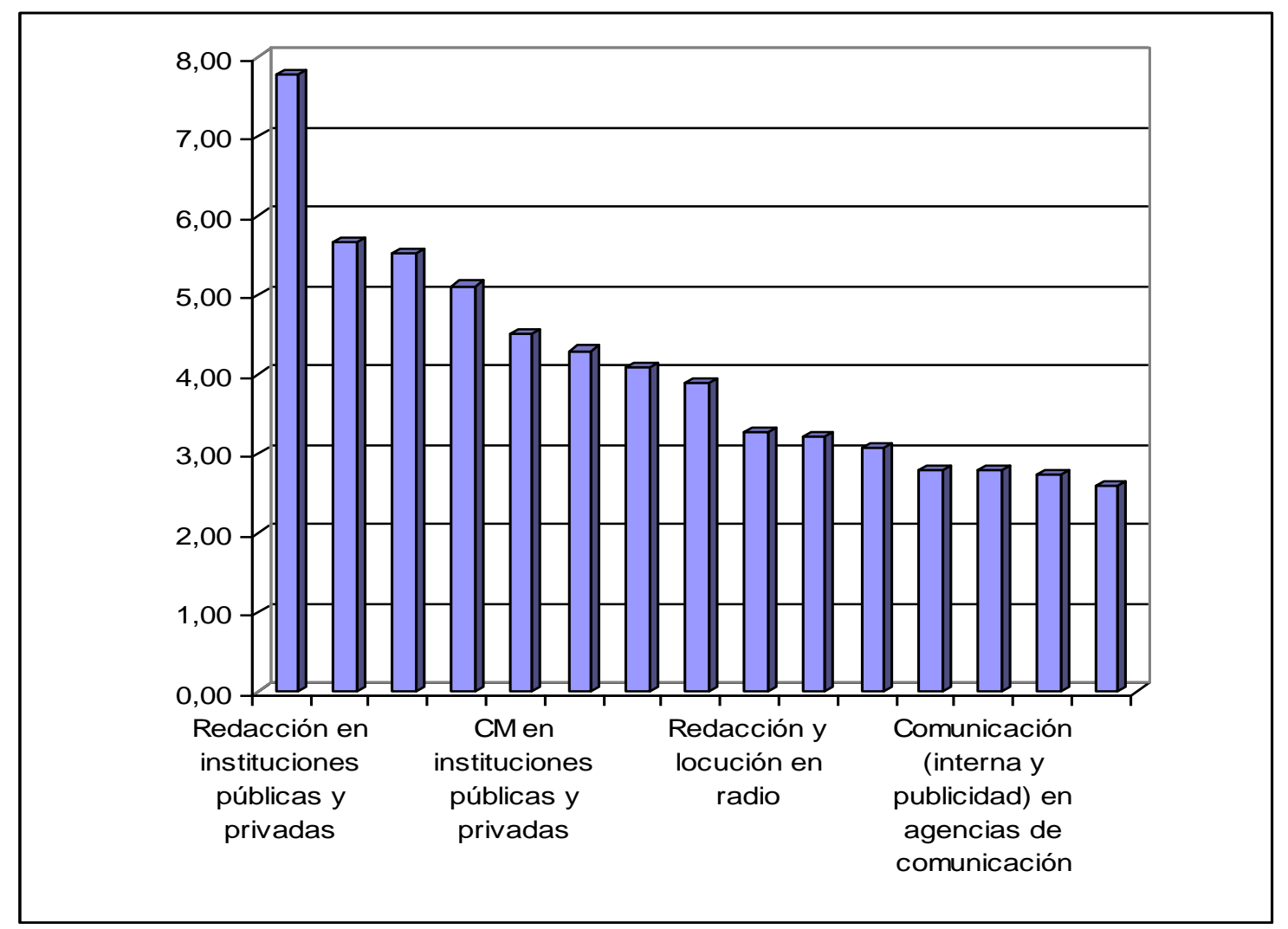

Fuente: Tesauro PIMCD no 176 y elaboración propia

Por el contrario, resalta el $0,05 \%$ de frecuencia del Community Manager en prensa diaria impresa que tampoco parece tiene perspectivas para la comunicación interna y externa $(0,09 \%)$

4.4 Los medios demandan según la frecuencia que las empresas informativas y de comunicación requieren de las diferentes funciones, y dan a la prensa diaria en papel como la que mayor demanda genera de redactores para prácticas (300), seguida de la 
televisión (148) de las instituciones públicas y privadas (141) y de la radio (139). Se entiende que la menor frecuencia de la demanda en esta función sea de las Agencias de publicidad (19) y, algo menos normal, las agencias de comunicación (66)

\section{Tabla 5. Las 15 funciones más frecuentes que aparecen en el estudio (según $\mathrm{n}^{\mathrm{o}}$ de apariciones en los contratos y \%)}

\begin{tabular}{|c|c|c|c|}
\hline $\mathbf{N}^{\mathbf{o}}$ & Descripción de la función & $\begin{array}{l}\text { Frecuencia } \\
\text { aparición en } \\
\text { contratos }\end{array}$ & $\%$ \\
\hline 1 & Redacción en prensa diaria impresa & 300 & 13,52 \\
\hline 2 & Redacción y locución en televisión & 148 & 6,67 \\
\hline 3 & Redacción en instituciones públicas y privadas & 141 & 6,35 \\
\hline 4 & Redacción y locución en radio & 139 & 6,26 \\
\hline 5 & $\begin{array}{l}\text { Comunicación (interna y publicidad) en } \\
\text { instituciones públicas y privadas }\end{array}$ & 110 & 4,96 \\
\hline 6 & Redacción en prensa diaria on-line & 108 & 4,87 \\
\hline 7 & Redacción en prensa no diaria on-line & 86 & 3,88 \\
\hline 8 & Redacción en prensa no diaria impresa & 79 & 3,56 \\
\hline 9 & $\begin{array}{l}\text { Redacción (también on-line) en agencias de } \\
\text { información }\end{array}$ & 77 & 3,47 \\
\hline 10 & $\mathrm{CM}$ en instituciones públicas y privadas & 73 & 3,29 \\
\hline 11 & Redacción en empresas del sector publicitario & 69 & 3,11 \\
\hline 12 & Diseño y postproducción en televisión & 67 & 3,02 \\
\hline 13 & Redacción en agencias de comunicación & 66 & 2,97 \\
\hline 14 & $\begin{array}{l}\text { Comunicación (interna y publicidad) en } \\
\text { agencias de comunicación }\end{array}$ & 48 & 2,16 \\
\hline 15 & CM en empresas del sector publicitario & 46 & 2,07 \\
\hline
\end{tabular}

Fuente: Tesauro PIMCD no 176 y elaboración propia

Si de diseño se trata, la televisión (67) abre esta página seguida de las instituciones (42), de las empresas del sector publicitario (29) y de la 
radio y la prensa digital no diaria (22) Sorprende la escasa frecuencia de las agencias de publicidad en este apartado con 9 y los 7 puntos de la prensa no diaria impresa (revistas)

Cuando de Comunicación se trata, se imponen las instituciones públicas y privadas con 110 referencias, seguidas de las agencias de comunicación (48) y de las empresas del sector publicitario (36) Es la televisión la que sigue con 19, mientras las que tienen menos frecuencia en la demanda son la prensa diaria en papel (2) y la prensa digital (3)

\begin{tabular}{|l|l|l|l|l|l|}
\hline \multicolumn{6}{|l|}{$\begin{array}{l}\text { Tabla 6. Relación de funciones según demanda de medios/empresas } \\
\text { (según la frecuencia de aparición en los contratos) }\end{array}$} \\
\hline Redacción & Diseño & Comunicación & $\begin{array}{l}\text { C. } \\
\text { Manager }\end{array}$ & Documentación & Empresas \\
\hline $\mathbf{3 0 0}$ & 17 & 2 & 1 & 30 & Diarios papel \\
\hline 108 & 21 & 3 & 6 & 9 & Prensa digital \\
\hline 79 & 7 & 7 & 8 & 13 & Prensa no diaria \\
\hline 86 & 22 & 7 & 20 & 6 & $\begin{array}{l}\text { Digitales no } \\
\text { diarios }\end{array}$ \\
\hline 139 & 22 & 5 & 4 & 4 & Radio \\
\hline 148 & $\mathbf{6 7}$ & 19 & 22 & 33 & Televisión de \\
\hline 77 & 17 & 8 & 10 & 17 & $\begin{array}{l}\text { Agencias } \\
\text { Información de }\end{array}$ \\
\hline 66 & 10 & 48 & 30 & 29 & $\begin{array}{l}\text { Agencias de } \\
\text { comunicación de }\end{array}$ \\
\hline 19 & 9 & 8 & 11 & 5 & $\begin{array}{l}\text { Agencias } \\
\text { Publicidad de }\end{array}$ \\
\hline 141 & 42 & 110 & $\mathbf{7 3}$ & $\mathbf{3 9}$ & $\begin{array}{l}\text { Instituciones } \\
\text { Públicas/privadas }\end{array}$ \\
\hline 69 & 29 & 36 & 46 & 15 & $\begin{array}{l}\text { Empresas Sector } \\
\text { Publicidad }\end{array}$ \\
\hline
\end{tabular}

Fuente: Tesauro PIMCD n 176 y elaboración propia

La figura del Community Manager se reclama sobre todo en las instituciones (73) seguida de las empresas publicitarias (46) y de las agencias de comunicación (30). No está mal la televisión (22) y la prensa digital no diaria (20) Son los diarios en papel los que menos frecuencia demandan de esta figura tan vanguardista junto con la radio. 
Si se trata de comprobar la frecuencia de la demanda de la Documentación según empresas y medios, nuevamente son las instituciones las que se sitúan en primer lugar (39) por encima de la televisión (33) y la prensa diaria impresa (30) Las agencias de comunicación dan importancias a la documentación (29) al igual que las agencias de información (17) Por el contrario está la radio (4) las agencias de publicidad (5) y la prensa digital no diaria (6)

\section{Conclusiones}

El alumno que realiza prácticas tiene 21 años de media, a consecuencia del adelanto del segundo ciclo del Grado de Periodismo, y con una representación de mujeres del 60,9\%, proporcional al total de los matriculados en el centro.

Mujeres que resultan las principales perjudicadas de un sector en crisis en el que los medios tradicionales no parece que estén pasando por su mejor momento. Todo esto provoca que el periodista tenga perspectivas futuras más amplias y su adaptación a la realidad del mercado sea camaleónica.

No obstante, la formación adecuada para transformar ese perfil de inicio y el avance de la comunicación sobre la información están variando los rasgos del profesional de la información, ya en los medios clásicos como el diario de papel, la radio o la televisión a los electrónicos de última generación como la prensa digital y los medios on-line.

De las empresas que tiene un mayor porcentaje de contratos, cuatro son empresas editoras de prensa diaria impresa: Unidad Editorial (El Mundo), Abc, Prensa Asturiana (La Nueva España) y Audiovisual Española 2000 (La Razón); Dos cadenas de radio nacionales generalistas (Cadena SER y COPE); dos corporaciones de televisión (Atresmedia y Mediaset) una televisión autonómica (RTVCLM) y una productora (Boomerang); dos agencias de información (Efe y Europa Press); una corporación de medios (Intereconomía) y una empresa de comunicación (Incondicionales Sports SL) Esto implica una permanencia de los medios tradicionales como demandantes de la mayoría de becarios que puede significar que son los más necesitados para socorrer a sus plantillas con colaboradores y auxiliares a bajo 
coste. Incluso existen los que no aportan cantidad alguna a sus becarios (Boomerang TV SA)

Las prácticas ayudan a conocer el estado del mercado laboral, el futuro de los graduados en Periodismo y diseñar un perfil profesional favorable a las empresas. Se mantiene la especialización sobre la polivalencia: de las quince empresas más demandantes de contratos en prácticas, nueve prefieren una única función en el desarrollo profesional y seis la multifunción.

El número de alumnos que en su contrato se refiere a una funcionen concreto es de $762(54,98 \%)$ mientras que a los que se les pide la multifunción son $624(45,02 \%)$ A un 73,08\% se le ha demandado dos funciones (456 alumnos) y a 119 se le demandaron hasta tres funciones $(19,07 \%)$. La función que domina sobremanera es la de redacción, razón por la que se debe seguir formando al alumno de Grado de Periodismo en las tareas propias de redacción adaptadas a la realidad tecnológica imperante, muy por encima de nuevas opciones como diseño, producción, documentación o Community manager que con un único periodo de análisis no permite contrastar y obtener resultados más satisfactorios que se puedan aplicar ciertamente a la realidad del mercado.

Figura 4. Funciones demandas en cada contrato de prácticas

\begin{tabular}{|l|l|l|}
\cline { 2 - 3 } \multicolumn{1}{c|}{} & $\mathrm{N}^{\circ}$ de alumnos & $\%$ \\
\hline Una función & 762 & 54,98 \\
\hline Multifunción & 624 & 45,02 \\
\hline Dos funciones & 456 & 73,08 \\
\hline Tres funciones & 119 & 19,07 \\
\hline Cuatro o más funciones & 49 & 7,85 \\
\hline
\end{tabular}

Fuente: Tesauro PIMCD no 176 y elaboración propia

La escasa demanda en ciertas labores, como la de documentación, muestra que para estas labores los acuerdos de prácticas se propondrán mayoritariamente en la facultad de Biblioteconomía y Documentación.

El momento de mayor demanda es el verano. La media de días de prácticas asciende a 107,7, con unas 5,3 horas/día, 4,9 días a la semana. Se necesita un perfil de periodista para trabajar en las 
instituciones públicas o privadas, y se mantiene la demanda de medios diarios impresos y digitales.

Se puede defender, como se plantea en la hipótesis que las funciones que demandan mayoritariamente las empresas han cambiado a consecuencia de una evolución de los medios y el alcance de esa nueva demanda afecta a los futuros profesionales.

\section{Tabla 7. Resumen de características de las prácticas en los medios tradicionales (medias y modas)}

\begin{tabular}{|c|c|c|c|c|c|c|c|}
\hline $\begin{array}{l}\text { Tipo de } \\
\text { empresa }\end{array}$ & Días & $\begin{array}{l}\text { Época } \\
\text { del año }\end{array}$ & $\begin{array}{l}\text { Días a la } \\
\text { semana }\end{array}$ & $\begin{array}{c}\text { Horas al } \\
\text { día }\end{array}$ & $\begin{array}{c}\text { Ayuda al } \\
\text { estudio en } \\
\text { euros } \\
\text { brutos/mes }\end{array}$ & Sector & Función \\
\hline $\begin{array}{c}\text { Medios } \\
\text { tradicionales } \\
\text { (información } \\
y \\
\text { Periodismo). } \\
\text { Prensa diaria }\end{array}$ & 107,7 & Verano & 4,9 & 5,3 & 223,3 & $\begin{array}{c}\text { Medios } \\
\text { tradicionales } \\
\text { (información } \\
y \\
\text { Periodismo). } \\
\text { Prensa diaria } \\
\text { impresa }\end{array}$ & Redacción \\
\hline
\end{tabular}

Fuente: Tesauro PIMCD nº 176 y elaboración propia

En principio, no es concluyente a raíz de los resultados expuestos. Además, esta investigación cuenta con limitaciones temporales y metodológicas, mejorables si se mantiene una periodicidad del estudio y ampliar la muestra de la investigación, a la vez que se completan los datos cuantitativos con cualitativos (entrevistas personales)

Estas conclusiones se aproximan a la realidad del mercado, comparativa de la oferta de las tareas y multitareas que ayudan a entender qué nuevos perfiles hay que desarrollar y como los docentes deben preocuparse para mejorar la calidad docente del centro.

*Este trabajo es consecuencia de un Proyecto interdepartamental de Innovación y Mejora de la Calidad Docente (PIMCD no 176 de la UCM) sobre la inserción laboral de los estudiantes de Periodismo y sus necesidades, titulado "Qué necesitan los estudiantes de periodismo para su inserción laboral. Análisis de la demanda del mercado laboral de las empresas de comunicación" y realizado por el grupo Research and Learning of Media and Communications Management. Investigación (MediaCom UCM) www.ccinf.es/mediacom 


\section{Las radios universitarias en España: Equipos de trabajo, participación y función social}

Daniel Martín Pena (Universidad d Extremadura) orcid.org/0000-0003-2676-5821 https://scholar.google.es/citations?hl=es\&user=c3neDSYAAAAJ Ana Segura Anaya (Universidad de Zaragoza) orcid.org/0000-0003-0332-9445 http://scholar.google.es/citations?user=leAO8RkAAAAJ\&hl=es

\section{Radios Universitarias en España}

$\Psi$

L ENCUENTRO entre radio y universidad en España se produce en los años 70, cuando algunas emisoras con una programación convencional, comienzan a incluir en sus parrillas programas en los que la universidad y más aún, los universitarios, son los protagonistas. Como señala Ortiz (2012:16) hubo profesionales de la radio que "creyeron que la universidad y los universitarios tenían mucho que decir y aportar a este medio de comunicación”. Así, nacen programas como «Tiempo de Universidad», «A grifo abierto» o «Las tardes de la Inter» en los que alumnos de la Facultad de Ciencias de la Información de la Universidad Complutense tienen su primer contacto profesional con la radio. 
En 1987 nace la que se considera la primera radio universitaria española: Radio San Fernando (actual Radio Campus) de la Universidad de La Laguna, que se pone en marcha gracias a la iniciativa de los alumnos del Colegio Mayor San Fernando. De una forma más reglada, trece años antes, en 1974 habían comenzado las grabaciones para el proyecto educativo que de la mano de las posibilidades que ofrecía la red de Radio Nacional de España, estaba desarrollando la Universidad Nacional de Educación a Distancia, la UNED.

Martín-Pena $(2013,2014)$ diferencia tres etapas de desarrollo de las emisoras universitarias en España:

- Fase 1 (aparición e inicio de las ocho primeras experiencias), que cronológicamente llega a finales del siglo XX y que muestra un desarrollo tardío y lento, aunque contempla el nacimiento de algunas de las emisoras universitarias históricas españolas, como es el caso de Radio Complutense, Radio Universidad de Salamanca o la 98.3 Radio.

- Fase 2 (consolidación y expansión del fenómeno), en los primeros diez años del siglo XXI, cuando surgen más de quince estaciones, gracias a la creación de nuevas facultades de comunicación, el desarrollo de las TICs, el acercamiento a la sociedad y el trabajo cooperativo en red.

- Fase 3 (replanteamiento y unión del fenómeno), que vivimos en la actualidad y que está condicionada por la crisis económica que afecta a la sociedad española en general, y a la universidad en particular. Es también el momento de la Asociación de Radios Universitarias de España (ARU), la primera iniciativa de éxito de unión a gran escala de radios universitarias españolas y que tuvo lugar en junio de 2011 en Badajoz (Universidad de Extremadura). En los últimos años, han surgido apenas 3 emisoras, todas ellas en universidades con estudios de comunicación, bajo el amparo y desarrollo de las TIC y en forma de plataformas hipermedias, que permiten la formación integral del alumnado de la rama de las ciencias de la información. 
En España funcionan en la actualidad aproximadamente 30 emisoras universitarias, que emiten en FM, 'streaming' o 'podcast' y de las que 23, pertenecen a la ARU. Esto implica que en una de cada tres universidades españolas existe un proyecto radiofónico universitario.

\section{Los colaboradores de las emisoras universitarias}

Muchos autores (Contreras, González y Aguaded, 2014; Martín-Pena, 2013; Fidalgo 2009) que señalan como gran rasgo característico de las emisoras universitarias españolas su gran heterogeneidad. Este concepto se observa desde la misma puesta en marcha del proyecto radiofónico, con emisoras que tienen como objetivo fundamental servir de plataforma a las prácticas de los alumnos de titulaciones vinculadas al mundo de la comunicación, a aquellas que pretenden ser un altavoz de la propia universidad e incluso vía de comunicación con la sociedad en general. En lo que sí coinciden es que el éxito de este tipo de emisoras se basa en muchas ocasiones en su capacidad de congregar a la comunidad universitaria y no universitaria, tanto delante de los micrófonos como detrás de ellos, es decir, no sólo como oyentes pasivos, sino como emisores activos y receptores participativos.

Vázquez (2012: 69) señala que partiendo de los modelos propios de cada emisora se puede tener una idea aproximada de la participación que tienen cada una de ellas, ya que existen estaciones con distintos propósitos, que van desde las que son un apoyo para las prácticas estudiantiles hasta las que sirven de foro de expresión de la comunidad universitaria, pasando por las que son emisoras de corte más institucional y menos abiertas, a las emisoras que funcionan como laboratorios experimentales de nuevas formas y contenidos. En el conjunto de las emisoras universitarias españolas observamos una participación muy abierta, tal y como se refleja en el reglamento de funcionamiento de cada una de las emisoras, que abren la posibilidad de producir contenidos a un segmento muy amplio de la comunidad universitaria y en ocasiones, a la sociedad en general. Un ejemplo de esta accesibilidad es Onda Campus, en la Universidad de Extremadura, que en su página web (www.ondacampus.es) detalla los colectivos implicados en su programación: 
- Alumnos del Grado en Comunicación Audiovisual de la UEx.

- Alumnos de los cuatro campus de la Universidad de Extremadura.

- Personal de Administración y Servicios de la UEx

- Personal Docente e Investigador de la UEx.

- Grupos de Investigación de la UEx.

- Servicios o Unidades de la estructura orgánica de la UEx.

- Colectivos, grupos sociales o personas individuales que así lo deseen.

En este último apartado se incluyen asociaciones, $\mathrm{ONG}$ 's y colectivos sociales y/o civiles, que encuentran en las emisoras universitarias un altavoz de expresión o denuncia que no les ofrecen la radio comercial, con una gestión centrada en la consecución de objetivos de otra índole. En este sentido, Vázquez (2012: 115) destaca que es habitual que las radios universitarias, que cuentan con un perfil más social y de servicio público abran sus micrófonos mucho más allá de las paredes del campus. Ahora bien, no todas las radios universitarias en España se caracterizan por tener esa gran diversidad de colaboradores, ya que en otras emisoras, orientadas básicamente a servir de plataforma a las prácticas de los alumnos, el abanico de colaboradores es algo más restringido, aunque todas coinciden en presentar una fuerte presencia estudiantil y juvenil.

\subsection{Estudiantes y jóvenes que sí participan}

En 2001 Livia Van der Graaf (2001: 20-21) analizó las características de once emisoras universitarias estudiantiles de España, Bélgica, Gran Bretaña y Francia. Concluyó que «las emisoras estudiantiles funcionan como herramientas de formación, información, de encuentro y diversión. Es importante que los estudiantes puedan aprender a hacer radio profesionalmente, que tengan un medio para expresarse y que la gente pueda escucharles. Por eso la libertad de expresión y opinión ocupa un lugar especial en la radio estudiantil, pues ser libre al dar e intercambiar sus opiniones es indispensable para una buena comprensión entre los jóvenes, y entre ellos y la sociedad en general» (Asuaga, 2007). 
El papel determinante que los jóvenes tienen en el desarrollo de la radio universitaria española es obvio, y en este sentido, Vázquez en varios estudios realizados en 2010 , cifra esta presencia juvenil en un $81 \%$ (de este porcentaje el $92 \%$ pertenece a estudiantes de la propia institución. Destaca además que este público es mayoritario en las emisoras con modelos estudiantiles y mixtos, y más reducido en modelos institucionalizados, en las que el grado de participación es mucho menor. De esta forma la radio universitaria rompe con el tópico de que los estudiantes no quieren participar en la vida universitaria y constata que cuando se ponen cauces de participación, los estudiantes responden, y hacen parte del día a día universitario.

Ahora bien, más allá de la participación voluntaria y desinteresada es necesario destacar de nuevo lo que refleja Martín-Pena (2013), que advierte que en España encontramos emisoras poco profesionalizadas, con plantillas en las que se multiplican los contratos precarios, e incluso emisoras en las que se funciona a coste cero y gracias a la voluntad de sus colaboradores, tanto profesores como jóvenes que se acercan al medio por completar su formación en el ámbito de las ciencias de la información o para expresar sus inquietudes.

\subsection{E1 perfil de los colaboradores externos}

Servicio público y su carácter social son dos conceptos con los que distintos autores vinculan a las radios universitarias, (Aguaded y Contreras, 2011; Aguaded y Martín-Pena, 2013 y Marta y MartínPena, 2014) al entender que estas emisoras realizan labores de servicio público, en cuanto ofrecen un altavoz a sectores de la sociedad que no tienen acceso a los medios de comunicación convencionales. Son, por otra parte, miembros que no forman parte de la comunidad universitaria, pero que tienen que aportan mucho en el debate social como asociaciones, agrupaciones, ONG o colectivos sociales y/o civiles, que encuentran en las emisoras universitarias un altavoz de denuncia y expresión que les está cerrado en otros medios.

Para Aguaded y Contreras (2011), el modelo ideal de radio universitaria es aquel en el que la radio es generadora de conocimiento, ofrece una transferencia social, contiene publicidad social, juega un rol humanístico y tiene fines solidarios y cooperativos, con 
sentido de equipo. Como apunta Martín-Pena (2013:189) son numerosas las organizaciones sociales que necesitan la ayuda de las estaciones universitarias para difundir su actividad, y que no encuentran otro altavoz que el universitario para dar a conocer su labor. En contrapartida, al abrir sus puertas a estas iniciativas, las radios universitarias demuestran que su apuesta por la formación de la ciudadanía, por los contenidos alternativos a las emisoras comerciales y por el fomento de la cultura científica es real.

\section{Los alumnos de Ciencias de la Información}

Destacábamos ya en apartados anteriores que uno de los objetivos principales de muchas de las radios universitarias es servir de soporte para las prácticas de los alumnos y por tanto, se constituyen en medios que ofrecen una formación complementaria ideal para el alumno de disciplinas relacionadas con las ciencias de la información (Periodismo, comunicación audiovisual, publicidad y relaciones públicas, e incluso, los nuevos grados que abordan temáticas similares en un contexto digital y transmedia), a los que ofrecen la posibilidad de adquirir una capacitación profesional más cercana a auténticos escenarios de trabajo. En esta misma línea, coincide Araya (2009), que señala que el hecho de que muchas emisoras sean utilizadas como laboratorios para aprender la disciplina del trabajo en el medio radio es una característica muy común en la realidad de estas emisoras.

Esta función formadora se adecua además a los propósitos que atribuye la Universidad la Ley Orgánica de Universidades; «entendidos como entornos educativos, los medios audiovisuales, en general, y la radio universitaria, en particular, se presentan como espacios donde los alumnos pueden experimentar aprendizajes que se suman a la formación reglada, adquirir habilidades y valores». Álvarez y Ramírez (2005) entienden que la participación de los alumnos es clave en el desarrollo de proyectos de estas características, pero se hace necesario establecer mecanismos de coordinación para garantizar el éxito de esta participación.

En España, los trabajos de Espino y Martín (2012) y Piñeiro y Ramos (2011) confirman que la mayoría de las emisoras se desarrollan en universidades que ofrecen titulaciones relacionadas con ciencias de la información y de hecho son muchas las emisoras universitarias que 
surgen al amparo de las facultades de comunicación, con la intención de configurar unas prácticas lo más reales posibles para los estudiantes matriculados. Marta y Segura (2012) destacan que la mayoría de las emisoras que cuentan con estudios relacionados con las ciencias de la información, se nutren de las prácticas realizados por sus alumnos y entre ellas, el referente por su trayectoria y modelo es sin duda la emisora de la Universidad de Navarra, la 98.3 Radio, con una programación de microespacios informativos que trasciende a la propia comunidad universitaria y adopta en ocasiones un rol de radio local. Como apunta Vázquez (2012: 102-140), esta emisora tiene muy avanzado un modelo pedagógico mezcla de medio profesional y formador integral, siendo pionera a la hora de integrar a estudiantes en la producción de programas y en vincular las prácticas de sus alumnos con el mundo profesional.

Son muchos los autores que señalan que este tipo de emisoras constituyen la mejor herramienta práctica para este alumnado (Sauls, 1995; Desztich y McLung, 2007). Estas prácticas afianzan su confianza, su potencial, su capacidad competencial y su iniciativa, y hace que se sientan preparados para afrontar la vida laboral en la especialidad que ellos mismos han elegido (Ceballos, Lemrini, Mateos, Vázquez, Muñoz, Sanz et al, 2010). Para Parejo y MartínPena (2011) los alumnos ejercen en estas emisoras cada uno de los roles que se encuentran en una radio comercial y estos futuros profesionales de la comunicación van conociendo así las dificultades y la responsabilidad que entraña cada uno de los perfiles profesionales.

\section{Colaboradores en las emisoras de la ARU (Asociación de Radios Universitarias)}

Una vez descrito el panorama de la radio universitaria en España, analizamos la presencia de los distintos perfiles de colaboradores en las emisoras universitarias españolas, a través de la muestra que constituyen las 24 emisoras universitarias que pertenecen a la Asociación de las Radios Universitarias de España, que suman el 80\% del total de estaciones universitarias en el país. En 16 de esas 24 emisoras existen estudios del área de la información y comunicación, en algunas de ellas con vinculación directa a los mismos y en otras, sin ella, lo que confirma que, como señalábamos anteriormente, la 
mayoría de emisoras surgen al amparo de titulaciones del área de la comunicación, y son consecuencia directa de la expansión del fenómeno en la primera parte del siglo actual.

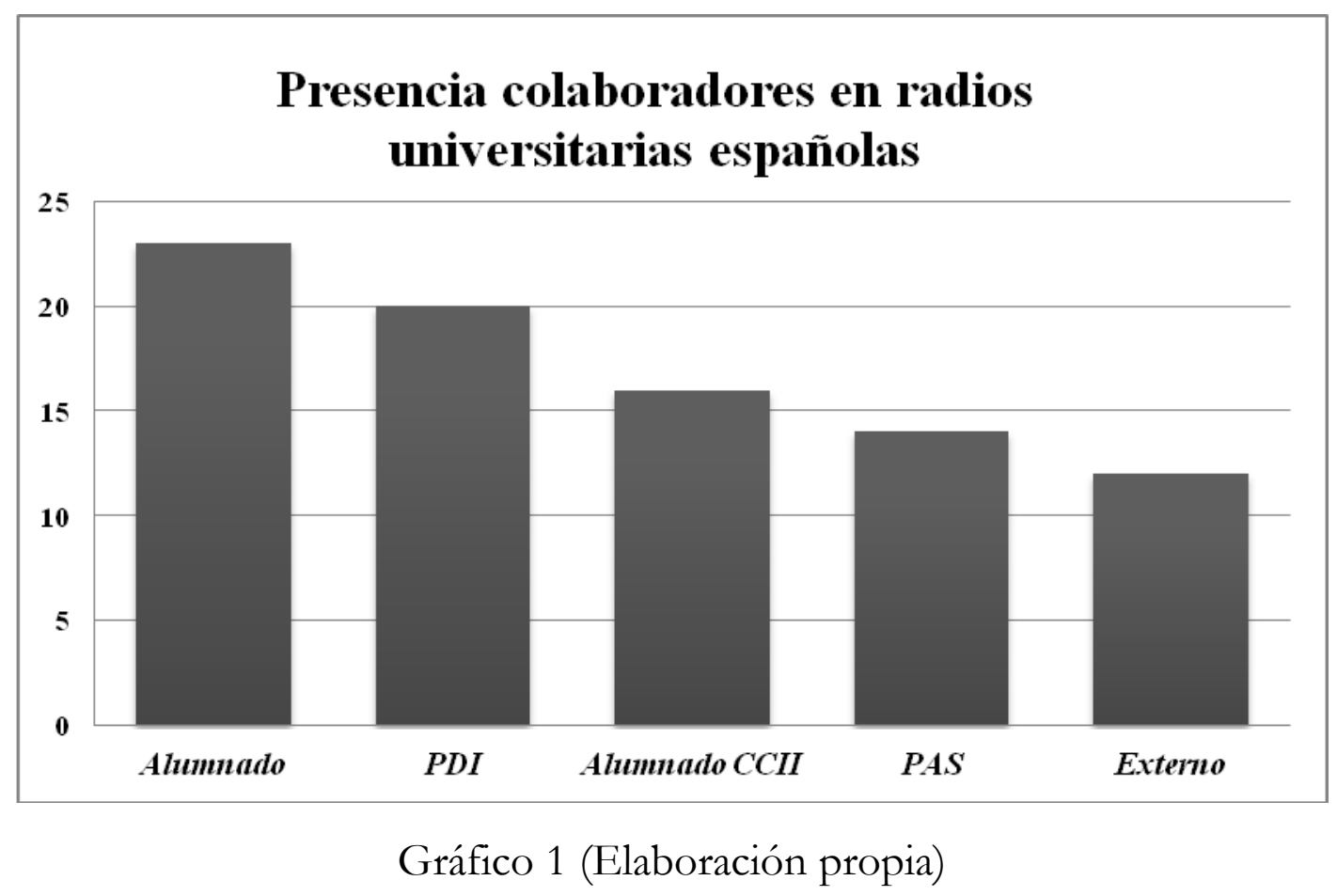

En las emisoras analizadas hemos detectado todos los posibles perfiles que hemos descrito a lo largo de esta comunicación, tanto de dentro de la comunidad universitaria (PDI, PAS y alumnado) como de fuera de la misma, es decir, asociaciones o personas anónimas para las cuales la estación universitaria se convierte en el altavoz que les es negado en las emisoras de tinte comercial, más preocupadas por fines mercantilistas, quedando claramente demostrado el papel de servicio a la ciudadanía que ejercen las estaciones de tipo universitario. Es un hecho que en la mitad de estaciones de la ARU (doce) se permite el acceso a este tipo de perfil como productora de contenidos, convirtiendo la emisora universitaria, no sólo en fiel reflejo de la realidad que se vive en las aulas, sino también del espejo de la ciudad o sociedad que acoge esa institución de educación superior. De la otra mitad de estaciones que no cuentan con colaboradores externos, un total de ocho (67\%) corresponden a emisoras de universidades que cuentan con grados relacionados con el área de la comunicación. La noticia positiva, y que demuestra el nivel de diversidad y de apertura que están adquiriendo este tipo de estaciones, es que en casi la mitad de las emisoras $(46 \%)$ hemos encontrado todos los perfiles presentes 
en la producción de programas radiofónicos, teniendo en cuenta que cuatro de esas once emisoras no tienen el perfil de estudiantes del área de ciencias de la información porque no acogen esos estudios sus respectivas universidades.

Como no podía ser de otra manera, y como la radio universitaria es representativa de la realidad de la institución educativa, el perfil de colaborador mayoritario es el alumnado ( $96 \%$ ); de hecho en el 58\% de las emisoras (catorce) son mayoría los estudiantes relacionados con las ciencias de la información, y de éstas, sólo son tres las que restringen el acceso exclusivamente a alumnos de otras áreas, e incluso a otros perfiles de colaboradores (Radio Universitat, Radio UniZar y Radio USJ, emisoras que han surgido a partir de 2011 vinculadas a los estudios). En otras nueve estaciones (38\%) el perfil con mayor presencia es el alumnado de otras disciplinas, quedando el PDI como perfil mayoritario en Radio UNED (4\%). PDI y PAS, por este orden, tienen una presencia mucho más reducida en el plantel de colaboradores de las estaciones universitarias españolas.

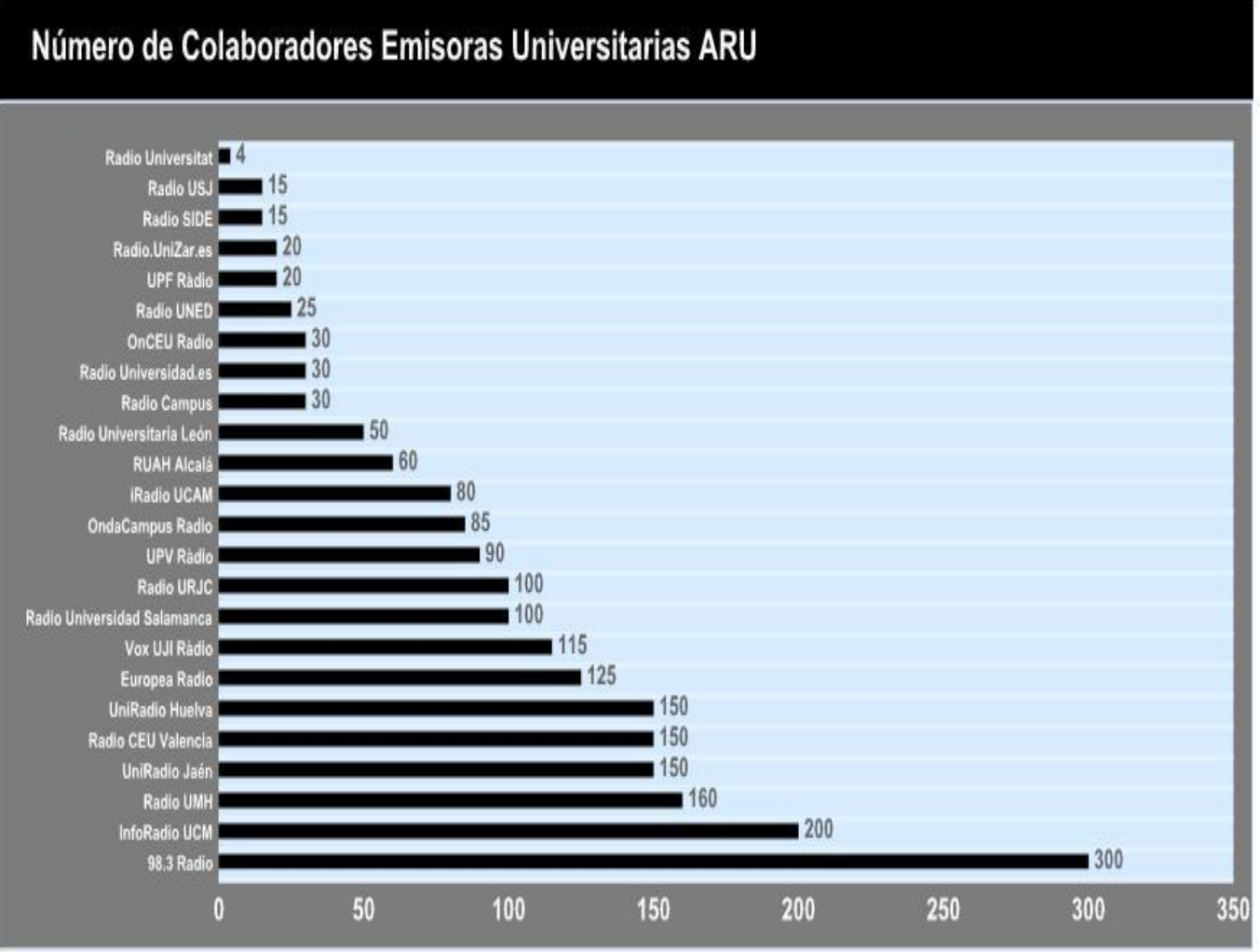

Gráfico 2 (Elaboración propia). 
Otro dato a tener presente para ver la importancia que tiene este tipo de estaciones para el alumnado de ciencias de la información es el número de colaboradores con el que cuentan las distintas estaciones universitarias. En cuanto al número de colaboradores, en

\begin{tabular}{|c|c|c|c|c|c|}
\hline EMISORA & $\begin{array}{l}\text { ALU. } \\
\text { CCII }\end{array}$ & ALUMNOS & PDI & PAS & EXTERNO \\
\hline Radio UNED & & & $\mathrm{X}$ & & $\mathrm{X}$ \\
\hline Radio Campus & & $\mathrm{X}$ & $\mathrm{X}$ & $\mathrm{X}$ & $\mathrm{X}$ \\
\hline InfoRadio UCM* & $\mathrm{X}$ & $\mathrm{X}$ & $\mathrm{X}$ & $\mathrm{X}$ & \\
\hline $\begin{array}{l}\text { Radio Universidad } \\
\text { Salamanca* }\end{array}$ & $\mathrm{X}$ & $\mathrm{X}$ & $\mathrm{X}$ & $\mathrm{X}$ & $\mathrm{X}$ \\
\hline 98.3 Radio* & $\mathrm{X}$ & $\mathrm{X}$ & $\mathrm{X}$ & $\mathrm{X}$ & $\mathrm{X}$ \\
\hline Radio Universitaria León & & $\mathrm{X}$ & $\mathrm{X}$ & & \\
\hline Europea Radio* & $\mathrm{X}$ & $\mathrm{X}$ & $\mathrm{X}$ & & \\
\hline UPV Ràdio* & $\mathrm{X}$ & $\mathrm{X}$ & $\mathrm{X}$ & $\mathrm{X}$ & $\mathrm{X}$ \\
\hline Vox UJI Ràdio* & $\mathrm{X}$ & $\mathrm{X}$ & $\mathrm{X}$ & $\mathrm{X}$ & $\mathrm{X}$ \\
\hline OndaCampus Radio* & $\mathrm{X}$ & $\mathrm{X}$ & $\mathrm{X}$ & $\mathrm{X}$ & $\mathrm{X}$ \\
\hline RadioCEU Valencia* & $\mathrm{X}$ & $\mathrm{X}$ & $\mathrm{X}$ & & \\
\hline UniRadio Huelva & & $\mathrm{X}$ & $\mathrm{X}$ & $\mathrm{X}$ & $\mathrm{X}$ \\
\hline UPF Ràdio* & $\mathrm{X}$ & $\mathrm{X}$ & $\mathrm{X}$ & $\mathrm{X}$ & $\mathrm{X}$ \\
\hline Radio UMH* & $\mathrm{X}$ & $\mathrm{X}$ & $\mathrm{X}$ & $\mathrm{X}$ & \\
\hline RUAH Alcalá & & $\mathrm{X}$ & $\mathrm{X}$ & $\mathrm{X}$ & $\mathrm{X}$ \\
\hline Radio URJC** & $\mathrm{X}$ & $\mathrm{X}$ & $\mathrm{X}$ & $\mathrm{X}$ & $\mathrm{X}$ \\
\hline iRadio UCAM* & $\mathrm{X}$ & $\mathrm{X}$ & $\mathrm{X}$ & & \\
\hline Radio Universidad.es & & $\mathrm{X}$ & $\mathrm{X}$ & $\mathrm{X}$ & \\
\hline UniRadio Jaén & & $\mathrm{X}$ & $\mathrm{X}$ & $\mathrm{X}$ & $\mathrm{X}$ \\
\hline OnCEU Radio* & $\mathrm{X}$ & $\mathrm{X}$ & & & \\
\hline Radio SIDE & & $\mathrm{X}$ & $\mathrm{X}$ & & \\
\hline Radio.UniZar.es* & $\mathrm{X}$ & & & & \\
\hline Radio Universitat* & $\mathrm{X}$ & & & & \\
\hline Radio USJ* & $\mathrm{X}$ & & & & \\
\hline
\end{tabular}

Tabla 1 (Elaboración propia).

* Emisoras que cuentan con estudios relacionados con el área de Ciencias de la Información

las diez primeras posiciones del ranking localizamos a ocho emisoras $(33 \%)$ que acogen alumnos de ciencias de la información, que son arrastrados directamente desde la docencia (98.3 Radio o Radio CEU) o simplemente por el interés del estudiante de estas áreas por asegurarse una mejor formación de cara a su futuro acceso al mercado laboral. 
Entre esas diez emisoras que encabezan este ranking destacan las estaciones de UniRadio Huelva y Jaén, ambos con una gran participación estudiantil, y abiertas a colaboradores externos, que amplían y enriquecen sus parrillas.

\section{Conclusiones}

El análisis realizado en la muestra constituida por las emisoras miembros de la ARU, que constituyen el $80 \%$ de las existentes en España permite constatar que la presencia del alumnado en la producción de los contenidos en claramente mayoritaria.

El perfil de estudiante se impone sobre PDI y PAS, ya sean estudiantes del área de ciencias de la información o de otras áreas del conocimiento, de forma que el colectivo se convierte en el gran movilizador y dinamizador de este tipo de emisoras en España.

Más allá, se observa que el perfil de los estudiantes de especialidades relacionadas con la comunicación es mayoritario, tanto en las universidades que contemplan la radio universitaria como parte de las prácticas obligatorias vinculadas a una u otra asignatura, como en aquellas en las que los alumnos tienen en la radio una opción complementaria y no obligatoria a los planes de estudios.

Se constata también que debido a la crisis económica y laboral que afecta a la sociedad española en general y a los medios de comunicación en particular, resulta muy complicado para los recién licenciados su incorporación al mercado laboral, por lo que muchos de ellos deciden, en los casos en que la Universidad lo permite, continuar vinculados de forma voluntaria a la emisora universitaria para seguir formándose a la espera del ingreso en el tejido empresarial.

Además, en la mitad de las emisoras analizadas participan colaboradores de perfil externo al universitario, lo que viene a corroborar el carácter social y de servicio público de las emisoras. Falla todavía un contacto más cercano con el resto de personal vinculado a la universidad, PAS y PDI, ya que su presencia en la actualidad, a pesar de estar representados en la mayoría de emisoras, es cuasi testimonial en número real. 
En resumen, la gran diversidad de perfiles que se mueven alrededor de las radios universitarias españolas delimita de forma clara una de las características principales de estas emisoras en este país, su marcada heterogeneidad.

Y el hecho del gran número de futuros profesionales de los medios, alumnos cursando estudios de periodismo o comunicación, que se acercan día a día a estas emisoras, certifican claramente el valor formativo que adquieren esta tipología de emisoras para este colectivo, a la hora de adquirir las competencias necesarias para desarrollar su futuro trabajo en los medios de comunicación convencionales. 


\section{Nuevos perfiles formativos del periodista multimedia}

Pilar Sánchez-García (Universidad de Valladolid)

http://orcid.org/0000-0002-6223-182X

http://scholar.google.es/citations?user=eUalA-cAAAAJ\&hl=es

\section{Introducción}

— L NUEVO ENTORNO mediático provoca un profundo cambio en la profesión periodística dando lugar a nuevos perfiles profesionales traducidos en salidas laborales, hasta ahora inexplorables, bajo la premisa de que el periodista del siglo XXI "será digital o no será" (Álvarez, 2009) y que su trabajo está conectado de forma permanente e irremediable a un nuevo contexto global de comunicación de la Sociedad Red (Castells, 2008).

Un nuevo entorno comunicativo en el que el informador requiere renovadas competencias y habilidades. El periodista que trabaja en los medios digitales -el ciberperiodista o periodista digital- requiere potenciar nuevas cualidades y competencias que le permitan acceder, manejar, crear e integrar los mensajes informativos on-line (Tejedor, 2007). Debe contar con destrezas suficientes para trabajar en diferentes soportes (multimedia) manejando los lenguajes escrito y audiovisual (multilenguaje) en una realidad periodística que ha dejado de ser lineal, tanto en la información que ofrece como en el lenguaje que utiliza. 
Todo ello se traduce en mayor polivalencia y versatilidad desde diferentes perspectivas: polivalencia mediática para producir contenidos en distintos soportes; polivalencia tecnológica para el proceso productivo; y polivalencia temática para tratar noticias de distintos ámbitos o secciones (Masip \& Micó, 2009). El actual informador profesional debe agudizar la capacidad de análisis y síntesis, sin olvidar que requiere "un enfoque integrador de capacidades en línea con la creatividad y la innovación en que se desenvuelven las industrias y la propia sociedad del conocimiento" (Lorente, 2010: 26).

El periodista del siglo XXI desempeña ya nuevas tareas transformadas, muchas de ellas, en nuevos perfiles periodísticos cuyo debate permite plantear la oportunidad y pertinencia de relacionarlo con las nuevas necesidades formativas y la conveniencia de integrarlos de forma específica en los planes de estudio de Periodismo.

\section{E1 debate abierto de los nuevos roles profesionales}

Esta investigación parte de un marco teórico relativamente incipiente pero fructuoso que evidencia el profundo cambio en la profesión dando lugar a nuevos roles profesionales (López, 2010, 2012; Meso, et al, 2010) que requieren un ajuste de los perfiles formativos (Mellado et al, 2007; Balandrón, 2010; Sierra, 2010; Rosique, 2013) en la enseñanza universitaria del Periodismo. Dichos perfiles perio-dísticos emergentes surgen como nuevas oportunidades laborares en las que el periodista puede trabajar "al servicio de empresas, instituciones, organizaciones, etc., para ponerlas en contacto con sus públicos interlocutores sociales, con y sin mediación de la prensa" (Piñuel, 2000: 5). Diferentes roles que se corresponden con tres clasificaciones (Meso et al, 2010: 307):

- periodista multimedia (maneja diferentes soportes)

- periodista multitarea (asume varias labores a la vez)

- periodista multiplataforma (difunde su trabajo por diferentes canales)

Los perfiles emergentes tienen, además, relación con tres vertientes comunicativas: 
- las redes sociales

- la mayor presencia de empresas, instituciones o entidades

- la capacidad de interacción con el público

Se trata de un proceso de cambio en el que entran en juego una amplia variedad de roles, de los que algunos de ellos representan una ampliación de viejos cometidos, mientras otros constituyen ámbitos nuevos y, en buena medida, todavía experimentales.

\section{Del gatekeeper al curator, pasando por el periodista orquesta}

La concreción de los perfiles periodísticos se encuentra en pleno debate académico y puede resumirse en torno al refuerzo de tres tareas comunicativas del informador:

- filtro informativo

- documentalista o curator

- intérprete frente a la sobreabundancia informativa

El periodista recibe nuevas exigencias laborales encaminadas a reforzar, a grandes rasgos, su papel de filtro, de intérprete y documentalista. En el ámbito académico aún no se da por cerrada la discusión sobre las nuevas tareas. Por un lado, se defiende el papel de "experto gatekeeper" porque en "un entorno de creciente complejidad y proliferación de mensajes, cobra renovada importancia el papel del periodista como clarificador, selector, guía, filtro, anticipador, prescriptor, compresor" (Diezhandino, et al, 2012: 9). Es decir, que el periodista refuerza su labor de "buscar, jerarquizar y filtrar información dentro de la opulencia informacional existente" (Rosique, 2013: 118). Igualmente esta tarea puede verse notablemente amplificada con el uso de las redes sociales en el momento en que un periodista se dedica a retuitear o enlazar informaciones existentes (Noguera, 2013). Esta teoría, sin embargo, no es compartida por quienes señalan que la figura del gatekeeper "se tambalea" (Díaz, 2002: 182-183) porque la accesibilidad de la información y de las fuentes por parte de los usuarios les otorga el poder de filtro a éstos, desterrando la idea de que el público conoce sólo aquello de lo que informan los medios de comunicación. Una cuestión que se encuentra en estrecha relación con el nuevo papel del receptor como 
consumidor y productor de contenidos, el llamado prosumidor (Hermida y Thurman, 2008; López, 2012; Berrocal et al, 2014).

Otra de las tareas que se refuerzan en el periodista es la de documentalista o content curator, un profesional capaz de seleccionar, valorar y comentar (Varela, 2011) datos e informaciones en grandes cantidades. Se trata del especialista que selecciona y difunde el contenido más relevante sobre un tema o ámbito en diversas fuentes de información en la web (Guallar y Leiva-Aguilera, 2013).

Por último, cabe añadir el fomento de la tarea de intérprete que ofrece informaciones más completas y profundas que ayuden a una mejor orientación y comprensión de la realidad sobrecargada de información y fuentes interesadas. En definitiva, pueden cambiar las herramientas, las tareas o los soportes, pero la función seguirá siendo la misma, "informar con los criterios clásicos de veracidad, selección, jerarquización, interpretación y contextualización” (Diezhandino et al, 2012: 9).

Entre la diversidad de roles, aún sin especificar y en fase de experimentación empresarial, surge el peligro de confundir perfiles con 'multitareas' debido a que la urgencia mediática por asumir diferentes facetas promueve también la figura del "hombre orquesta" (Álvarez, 1996: 14) capaz de utilizar imágenes de vídeo en la edición cibernética de su periódico o de transmitir mensajes escritos a través de su emisora de radio. Una cuestión, agudizada en tiempos de crisis, que no se corresponde con la necesaria especialización, en el sentido de que el periodista digital debe saber trabajar en todos los medios y con todos los medios. Es decir, formado con perfiles polivalentes, flexibles y versátiles.

Aunque el debate académico al respecto se encuentra abierto se parte ya de la constatación de que los perfiles periodísticos cambian pero aún requieren ajustar la especificidad de sus tareas.

\section{Una propuesta revisionista de cuatro perfiles formativos}

La formación de los informadores requiere de una revisión porque "exigen una preparación distinta a la que hasta ahora han recibido los periodistas" (López, 2001: 14). Los actuales planes de estudio de Periodismo en las Facultades españolas se amoldan, poco a poco, a 
esta diversidad profesional. La adaptación al Espacio Europeo de Educación Superior (EEES) se ha guiado por el 'Libro Blanco de Títulos de Grado en Comunicación' de la Agencia Nacional de Evaluación de la Calidad y Acreditación (Aneca) con cuatro perfiles formativos (2005: 191):

1. Redactor de información periodística en cualquier tipo de soporte.

2. Redactor responsable de prensa o comunicación institucional.

3. Investigador, docente y consultor de comunicación.

4. Gestor de portales y editor de contenidos.

Los cuatro perfiles básicos parecen asumidos en la mayoría de los planes de estudios. Pero la realidad laboral no ofrece una delimitación tan nítida. En parte, por esa variedad de tareas mencionadas que empuja al periodista a cumplir con varios perfiles a la vez y por la rapidez con la que se producen los cambios tecnológicos y las nuevas demandas informativas.

Casi diez años después de la propuesta de perfiles realizada por la Aneca, y sin poner en duda su vigencia o validez, se propone su revisión con el objetivo de desarrollar perfiles y tareas concretas y específicas que el mercado ya demanda a los periodistas del siglo XXI. La revisión propuesta desarrolla cuatro perfiles multimedia con tareas o multitareas no excluyentes entre sí (Tabla 1) y que se exponen a continuación.

El primer perfil citado de informador en cualquier tipo de soporte que marca la Aneca requiere la formación de un periodista multimedia que es capaz de informar en múltiples soportes y dominando el multilenguaje. A su vez, puede convertirse en un 'redactor polivalente" o "redactor especializado', distinción referida tanto a soportes como a temáticas. Una cuestión reabre el debate de la conveniencia de que los periodistas o ciberperiodistas estén especializados en áreas más concretas y parcelas temáticas para ejercer su trabajo con conocimientos más específicos para las diferentes publicaciones multimedia. $O$ si debe ser, por el contrario, un periodista polivalente capaz de afrontar su trabajo a modo de multitarea digital (redacción de texto, vídeos y diseño) con conocimientos temáticos de carácter general. 
Tabla 1. Delimitación de nuevos perfiles formativos multimedia

\begin{tabular}{|c|c|}
\hline PERFILES PERIODÍSTICOS & MULTITAREAS \\
\hline 1. Informador multimedia & $\begin{array}{l}\text {-Redactor polivalente en soporte o } \\
\text { temática } \\
\text {-Redactor especializado en soporte o } \\
\text { temática } \\
\text {-Gestor periodístico de información y } \\
\text { contenidos con base de programación } \\
\text { (Periodismo de Datos) } \\
\text {-Gestor de contenidos audiovisuales }\end{array}$ \\
\hline $\begin{array}{l}\text { 2. Gabinete multifacético o } \\
\text { multimedia }\end{array}$ & $\begin{array}{l}\text {-Periodista multidisciplinar } \\
\text {-Informador corporativo multimedia } \\
\text {-Agente de información (Information } \\
\text { Broker) }\end{array}$ \\
\hline $\begin{array}{l}\text { 3. Profesor de laboratorio y } \\
\text { consultor }\end{array}$ & $\begin{array}{l}\text { - Docente e investigador } \\
\text {-Mediador entre Universidad y } \\
\text { empresa } \\
\text {-Periodista colaborador en } \\
\text { investigación de medios y mercados } \\
\text {-Periodista-profesor en otras } \\
\text { titulaciones y niveles educativos que } \\
\text { forma sobre los medios }\end{array}$ \\
\hline $\begin{array}{l}\text { 4. Gestor de portales y contenidos } \\
\text { on line }\end{array}$ & $\begin{array}{l}\text { - Gestor multimedia freelance } \\
\text { - Community manager } \\
\text { - Gatekeeper en Facebook } \\
\text { - Gatekeeper de redes sociales }\end{array}$ \\
\hline
\end{tabular}

Fuente: Elaboración propia a partir del Libro Blanco de ANECA (2005)

Incluido en el perfil general de redactor o informador multimedia ya se puede hablar también de 'gestor periodístico de información', ante la compleja labor de filtro de información que debe realizar el periodista. Este perfil puede ir ligado a la faceta de programador, no tanto para programar como un técnico informático sino para desenvolverse con soltura al navegar en algunos sistemas informáticos de gestión de contenido (Azócar, 2011). Nuevas habilidades para afrontar también el llamado 'Periodismo de Datos' (Big Data o sistema de grandes conjuntos de datos) que lleva a los redactores a bucear en las ingentes bases de datos que pone a su disposición las nuevas tecnologías, especialmente, las bases de datos oficiales sin depender tanto de los portavoces gubernamentales de turno o la mayor o menor transparencia pública que sigue al capricho 
de los políticos. El periodista realiza ahora labores de documentalista buceando en la información, en un perfil de gestor documental. De forma idéntica, puede extenderse esta figura emergente al campo audiovisual con un nuevo perfil de 'gestor de contenidos', una figura encargada de "controlar y administrar una ingente cantidad de materiales, distribuidos a través de distintos canales, ya sea TDT, Internet o teléfonos móviles" (Bernaola et al, 2011: 187). Es decir, las labores del informador que controla múltiples fuentes audiovisuales y sistemas de difusión diversos.

En segundo lugar, el periodista de gabinete que cita la Aneca requiere la formación propia de un profesional de un gabinete multimedia puesto que el mercado cada vez más competitivo del marketing y la imagen pública-comercial demanda profesionales con conocimientos multidisciplinares $y$, sobre todo, con una fuerte preparación en la información digital que le permite difundir información de la empresa o institución por muchas más vías y soportes, es decir que, valga la redundancia, genera información multimedia (notas de prensa escritas, con contenido de audio, vídeo, documentos adjuntos, etc.), en lo que podría denominarse también como un informador corporativo multimedia'.

La singularidad de este perfil radica en que puede ajustarse a contratos por cuenta propia o ajena y lo que exige son importantes conocimientos sobre cómo aumentar y hacer más efectiva la presencia y diversificación informativa y corporativa en la red, en diversos soportes y con dominio de diversos lenguajes. Incluso de este perfil salen ya ramificaciones como el llamado "agente de información" (information broker), encargado de buscar información específica en Internet y suministrársela a un tercero (personas individuales, empresas o instituciones) que, previamente, haya contratado sus servicios (Real, 2004). Y la variedad de facetas de este perfil sigue en aumento.

El tercer perfil de consultor, docente e investigador que marca la guía académica de la Aneca, inmerso ya en el estudio de las nuevas tecnologías, encuentra una variante que podría considerarse en coherencia con el llamado Plan Bolonia que busca mayor relación entre lo académico y lo empresarial. Se trata de la figura del 'profesor de laboratorio', un mediador entre la Universidad y la empresa, que 
combina la docencia con la investigación y que, a la vez, conecta realmente los descubrimientos teóricos y los efectos sociales de la Comunicación con la práctica profesional, para dar así respuestas al colega periodista que trabaja del otro lado y a la empresa ávida de nuevos modelos de negocio y de informaciones sobre tendencias de los usuarios. Un perfil más bien de futuro, enfocado a nuevas narrativas, soportes y tendencias que quizás requiera de mayores conocimientos técnicos.

Por otro lado, surgen facetas complementarias a este rol académico por la posibilidad de que periodistas con experiencia en medios de comunicación colaboren o participen en diferentes estudios, especialmente empíricos, y en investigaciones académicas o en informes demandados por consultorías, centrados en medios, audiencias y mercados que ayuden tanto a profesionales como académicos a estar al día de los efectos tecnológicos.

$\mathrm{E}$ igualmente, puede incluirse en este apartado como nuevo rol académico a potenciar el del periodista-profesor en otras titulaciones y en otros niveles educativos. Es decir, el fomentar que el estudio de los medios de comunicación llegue a diferentes ámbitos de manera que docentes de Periodismo puedan instruir sobre los medios de comunicación en otras carreras universitarias desde el punto de vista de la influencia social de los medios; y con igual o más relevancia, potenciar esta figura en los niveles educativos de Secundaria y Bachillerato para ayudar a los más jóvenes a tener claves de análisis y filtros ante los medios de comunicación. Una figura que podría contar con una formación específica para este cometido.

Por último, el gestor de portales y editor de contenidos, resulta el perfil más actualizado al ámbito digital y que podría ajustarse más a la denominación de 'gestor de portales y contenidos on line' que trabaja generando información en la Red y puede, a su vez, incluir facetas complementarias que requieren mayor detenimiento por su reciente implantación en la realidad laboral que pueden resumirse en gestor multimedia independiente y gestor de redes sociales.

Por un lado, el periodista denominado 'gestor multimedia freelance' requiere destrezas para manejar los criterios periodísticos y el lenguaje de los diferentes soportes tanto para medios de comunicación como 
para empresas de otros sectores, trabajando como autónomo. Es decir, que es capaz de escribir para una web, al tiempo que prepara vídeos para internet o realiza labores de estrategias comunicativas para una o varias empresas; un periodista que, en sí mismo, constituye una 'miniempresa' informativa.

En este contexto se ubica la figura del 'community manager', autónomo o por cuenta ajena, que puede considerarse como parte del perfil del 'gestor del gabinete multimedia' o estar especializado en este servicio de forma exclusiva para medios de comunicación y diferentes organismos. Gestiona las redes sociales de una empresa, institución, entidad o medio de comunicación para reforzar la presencia destacada de su marca en la red y lograr mayor difusión de contenidos y efectividad comercial. Se trata de una labor ya imprescindible y que realizan muchos periodistas con una formación autodidacta. De una forma relacionada, se plantea, expresamente, la figura del "gatekeper en Facebook", por ejemplo, dedicado a seleccionar de manera profesional los contenidos informativos del medio en esta red social, evitando la figura del periodista multiuso (Rodríguez, M.I., Herrero, F.J. \& Sánchez, F., 2010) y que podría extenderse al 'gatekeper de redes sociales'. En sus diferentes facetas, este perfil, en su vertiente más periodística, requiere una formación adecuada para buscar, seleccionar, recuperar, organizar, jerarquizar, analizar y procesar la información y una de sus habilidades básicas es la de saber escribir bien, mostrar creatividad e innovación y contar con una base de ética y deontología del uso de la red con los llamados "valores 2.0" (Baladrón, 2010: 213). En definitiva, el gestor de portales y contenidos on line constituye un perfil en plena expansión y con cometidos en fase de experimentación.

La propuesta de perfiles aquí planteada no puede considerarse hermética o consolidada, sino que ha de entenderse como un punto de partida para continuar con el debate formativo del periodista multimedia en contante revisión.

\section{A modo de conclusión}

Los perfiles periodísticos emergentes constituyen nuevas oportunidades laborales especialmente ligadas a tres vertientes: las 
redes sociales, la mayor presencia interactiva de empresas y entidades, y la capacidad de interacción con el público.

En este contexto, el debate académico afronta la necesidad de ligar los nuevos roles profesionales con las necesidades formativas de los periodistas del siglo XXI atendiendo a cuatro perfiles formativos multimedia: redactor multimedia polivalente o especializado; profesional de un gabinete de comunicación multifacético; profesorinvestigador de laboratorio y consultor; y gestor de portales $y$ contenidos on line.

Estos cuatro grandes perfiles pueden considerarse, pues, como salidas laborales de los periodistas actuales que no resultan excluyentes entre sí y que no se agotan en estas referencias, sino que pasan por un período de expansión y acomodo tanto en la realidad laboral como en la académica. La propuesta expuesta viene a confirmar que los perfiles profesionales y formativos de los periodistas ya no pueden considerarse inamovibles, como hasta ahora, sino que ofrecen mayor interdependencia con la demanda del mercado laboral donde ya están en auge muchos de ellos, susceptibles de ampliación o supresión, dependiendo de la mayor definición de los propios modelos periodísticos digitales en período de transición.

La definición de los perfiles periodísticos y formativos se encuentra en evolución y dependiente del mercado tecnológico y comunicativo cambiante por lo que debe seguir siendo objeto de investigación con un esfuerzo de delimitación en el que confluyan las respuestas del ámbito académico y profesional. Se trata, pues, de dar una respuesta formativa adecuada a los futuros periodistas mediante la revisión de los planes de estudio de forma progresiva y permanente en el nuevo entorno mediático en transformación. 


\section{El estudiante de Ciencias de la Comunicación de la UANL: consumo, perfil y aspiraciones}

Laura Lizeth Campos Guido (Universidad Autónoma de Nuevo León, Monterrey, México) http://orcid.org/0000-0002-8958-4836?lang=en http://scholar.google.es/citations?user=bWlsopYAAAAJ\&hl=es

Juan Antonio Garza Sánchez (Universidad Autónoma de Nuevo León, Monterrey, México) orcid.org/0000-0002-8536-6321 http:// scholar.google.es/citations?user=8K4oSoAAAAAJ\&hl=es

\section{Introducción}

T OS ÚlTimOS AÑOS, a partir de la crisis mundial del 2008, Whemos enfrentado retos económicos y sociales de gran envergadura en distintos rincones del planeta. Entre todos los actores, el sector juvenil afronta además la incertidumbre laboral provocada por los altos índices de desempleo que nos "impiden aprovechar el potencial de la generación mejor formada y educada que hemos tenido" (OIT, 2012). Millones de jóvenes alrededor del mundo se preguntan si obtener una educación cualificada garantizará el ascenso social que hasta hace pocos años prometían los estudios superiores y; con ello, se cuestiona nuevamente el papel de la Universidad en la formación de las sociedades contemporáneas. 
Por su parte, las Instituciones de Educación Superior (IES) ocupan un papel sumamente relevante en la construcción social. Su rol se ha modificado por el proceso globalizador y con especial énfasis en los dinámicos sectores económicos e informativos que demandan a las Universidades "respuestas que, por vía de las funciones canónicas de enseñanza, investigación y difusión coadyuven al crecimiento económico, al desarrollo y la cohesión social, a la construcción de ciudadanía y la integración cultural, y a la protección del medio ambiente, por citar algunas" (Rodríguez, 2014: 14).

El complejo panorama que envuelve a estudiantes desorientados e instituciones saturadas de demandas sociales obliga a hacer un alto en el camino para cuestionar sobre las necesidades que ambos entes requieren $y$, sobre todo, para conocer al joven universitario en un plano integral. Sus prácticas, su construcción de sentido, su identidad, su condición socioeconómica y familiar, sus aspiraciones, ayudarán a las universidades a contribuir en la formación de un sector demográfico crucial, y muy cuantioso en nuestro país, para potenciar el cambio social.

En este sentido, como parte de un proyecto de investigación que los autores han realizado en los últimos años, el presente trabajo expone algunos resultados con la intensión de evidenciar, primeramente, las expectativas laborales en el mundo globalizado del estudiante de la Licenciatura en Ciencias de la Comunicación de la UANL, y en el que la crisis económica, las nuevas tecnologías y las constantes reestructuraciones familiares y sociales afectan también al desarrollo de la Educación Superior en México.

\section{Metodología y muestra}

El marco del estudio descrito con anterioridad obliga a emplear una metodología mixta, con elementos cuantitativos y cualitativos, debido a que los números que podría arrojar sólo un instrumento metodológico (encuesta) resultarían frívolos y sesgaría la información cayendo en inconvenientes. Posterior a la aplicación de la encuesta se efectuaran dos grupos de discusión entre los estudiantes con el objetivo de matizar y/o validar los resultados obtenidos. 
Para determinar el tamaño de la muestra se consultó la calculadora de muestras netquest (http://www.netquest.com), instrumento que determinó aplicar 340 encuestas con un margen de error de 5\% y un nivel de confianza de 95\%, la población en la Facultad de Ciencias de la Comunicación registrada a finales del curso del ciclo escolar Agosto-Diciembre 2014, eran un total de 2950.

\section{Resultados}

La población estudiantil de la Facultad de Ciencias de la Comunicación oscila principalmente entre los 17 y 21 años y el 60\% de la misma son mujeres. Por lo que respecta al género, llama la atención la composición casi equitativa ya que los estudiantes expresaron en los grupos de enfoque que los estudios en comunicación "son para mujeres" y que se estudian éstos "mientras me caso". Cabe aclarar que el 60\% de los estudiantes de la carrera son mujeres, pero hace 10 años el 80\% de los estudiantes era del género femenino por lo que ha quedado el estereotipo entre los jóvenes. En general el $94.7 \%$ vive con su familia, el $2.9 \%$ vive solo y el $1.5 \%$ con amigos.

\section{R1. Hábitos de consumo mediático}

Por lo que se refiere al consumo mediático, consideramos pertinente exponer los resultados obtenidos en torno a su uso y percepción toda vez que se trata de jóvenes que se preparan para, posiblemente, ejercer su profesión en los medios masivos o en áreas relacionadas con ellos.

En lo que se refiere al consumo de la televisión destaca que de las 340 personas entrevistadas, 95 mujeres $(47.5 \%)$ contestaron que dedican de 2 a 3 horas al día a ver televisión, mientras que el 40\% -56 entrevistados- del género masculino afirmaron ver la televisión en este mismo período de tiempo. Un total de 84 mujeres y 75 hombres respondieron ver la televisión una hora o menos; mientras que 19 mujeres y 13 hombres respondieron ver la televisión cuatro horas o más.

Vale la pena señalar que, durante los grupos de discusión, los estudiantes reconocieron preferir el consumo de series o programación por internet dada la carencia de anuncios comerciales 
que cortan la emisión del producto; sin embargo, en el mismo grupo uno de ellos reflexionó sobre lo decepcionante que era el que cada vez haya menos gente viendo la televisión convencional siendo el lugar en donde a él le gustaría laborar. El 60\% de los encuestados ve la televisión principalmente en la noche, el $35 \%$ por la tarde y solo un 5\% durante la mañana.

Es muy común que al momento de ver televisión los espectadores realicen otro tipo de actividades; en este sentido, los resultados indican que el 59.4\% de los entrevistados afirman hacer otras cosas además de ver televisión; el 35.6\% afirma que esto sucede "Con mucha frecuencia" y, tan sólo, el 3.5\% comentó nunca recurrir a este tipo de prácticas.

TABLA 1. ¿Qué otras actividades realizas al momento de ver televisión?

\begin{tabular}{lllllll}
\hline & \multicolumn{3}{l}{ Mujeres } & \multicolumn{3}{l}{ Hombres } \\
\cline { 2 - 7 } Respuesta & Frec. & $\%$ & Frec. & $\%$. & Frec. & $\%$. \\
\hline No contestó & 0 & 0 & 7 & 5,0 & 7 & 2,1 \\
Comer & 83 & 41,5 & 55 & 39,3 & 138 & 40,6 \\
Hacer tarea & 28 & 14 & 22 & 15,7 & 50 & 14,7 \\
Hacer deberes del hogar & 22 & 11 & 11 & 7,9 & 33 & 9,7 \\
Navegar por redes sociales & 42 & 21 & 40 & 28,6 & 82 & 24,1 \\
Arreglarse para salir & 16 & 8 & 2 & 1,4 & 18 & 5,3 \\
Varias actividades & 9 & 4,5 & 3 & 2,1 & 12 & 3,5 \\
\hline Total & $\mathbf{2 0 0}$ & $\mathbf{1 0 0}$ & $\mathbf{1 4 0}$ & $\mathbf{1 0 0 , 0}$ & $\mathbf{3 4 0}$ & $\mathbf{1 0 0 , 0}$ \\
\hline
\end{tabular}

Respecto al tiempo que los entrevistados dedican a navegar en internet, 67 mujeres y 41 hombres contestaron más de 3 horas diarias; mientras que 56 mujeres y 47 hombres mencionaron que de 2 a 3 horas cada día. Tan sólo 51 entrevistadas y 31 hombres dijeron que de 1 a 2 horas y un hombre no contestó.

Este dato se enfatizó aún más durante los grupos de discusión en donde nuestros estudiantes comentaron que prácticamente se encontraban conectados a la red de redes las 24 horas del día. Mencionando que incluso los tiempos muertos, como transportarse en el autobús, son utilizados para navegar por la red. Este tópico fue muy comentado en los grupos de discusión, entre las aseveraciones más relevantes podemos identificar que los estudiantes navegan o 
conversan por su teléfono en todo momento, incluso cuando están en clase o con su pareja o familia.

Hace décadas, los espectadores ocupan su tiempo frente a la televisión para convivir con la familia y el televisor generalmente se encontraba en áreas comunes de su hogar como la sala o la cocina. En este sentido, y a pesar de que como se señala líneas arriba la mayoría de los encuestados vive con su familia, nuestros estudiantes confirmaron que esto ya no sucede así; el $55.9 \%$ de los encuestados afirma ver televisión "en la habitación” y, el 38.2\% mencionó que lo hace "en la sala". El 47.6\% consumo la televisión solo, el 4.4\% con su pareja, el $4.1 \%$ con amigos, el $25 \%$ con los hermanos y el $17.9 \%$ con sus padres.

Por lo que se refiere al consumo de otros productos culturales, el $32.1 \%$ de los estudiantes entrevistados afirmó que dedica "de 1 a 2 horas" diarias a escuchar música; el 31.5\% "menos de 1 hora"; mientras que el 17.9\% emplea "de 2 a 3 horas" y, el 16.2\% "más de 3 horas".

Otro aspecto analizado es el tiempo que los entrevistados dedican a la lectura; sin hacer distinción entre los tipos de lectura (didáctica, informativa, recreativa) los resultados obtenidos arrojaron que el 62.1\% dedican "menos de 1 hora" a leer; el 24.7\% afirma emplear "de 1 a 2 horas" al día a esta actividad; mientras que 10.3\% invierte 2 horas o más diarias a la lectura. Al analizar la asistencia al cine, se encontró que la gran mayoría dedica poco tiempo diario a esta actividad; esto puede deberse a que en México es costoso adquirir una entrada para el cine, así mismo, es una acción que usualmente no se hace sólo y se realiza en épocas cuando hay grandes estrenos y/o promociones tal como lo indica el 33.5\% que afirma dedicar "menos de 1 hora" y, otro $33.5 \%$, de 1 a 2 horas.

\section{R2. Educación y aspiraciones profesionales}

Un aspecto muy relevante evaluado dentro de la aplicación de esta encuesta es el nivel educativo y las aspiraciones profesionales de los entrevistados. En este tenor fueron cuestionados acerca del tiempo diario dedicado a la escuela; el $48.8 \%$ de los entrevistados afirma que dedica "de 4 a 5 horas" diarias a sus deberes escolares; el 28.8\% 
afirma dedicar "más de 5 horas"; el 16.8\% "de 3 a 4 horas"; mientras que el 5.6\% dedica menos de 3 horas a esta actividad. En este sentido, durante los grupos de discusión sobresalió la idea de que la escuela es únicamente el lugar en donde se podrá obtener un título: "Hay que venir pues necesitamos el papel para laborar, sin embargo aquí hace falta que se actualicen, nuestros maestros en su mayoría son gente a punto de jubilarse y que no le saben a las nuevas tecnologías. Además muchos no tienen experiencia laboral o te cuentan cosas que ya no pasan en el medio", aseguró un estudiante.

En lo que corresponde a las aspiraciones profesionales de los entrevistados, el 30\% de los encuestados afirma que al egresar de su carrera le gustaría trabajar como publicista; al 17.6\% como mercadólogo; al 16.2 como periodista; el 9.1\% como organizador de eventos; al $8.8 \%$ como relacionista público y, con porcentajes menores, se encuentran quienes desean laborar como Investigadores, Maestros y Empresarios.

"A todo se acostumbra uno menos a no comer, el campo laboral está muy reducido y creo que como publicista hay espacio laboral", afirmaron en los grupos de discusión. En ocasiones, cuando un estudiante concluye sus estudios de licenciatura considera que este logro representa el final de su carrera académica; sin embargo, para nuestros entrevistados esto no debe ser así ya que según los grupos de discusión "el campo laboral está muy competido y hay que continuar preparándose" por lo que optan por inscribirse en un posgrado. Al ser cuestionados, los estudiantes de licenciatura en Ciencias de la Comunicación señalan en un $89.1 \%$ que sí desean continuar estudiando un posgrado; mientras que el $9.7 \%$ se inclinará por no hacerlo.

El 40.7\% de los encuestados afirma que desea continuar estudiando un posgrado para obtener una mayor "Superación personal"; el $36.0 \%$ busca hacerlo para contar con una "mejor preparación académica"; el $10.1 \%$ para tener acceso a "mejores oportunidades laborales" y el 5.1\% por obtener mayores ingresos. Estos datos reflejan que entre los jóvenes que cursan la carrera de Ciencias de la Comunicación existe la idea clara de que estudiar un posgrado maestría o doctorado- puede representar para ellos mejores oportunidades académicas, laborales y económicas. 
Cabe aclarar que durante los grupos de discusión nuestros entrevistados coinciden en que los estudios de licenciatura no son suficientes. La mayoría desean especializarse y aluden a dos situaciones principales: por un lado sienten que lo estudiado en la licenciatura no es suficiente y por otro, perciben desorientación y temor sobre el futuro laboral por lo que continuar con los estudios representa una manera de postergar esa realidad.

Para un gran número de universitarios estudiar comunicación no era su primera opción e incluso, pese a estudiar actualmente la carrera, han decidido estudiar una segunda carrera o alguna especialización. Entre los participantes en el focus group existían estudiantes que cursaban grados de educación, artes visuales o actuación. Por otro lado reconocieron en los amigos una fuerte influencia en los temas educativos y eran estos los que les hacían ver qué comunicación no era suficiente.

\section{R3. La preferencia en la televisión de Monterrey}

Actualmente, el contenido televisivo que se transmite en la Ciudad de Monterrey es altamente criticado y se considera que es ofensivo y de escaso contenido cultural. La gran mayoría de los entrevistados aludían a que la televisión local era pésima, con escasa creatividad y que no fomentaba la cultura. Sin embargo, muchos de ellos se veían laborando ahí y sabían que si querían trabajar tenían que hacerse a la línea que manejaba el medio. En este sentido, como parte del estudio, se cuestionó sobre los temas que a los entrevistados les gustaría ver en las señales de televisión regiomontana.

"Ya nadie estudiado ve la televisión local, es una basura", dijo alguno de los participantes en los grupos de discusión; "la televisión en señal abierta está hecha para gente de escasos recursos, la verdad por eso México no progresa"; "al pueblo pan y circo, eso es lo que les dan", fueron algunas de las aseveraciones. Ellos gustan de las series estadounidenses y de la televisión internacional, la cual se ve en televisión de paga y/o internet. Desde chicos sus padres los exponían a la televisión y crecieron con ella. La gran mayoría aceptaba que la encendía solo para escuchar ruido mientras realizaba otras actividades. La televisión fungía como reloj biológico pues se levantaban, comían y se dormían con ella. 
Los medios de comunicación, además de ser una fuente de entretenimiento e información, también representan un medio a través del cual los miembros de la audiencia pueden aprender sobre diversos temas. En este sentido, se les cuestionó a los estudiantes de Ciencias de la Comunicación sobre el lugar del cual obtienen información de diversos temas como moda, música, sexualidad, valores y comportamiento para determinar si los medios de comunicación tienen un papel preponderante en la adquisición de conocimientos sobre estos temas.

La sexualidad es uno de los temas más importantes entre los jóvenes; sobre todo porque la educación sexual en los planteles escolares mexicanos es escasa; así mismo, este tópico es, con frecuencia, visto como un tabú o un tema del que no se habla con Los estudiantes de Ciencias de la Comunicación afirman que, en lo que a sexualidad respecta, la primera fuente de información son los amigos con una media de 3 en la misma escala. En segundo puesto están los padres con una media de 3.2; seguido por los profesores con 3.6 y cuarto sitio la televisión con una media de 3.7.

Es importante destacar que, en este aspecto fundamental, la televisión no juega un papel preponderante como fuente de aprendizaje sobre sexualidad entre los jóvenes entrevistados.

En últimas fechas las campañas para promover los valores abundan en los medios de comunicación; diversas cadenas televisivas dedican grandes espacios a esta actividad. Sin embargo, los resultados encontrados al entrevistar a los estudiantes de Ciencias de la Comunicación indican que no es la televisión la principal fuente de educación respecto a valores.

TABLA 2. ¿Cuáles son los temas que te gustaría que abordara la televisión regia?

\begin{tabular}{|c|c|c|c|}
\hline Temas & Mujeres & Hombres & Total \\
\hline Chistes en doble sentido y bromas a la gente & 8,1 & 6,2 & 7,3 \\
\hline Información sobre la región donde vives & 4,3 & 4,5 & 4,4 \\
\hline $\begin{array}{l}\text { Información sobre otras regiones a nivel } \\
\text { nacional }\end{array}$ & 4,5 & 4,3 & 4,4 \\
\hline $\begin{array}{l}\text { Información sobre otras regiones a nivel } \\
\text { internacional }\end{array}$ & 4,2 & 4,6 & 4,4 \\
\hline Historias de la vida de otros que pueden servir & 4,7 & 4,8 & 4,8 \\
\hline
\end{tabular}


de ejemplo

Moda

Temas de manualidades, diseño y recetas de cocina

Deportes

Política

Chismes y espectáculos

5,9

6,8

6,3

*Nota: Medida en una escala del 1 al 10, donde 1 es el que más gusta y 10 el que menos.

TABLA 3. ¿En dónde has aprendido sobre moda?

\begin{tabular}{llll}
\hline Temas & Mujeres & Hombres & Total \\
\hline Padres & 5,9 & 5,3 & 5,7 \\
Hermanos & 5,6 & 4,7 & 5,2 \\
Amigos & 3,9 & 3,2 & 3,6 \\
Profesores & 7,3 & 6,6 & 7,0 \\
Televisión & 3,2 & 3,7 & 3,4 \\
Cine & 3,8 & 3,9 & 3,8 \\
Radio & 6,1 & 5,9 & 6,0 \\
Prensa & 4,6 & 5,6 & 5,0 \\
Internet & 3,0 & 4,2 & 3,5 \\
\hline
\end{tabular}

*Nota: Medida en una escala del 1 al 9, donde 1 es el que más gusta y 9 el que menos.

TABLA 4. ¿En dónde has aprendido sobre música?

\begin{tabular}{llll}
\hline Temas & Mujeres & Hombres & Total \\
\hline Padres & 5,8 & 5,5 & 5,7 \\
Hermanos & 5,2 & 4,8 & 5,0 \\
Amigos & 3,8 & 3,8 & 3,8 \\
Profesores & 7,4 & 6,6 & 7,1 \\
Televisión & 3,7 & 3,5 & 3,6 \\
Cine & 4,9 & 4,8 & 4,8 \\
Radio & 3,2 & 3,9 & 3,5 \\
Prensa & 5,9 & 5,9 & 5,9 \\
Internet & 3,5 & 4,1 & 3,7 \\
\hline
\end{tabular}

*Nota: Medida en una escala del 1 al 9, donde 1 es el que más gusta y 9 el que menos.

TABLA 5. ¿En dónde has aprendido sobre valores?

\begin{tabular}{llll}
\hline Temas & Mujeres & Hombres & Total \\
\hline Padres & 1,3 & 1,4 & 1,4 \\
Hermanos & 3,1 & 3,3 & 3,1 \\
Amigos & 3,9 & 3,3 & 3,9
\end{tabular}


Profesores

Televisión

Cine

Radio

Prensa

*Nota: Medida en una escala del 1 al 9, donde 1 es el que más gusta y 9 el que menos.

Por último, al ser cuestionados sobre sus hábitos de comportamiento, se encontró que la fuente de información más importante respecto a este tema son los "padres" con un promedio de 1.4; en segundo puesto se sitúan los "hermanos" con una media de 3; los "amigos" con 3.6 y los "profesores" con 3.7.

Entre los medios de comunicación, destaca la televisión que alcanzó una media de 5.5; sin embargo, en este rubro los medios de comunicación no son una fuente importante de aprendizaje.

\section{Conclusiones}

Entre los jóvenes universitarios que cursan la licenciatura en Ciencias de la Comunicación de la Universidad Autónoma de Nuevo León encontramos una población con una alta exposición a los medios masivos. En esta primera etapa de nuestro estudio, se profundizó sobre todo en los contenidos audiovisuales a través de la televisión y el internet por ser los medios que mayores índices de consumo registran entre nuestra población de estudio que representa a los futuros comunicadores.

Sobre ello, se refuerza la idea ya generaliza de la caída en la hegemonía mediática de la televisión entre el sector juvenil que, cada vez con mayor intensidad, prefiere el consumo de productos audiovisuales en línea. Se trata, sin lugar a dudas, de una generación conectada a la red y en la que encuentra más y mayores beneficios y utilidades. Sin embargo, vale la pena resaltar que, los estudiantes de comunicación identifican en la televisión una herramienta con potencial formativo a través de la cual quisieran recibir información regional y nacional que contribuya positivamente a la sociedad en la que forman parte. 
A pesar de todo ello, la televisión no se ha erradicado por completo de la cotidianidad estudiantil, sus contenidos siguen funcionando como un elemento socializador y además, en un aspecto laboral, sigue apareciendo como el referente de muchos universitarios que se muestran preocupados por la falta de audiencia en el medio en el que aspiran trabajar.

En el mismo sentido de las aspiraciones laborales encontramos entre los alumnos de la Facultad de Comunicación una marcada preferencia a desempeñarse profesionalmente en el área de la publicidad y la mercadotecnia, seguido del periodismo y la comunicación organizacional. Esto podría obedecer a que en los diarios de circulación local, en la sección de avisos de ocasión, vemos que en la mayoría de los trabajos anunciados que buscan comunicólogos son para desempeñarse como publicistas; por desgracia, la mayoría de las veces estas ofertas se reducen a vendedores de espacios en medios locales.

La incertidumbre laboral, de la que ya hemos hablado, se comprueba con nuestro grupo de estudio con base en el deseo de permanecer por un mayor tiempo en las aulas, a pesar de las vastas críticas en torno a la vida universitaria. La idea de que los estudios de licenciatura no son suficientes para sobresalir en el ámbito laboral se refuerzan con la presencia de universitarios preparándose en otras áreas o, incluso, cursando otras licenciaturas. Lo mismo ocurre con los estudios de posgrado, cuyo deseo de matriculación se ve influido por la falta de empleo o como un factor de diferenciación frente a otros egresados.

Finalmente, es importante resaltar el gran papel que continúa desempeñando la familia en el desarrollo integral de nuestros jóvenes universitarios. Aún y en su etapa de independencia y madurez, el grupo primario sigue configurándose como el grupo de referencia y aprendizaje de cuestiones fundamentales tales como la sexualidad y los valores. En este sentido, vale la pena profundizar en posteriores investigaciones sobre el conocimiento que tienen las familias de nuestros universitarios, específicamente sobre sus perfiles, hábitos, aspiraciones y miedos.

Los datos hasta ahora obtenidos nos ayudan a reconocer áreas de oportunidad en la formación de los futuros egresados de la Facultad 
de Ciencias de la Comunicación. La incertidumbre laboral que enfrentan puede potenciar la aparición de cursos educativos que les permitan sentirse competentes en el exterior, por ejemplo; o bien modificar las prácticas educativas en las aulas con la intención de fomentar la seguridad entre los estudiantes. Con lo referente a los estudios de posgrado, las instituciones de educación superior tienen un área de oportunidad que deben aprovechar para continuar su labor formativa y para, además, fomentar e impulsar el desarrollo científico de nuestro país, situación que también brindaría datos provechosos en las diversas evaluaciones y certificaciones de las que ya hemos dado cuenta.

Las prácticas profesionales constituyen también áreas que requieren del fomento universitario y que pueden contribuir ampliamente al desenvolvimiento de los alumnos en el ámbito laboral, propiciando el conocimiento de la totalidad de las capacidades y habilidades de los futuros egresados en comunicación entre las empresas y la sociedad en general, y erradicando del imaginario colectivo la percepción del egresado como figura mediática exclusivamente. Las IES, por su parte, deben exigir el compromiso de los empleadores para aprovechar las competencias de sus practicantes y que sus actividades se avoquen verdaderamente al campo de estudio, fomentando no solo las labores profesionalizantes sino también aquellas relacionadas con el ámbito científico y la generación del conocimiento.

Una Universidad carece de sentido sin sus estudiantes, por ello, debe centrarse en los mismos y en su conocimiento profundo con la finalidad de cumplir su deber social mediante la formación de ciudadanos preparados en un marco de solidaridad, responsabilidad, crítica y humanismo. Las IES deben por lo tanto ahondar en la plena identificación de las necesidades de sus universitarios para favorecer una formación integral; solo así cobrarán sentido los rankings, evaluaciones, acreditaciones y certificaciones que ostentan. Solo así las universidades legitimarán su prestigio, porque estarán preparadas para formar estudiantes activos y participativos en nuestra sociedad.

* Este trabajo es resultado de un proyecto de investigación que cuenta con el apoyo de la Secretaría de Educación Pública de México, a través del Programa para el Desarrollo Profesional Docente para el Tipo Superior (PRODEP 2014-2015). 


\section{Perfil profesional que demandan las empresas periodísticas a la Universidad}

María José Pérez-Serrano (Universidad Complutense de Madrid) http://orcid.org/0000-0002-2190-7619 http://scholar.google.es/citations?user=zJeGeYgAAAAJ\&hl=es.

Dolores Rodríguez-Barba (Universidad Complutense de Madrid) orcid.org/0000-0001-8437-5536 http://scholar.google.es/citations? user=UCaysxIAAAAJ\&hl=es

Miriam Rodríguez-Pallares (Universidad Complutense Madrid) orcid.org/0000-0002-5486-0298 http://scholar.google.com/citations?user=WnTrATkAAAAJ\&hl=es\&oi=ao

\section{Introducción}

- UÉ PERFILES profesionales demandan las empresas informativas? ¿Cómo ayudar a los estudiantes de Periodismo a posicionarse mejor en este complejo contexto laboral? Son dos de las preguntas de investigación fundamentales que el Grupo MediaCom $\underline{\mathrm{UCM}}^{5}$ intenta responder a partir del análisis de los datos que han sido proporcionados por el Centro de Orientación e Información de Empleo (COIE) de la UCM.

El estudio está en primera fase y ha comenzado por los estudiantes de Periodismo, pero está en línea con las investigaciones que desarrolla

\footnotetext{
${ }^{5}$ Research and Learning of Media and Communications Management. Investigación y Enseñanza de la Gestión de los Medios y la Comunicación. MediaCom UCM www.ccinf.es/mediacom/
} 
MediaCom UCM en relación al perfil de demanda de las empresas y la futura inserción laboral de los estudiantes de cualquiera de las especialidades de la comunicación.

A partir de los datos oficiales a los que se ha accedido, se pueden extraer conclusiones que sirven para diseñar estrategias más adecuadas para lograr el mejor posicionamiento de los estudiantes en prácticas en las empresas, saber explicar mejor qué iniciativas pueden favorecer su inserción laboral, incluso, con la mirada puesta en el emprendimiento.

También se trata de proporcionar datos sobre las necesidades y capacitación de los estudiantes y cómo compaginarlo con las cualidades y capacidades que el mercado demanda. Cómo apoyar desde los procesos formativos con una revisión continua de la formación práctica, creando entornos de trabajo colaborativos en el aula y planificando de forma más eficaz el desarrollo de ciertas destrezas relacionadas con el equipamiento propio de la profesión periodística. En definitiva, trabajar para proporcionar información de calidad para organizar una enseñanza que cumpla las expectativas de la demanda (Ortiz-Sobrino, Peinado-Miguel \& Zapata-Palacios, 2014).

¿Cómo coordinar lo que se requiere desde las empresas y lo que los estudiantes aportan con sus prácticas durante el tiempo de realización de su beca? Habrá que ir más allá del diseño de procesos activos de adquisición de competencias y capacidades para el desempeño profesional. Es obligatorio mejorar los mecanismos de coordinación y tutela y los sistemas de control de calidad evitando prácticas abusivas, sustituciones de puestos reales de trabajo o trabajo no remunerado disfrazado de convenio con un centro educativo.

Así, se pueden resumir aquí brevemente los objetivos de esta fase de la investigación:

- Cuantificar las empresas que ofrecen prácticas en Periodismo a través del COIE de la UCM.

- Tipología de las prácticas.

- Elaboración de un cuadro de retribuciones.

- Elaboración de un mapa de la oferta por parte de las empresas. 
- Perfil demandado a los estudiantes en la actualidad.

- Nuevos perfiles profesionales.

\section{Un escenario complejo. Esperanzador desde el emprendimiento}

Partimos de antiguos rasgos ya muy conocidos como la evidente masificación en las aulas en los Grados de Periodismo. Quizá la ratio haya mejorado ligeramente, pero se mantienen los mismos problemas en cuanto a recursos económicos y falta de personal que hace dos décadas (Humanes \& Roses, 2014), agravados por la crisis económica. En contrapartida, han mejorado considerablemente los sistemas de acreditación y evaluación de la calidad docente, de las titulaciones, centros y profesorado y ha aumentado la incorporación a tiempo parcial de profesionales de reconocido prestigio que contribuyen con uno de los objetivos prioritarios de la Universidad española, que es mejorar la colaboración universidad-empresa.

El sistema universitario español lo conforman 83 universidades: 49 de ellas públicas, 32 privadas y 2 internacionales. Todas las universidades públicas y la mayoría de las privadas (excepto 9) cuentan con un Centro de Orientación e Información para el Empleo. Incluso alguna, como IE Universidad cuenta con un Centro de Desarrollo de la Carrera Profesional, al estilo de la empresa privada, u oficinas de apoyo al emprendimiento, como la del Proyecto UNIR Emprende.

De cualquier modo, hay que señalar que los COIE de las universidades públicas y privadas no cumplen las mismas funciones. De forma ideal, las privadas contemplan las prácticas en empresas en los estudios de Grado como curriculares, puesto que forman parte de su oferta docente, por lo que los COIE o similares realizan más una función de asesoría para la inserción laboral una vez terminados los estudios de Grado, que funciones complementarias.

Por el contrario, la universidad pública, sólo contempla las prácticas curriculares en empresas en el caso de los estudios de Postgrado, nunca en los estudios de Grado, principalmente, por las cuestiones de masificación expuestas al principio. Es por eso que los COIE se convierten en el lugar de referencia para los estudiantes cuando 
quieren hacer sus prácticas más allá de las aulas, estudios y laboratorios y es desde estos centros desde donde se articulan, intentando el equilibrio entre oferta y demanda. Es aquí, donde pondrá el foco este capítulo: sobre las empresas e instituciones que han declarado abiertamente, a través de la firma de acuerdos de colaboración con la UCM, su disposición a participar en la formación de los estudiantes de Periodismo a través de la oferta de prácticas no curriculares en sus centros de trabajo, asumiendo la tutela conjunta con la Universidad.

Las prácticas en empresas están consideradas como una actividad estratégica en el marco de la creciente importancia de revisión de los factores de empleabilidad al ser reconocidos como algo fundamental en el aprendizaje del desempeño profesional (Marhuenda Fluixá, Bernard i García \& Navas Saurin, 2010). Mirando la oferta en la universidad pública, parece que se deba esperar a los estudios de postgrado y esto, como se acaba de apuntar, no sólo no es acertado, sino que puede estar alejado de la realidad e inducir a tomar malas decisiones en la elección de másteres si lo que se busca es un enfoque totalmente profesional. De hecho, de los nueve programas de máster oficial que ofrece la Facultad de Ciencias de la Información de la UCM, sólo cuatro de ellos ofrecen prácticas externas o mediación para conseguir las prácticas en empresas de referencia en el sector de la comunicación, ya que el enfoque de los otros 5 es totalmente académico y científico. Por el contrario, en el caso de los quince títulos propios dependientes de mismo centro, sólo tres de ellos planifican sus prácticas a nivel interno, el resto en colaboración con diferentes empresas de primer nivel en su mayoría.

En España, fueron los propios centros universitarios los que iniciaron ya hace años las relaciones con la empresa para ayudar a incorporar a los estudiantes al mercado laboral (López-García, 2010; MontoroSánchez, Mora-Valentín \& Ortiz-de-Urbina-Criado, 2012), pero parece que no se han puesto límites suficientes a las funciones que debe cumplir un estudiante en prácticas en el entorno empresarial y, como ocurre siempre que se trata de profesiones de carácter vocacional (Peinado-Miguel \& Fernández-Sande, 2011; PeinadoMiguel, Rodríguez-Barba \& Pérez-Serrano, 2011), el mercado ha ido pervirtiendo esa figura y creado sucedáneos que no benefician a la 
calidad de los trabajos profesionales ni a los estudiantes. Un $22 \%$ de los universitarios trabajan sin contrato alguno, porcentaje que se eleva en el interanual respecto a 2013 en ocho puntos (GAD3 Consultores, 2014) cuando las prácticas reguladas hacen posible su incorporación con unos costes muy bajos para las empresas (Ortiz-Sobrino, Peinado-Miguel \& Zapata-Palacios, 2014).

Los nuevos medios se abren camino, pero aún no tienen definida su posición al relacionarse con la Universidad en esta cuestión y se abren posibilidades de emprendimiento y autoempleo (Paniagua Rojano, Gómez Aguilar \& González Cortés, 2014; Casero Ripollés \& CullelMarch, 2013).

Es obligatorio hacer una referencia al escenario laboral de la profesión periodística en el último quinquenio. Los años 2012 y 2013 han sido extraordinarios por haberse ejecutado varios expedientes de regulación de empleo pero, según datos del Servicio Público de Empleo Estatal (SEPE), en septiembre de 2013 había 10.560 periodistas registrados como parados, un 1\% más que en 2012, crecimiento pequeño, afortunadamente, puesto que, desde el comienzo de la crisis, el paro registrado de periodistas ha aumentado un $132 \%$. De esos periodistas parados, 6.661 (63\%) son mujeres y $3.899(37 \%)$ son hombres. Por comunidades autónomas, Andalucía, Cataluña y Madrid concentran el 56\% de los periodistas parados.

\section{La metodología y los límites de investigación para esta fase}

Se ha trabajado con las fichas de contratación en prácticas para estudiantes de Periodismo que maneja el COIE de la UCM cuyas firmas de beca se produjeron entre el 10 de enero de 2012 y el 22 de diciembre de 2013. Estas fechas se corresponden con periodos de prácticas que abarcan de 10 de enero de 2012 a 1 de octubre de 2013 (de inicio) y de 27 de julio de 2012 a 14 de julio de 2014 (de finalización). Aproximadamente, los dos últimos cursos académicos 2012/2013 y 2013/2014. 
Figura 1: Ficha técnica

\begin{tabular}{|c|c|c|}
\hline \multirow{3}{*}{$\begin{array}{l}\text { Ámbito geográfico } \\
\text { Centro }\end{array}$} & \multicolumn{2}{|r|}{ Madrid } \\
\hline & \multirow{2}{*}{\multicolumn{2}{|c|}{$\begin{array}{r}\text { Facultad de Ciencias de la Información } \\
\text { Universidad }\end{array}$}} \\
\hline & & \\
\hline & \multicolumn{2}{|r|}{ Complutense de Madrid } \\
\hline Método de recogida & Tipo & Fichas de contratos de prácticas \\
\hline de información & Procedencia & COIE. Prácticas y Empleo (UCM) \\
\hline Tamaño muestral & & 1.396 fichas \\
\hline & & 1.386 fichas válidas \\
\hline $\begin{array}{l}\text { Fechas del trabajo de } \\
\text { campo }\end{array}$ & & Mayo - julio 2014 \\
\hline Empresas & & 442 \\
\hline Destinos & & 87 \\
\hline $\begin{array}{l}\text { Funciones } \\
\text { profesionales }\end{array}$ & & 2.219 \\
\hline Errores & & $+-1,5$ individuos \\
\hline
\end{tabular}

Fuente: Tesauro PIMCD nº 176 y elaboración propia

El trabajo de campo, como se puede observar en la tabla anterior, se llevó a cabo los meses de mayo a julio de 2014 y alcanzó a 1.386 fichas válidas correspondientes a los mismos alumnos. Como precisión, se debe señalar que el retrato robot del alumno/a que hace prácticas en las áreas de la Facultad de Ciencias de la Información $(\operatorname{moda}=\mathrm{M})$ es una mujer de 21 años.

Figura 2: Características sociodemográficas de la muestra

\begin{tabular}{|c|c|c|}
\hline Sexo & Hombre & $39,10 \%$ \\
\hline \multirow{3}{*}{ Curso } & Mujer & $60,90 \%$ \\
\hline & 20 años & $15,04 \%$ \\
\hline 21 años & $42,86 \%$ \\
\hline 22 años & $16,54 \%$ \\
\hline & 23 años & $10,53 \%$ \\
\hline Igual o mayor de 24 & $13,53 \%$ \\
años & $1,50 \%$ \\
\hline
\end{tabular}

Fuente: Tesauro PIMCD nº 176 y elaboración propia

Se ha partido de la metodología Tuning en el diseño del proyecto, que "sirve para desarrollar perfiles profesionales y resultados de aprendizaje comparables y compatibles; facilita el empleo promoviendo la 
transparencia en las estructuras educativas (grados comparables y de fácil lectura, y desarrolla un lenguaje común que entienden todos los implicados (sector educativo superior y empresarios)" (CCT, 2005) y se ha abordado la elaboración y redacción de los resultados desde el método hipotético-deductivo con gran peso del método cuantitativo.

A partir de las fichas proporcionadas por el COIE de la UCM, se configuró una base de datos multivariable dividida en cinco bloques: "número de ficha", "contrato e intervinientes", "requisitos académicos", "características del puesto" y "perfiles profesionales demandados".

Para que la codificación fuera homologable y de fácil aprehensión, se confeccionó un tesauro que, a la vez, coincidía con uno de los grupos "diana" que señala la metodología Tuning, es decir, las empresas (los otros dos grupos son los estudiantes y los docentes).

La propuesta analítica cuenta con dos límites: uno temporal o cronológico, ya que nos ceñimos sólo a dos cursos académicos; y otro metodológico, que se aborda en la segunda fase, puesto que el estudio de campo se completa con entrevistas en profundidad a los empresarios/as y empleadores/as y a los estudiantes.

\section{Análisis y resultados en esta fase de la investigación}

El análisis y la exposición de resultados se estructura en torno a los siguientes ítems: mercado laboral; sector empresarial; y condiciones de contratación.

\subsection{El mercado laboral}

Tras estudiar las fichas que maneja el COIE en las que se registran las prácticas de los/as alumnos/as de Periodismo, se identificaron 442 descriptores empresariales ${ }^{6}$ como oferentes de contratos en prácticas. Los datos obtenidos se articulan de acuerdo a dos subsecciones: sectores empresariales y empresas; a su vez, cada subsector, atendiendo al índice de recepción de alumnos y la descripción cualitativa de los puestos.

\footnotetext{
${ }^{6}$ Se han respetado estrictamente los descriptores empleados por el COIE.
} 


\subsubsection{Por sectores}

De los resultados obtenidos se colige que los sectores más proclives a recibir a jóvenes periodistas en proceso de formación son las instituciones, tanto públicas como privadas, y la prensa tradicional, pero hay que señalar que, si dividimos a la prensa en diaria impresa, diaria online, no diaria impresa y no diaria online, aumenta el margen de error, puesto que muchas veces no se aclara si el estudiante dedica sus horas de prácticas a la producción de contenidos para distribución online o en soportes impresos.

Seguidamente, pero a gran distancia, se sitúan empresas del sector publicitario, agencias de comunicación y televisión. Finalmente, radio, agencias de publicidad y agencias de información que son, en este orden decreciente, los sectores que menos plazas de formación ofertan para estudiantes de Periodismo.

Figura 3: Sectores que demandan más alumnos

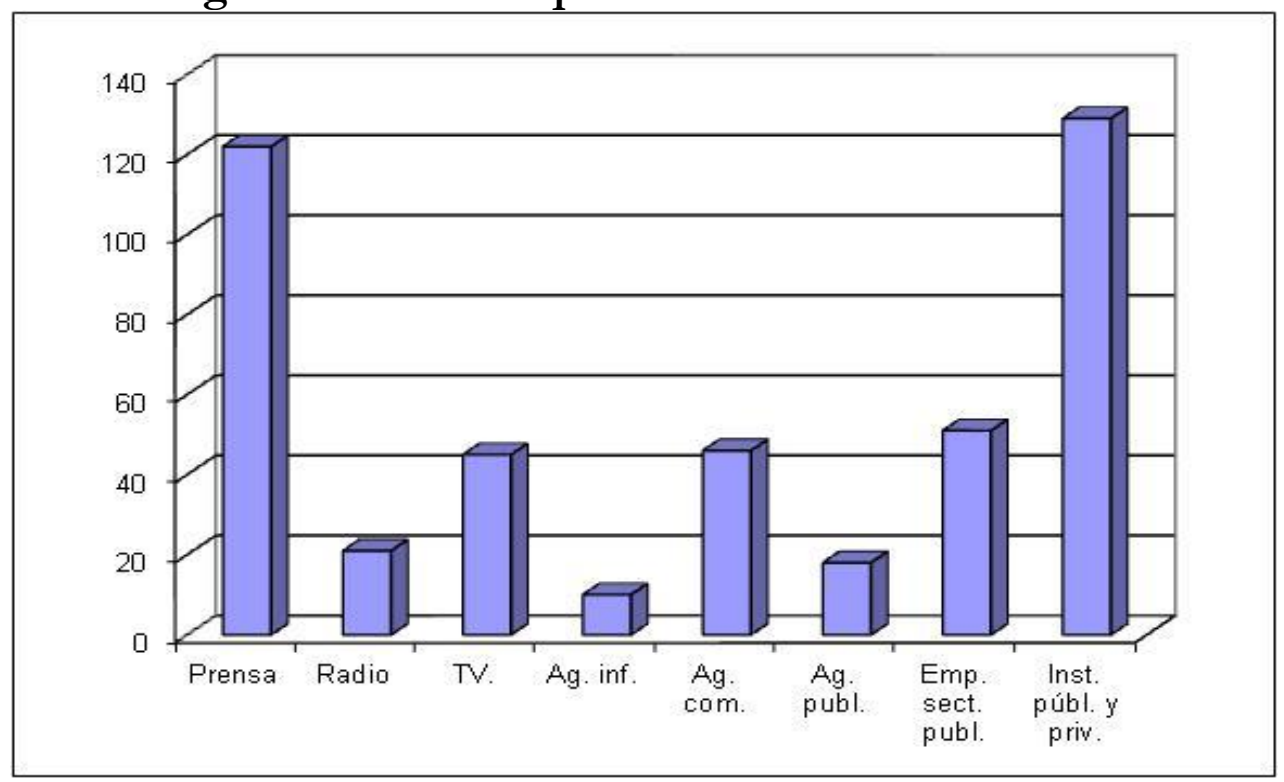

Fuente: Tesauro PIMCD nº 176 y elaboración propia

Hay que destacar que el sector que encabeza la lista de tutela de estudiantes en prácticas es el de las instituciones, tanto públicas como privadas, lo que confirma la creciente tendencia de acogida de periodistas en el ámbito de la comunicación corporativa e institucional.

La prensa es el segundo sector que presenta un mayor índice de oferta en prácticas aunque, contrariamente a lo que cabría pensar, 
parece que dicha oferta se hace más para los medios impresos que para los de distribución on-line.

La radio y las agencias de información están a la cola en la contratación en prácticas, por debajo de la televisión, sin embargo, la concentración de estos medios en menos marcas justifica el que la Cadena SER o la Agencia EFE sean dos de las empresas por donde pasan más estudiantes.

\subsubsection{Por empresas}

Desafortunadamente, la falta de sistematización en el registro de las contrataciones hace que los resultados obtenidos no se correspondan con los vinculados a los sectores empresariales y no arrojen unas conclusiones para el conjunto, sólo de forma individual.

El Grupo Unidad Editorial es quien más oferta lanza. Financia un 5\% más de becas que su inmediato seguidor, Intereconomía Corporación. Aunque hay que tomar este dato con cierta cautela puesto que en los registros se utiliza como descriptor al Grupo, independientemente de la cabecera o marca donde se destine al estudiante.

No ocurre lo mismo con Cadena SER, Agencia EFE y Europa Press, que son las siguientes empresas en la lista a pesar de que la radio y las agencias de información son los sectores que cuantifican menos receptores de estudiantes en prácticas, lo que se debe a su alto índice de concentración en el mercado.

En cuanto a los medios autonómicos y locales, sólo podemos mencionar al Ente Público Radio Televisión Castilla La Mancha (RTVCM) y a Editorial Prensa Asturiana.

Otros medios como ABC, Radio Popular (COPE) o La Razón, a pesar de pertenecer a grandes grupos de comunicación, concentran su demanda en la prensa diaria y la radio generalista, con lo que reducen su abanico de posibilidades de contratación con respecto a grupos multimedia como Unidad Editorial.

Boomerang TV y Mediaset España Comunicación se ubican a la cola en esta clasificación, justo por delante del Diario AS, editado por el Grupo Prisa. 
Puede interpretarse que las marcas generalistas, especialmente en prensa, y las deportivas siguen siendo las principales oferentes de contratos en prácticas, pero merecen especial atención las dos únicas empresas que hacen su oferta para el ámbito digital exclusivamente: Incondicionales Sports, de reciente creación, que elabora contenidos deportivos, y Antena 3 Multimedia.

Figura 5: Quince primeras empresas que demandan alumnos para sus prácticas $(\%$ de becarios)

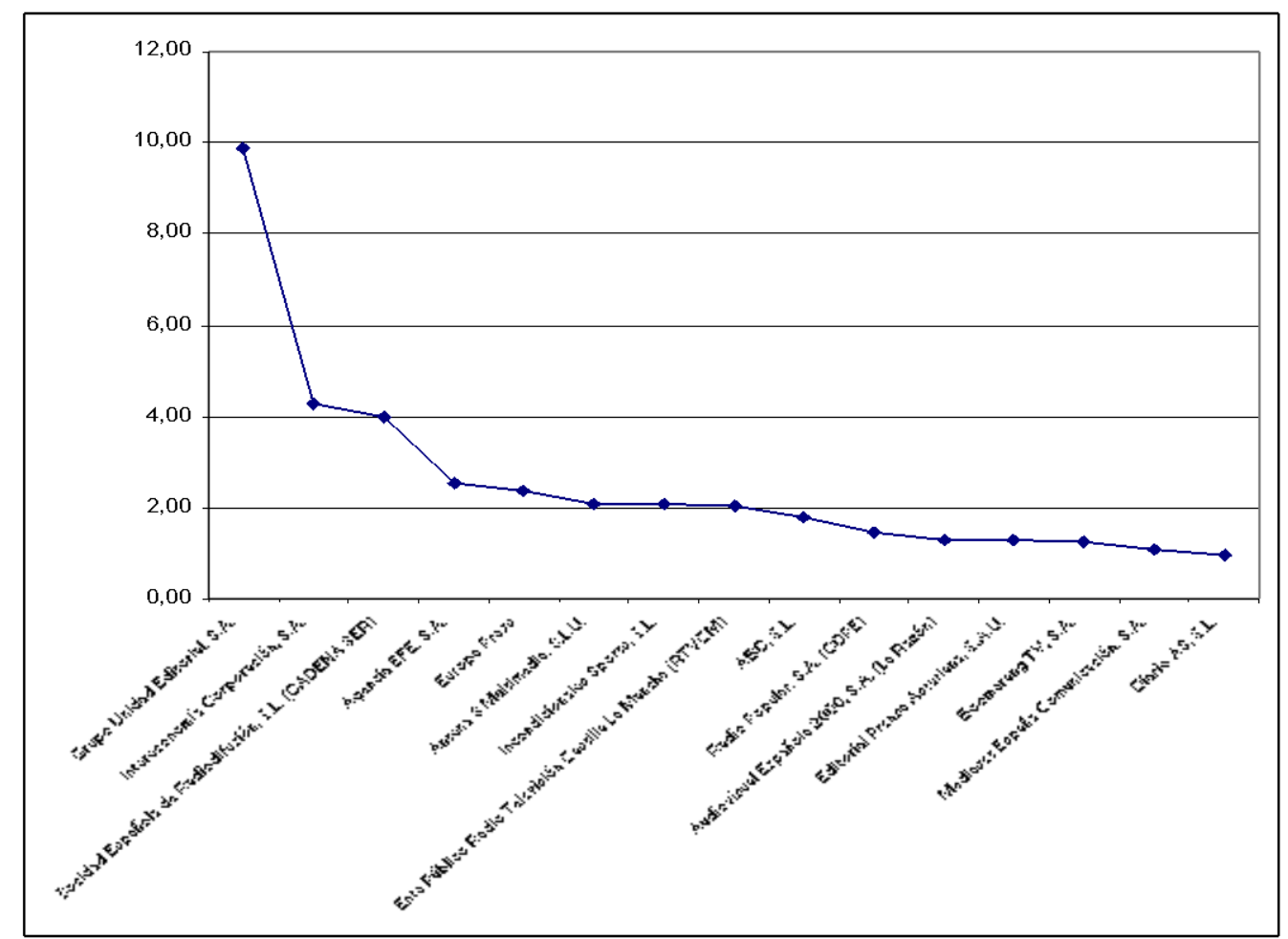

Fuente: Tesauro PIMCD nº 176 y elaboración propia

\subsection{La distribución geográfica}

Los alumnos de Periodismo de la Facultad de Ciencias de la Información de la UCM realizan prácticas en 87 destinos territoriales que incluyen todas las comunidades autónomas e incluso medios o ubicaciones internacionales aunque, lógicamente, por cercanía y concentración de empresas, la Comunidad Autónoma de Madrid, es la que absorbe el mayor número de contrataciones en prácticas (82,54\% de los resultados analizados) A gran distancia, Castilla La Mancha, con un 3,25\% de contratación del total, seguida por Galicia, con un 2,02\%. Levemente alejadas, las ubicaciones que comprenden 
entre el 1,1\% y el 2\% de las contrataciones estudiadas son Andalucía, Asturias, Castilla y León, Extremadura y Canarias.

Con índices que fluctúan entre el 0,51\% y el 1\% de contratación están Aragón, Islas Baleares y La Rioja. Cantabria, Cataluña, Comunidad Valenciana, Murcia, Navarra, País Vasco y las contrataciones internacionales no superan el $0,5 \%$ del total.

Figura 7: Distribución en el territorio de los alumnos en prácticas ${ }^{7}$

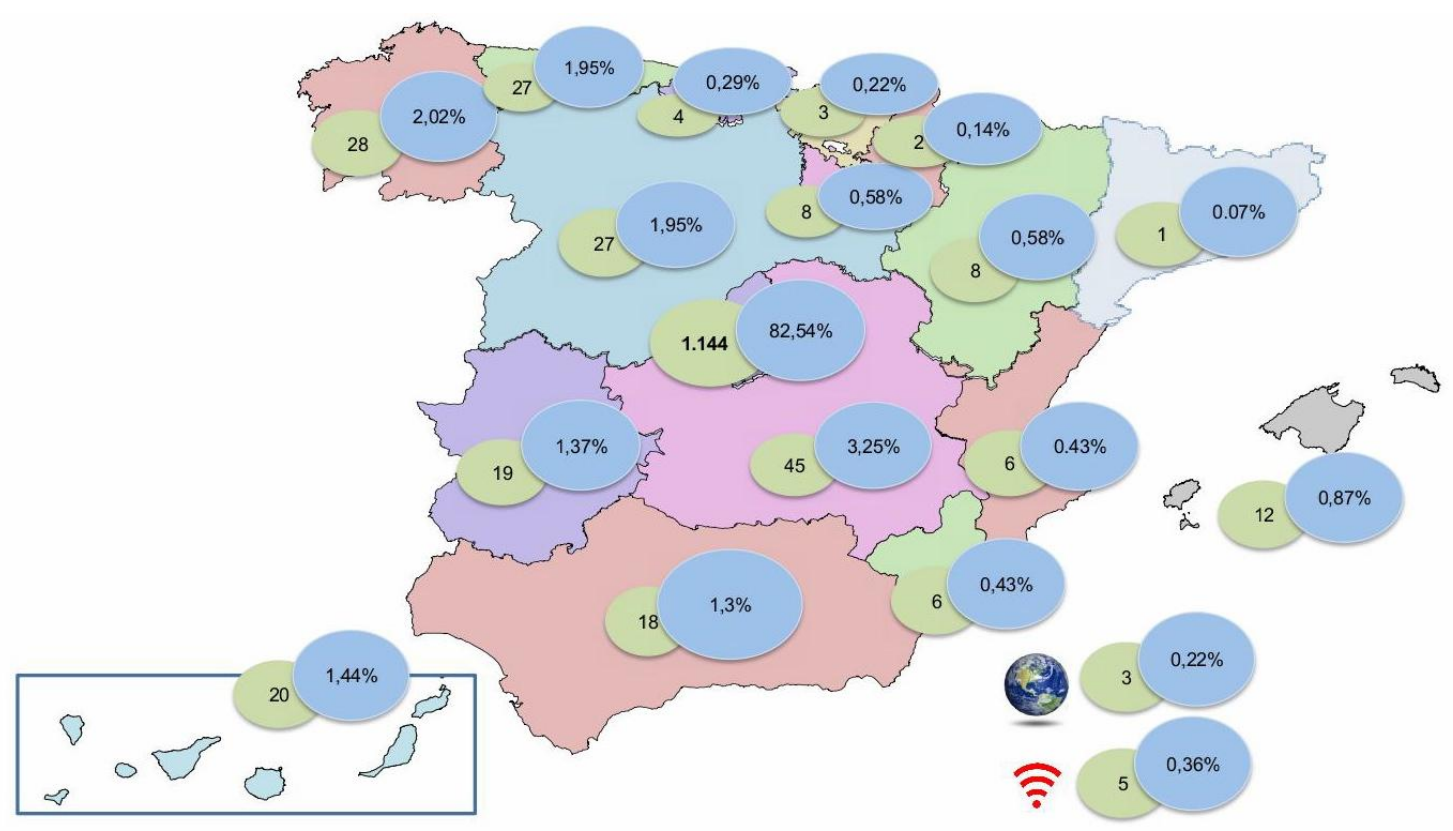

Fuente: Tesauro PIMCD no 176 y elaboración propia

\subsection{Las Condiciones de contratación}

El análisis utiliza tres variables: 1. Duración y carga laboral; 2. Remuneración económica; 3. Funciones.

\subsubsection{En cuanto a la duración y carga laboral}

\footnotetext{
${ }^{7}$ En el gráfico "Distribución en el territorio nacional de los alumnos en prácticas" quedan reflejados en color verde el número de alumnos/as de Periodismo de la UCM que realizan sus prácticas en cada comunidad autónoma y en azul el porcentaje sobre el total de alumnos/as que corresponde a cada división territorial-administrativa.
} 
La duración de las prácticas entre los medios con mayor índice de contratación oscila entre los dos y los cuatro meses, en su mayoría, en período estival. La agencia Efe, Europa Press, Grupo Unidad Editorial e Intereconomía Corporación superan la media de cuatro meses de contratación y, en el lado opuesto, Radio Popular (COPE) con una media de 63 días de contrato.

El número de horas de trabajo diarias fluctúa entre las cuatro y las siete horas, cinco días a la semana. La media es de unas cinco horas, cinco días a la semana.

\subsubsection{En cuanto a la "ayuda al estudio", la remuneración económica}

Mayores diferencias se pueden observar en lo que respecta a la remuneración de las prácticas. Existen ejemplos de trabajo "gratis total" o con remuneraciones simbólicas por pequeños conceptos, como la productora Boomerang TV, que no ofrece remuneración alguna; Incondicionales Sports y el Ente Público Radio Televisión Castilla La Mancha, con cuantías de 8,62€ y 41,07€ mensuales.

Cadena SER, Europa Press y Radio Popular ofrecen una remuneración que fluctúa entre los $100 €$ y los $200 €$ al mes. Con beca superior a $300 € /$ mes están Grupo Unidad Editorial, La Razón, Mediaset España y Diario AS. Se destaca la Agencia EFE que remunera sus becas con 474,86€ de media.

Una vez más, no hay patrón que seguir. Parece que la libre interpretación de cada empresa marca la norma de su oferta.

\subsubsection{En cuanto a las funciones}

¿Qué prefieren las empresas periodísticas: especialistas o profesionales polivalentes? ¿Buenos redactores o fluidez en el uso de las nuevas tecnologías? Parece que, por el momento, la preferencia es bastante tradicional: en nueve de las quince empresas con mayor índice de contratos en prácticas se encarga una sola función por becario/a y la tarea más tradicional vinculada al Periodismo, la de redacción, sigue siendo la más demandada, con una clarísima ventaja con respecto a otras actividades como diseño, producción, documentación o community management. 


\section{A modo de conclusiones}

Parece que la coyuntura socioeconómica actual sumada a la denominada "crisis del periodismo" hace que los periodistas estén ampliando fronteras hacia sectores menos afectados por la mala situación económica, principalmente hacia la comunicación corporativa e institucional. En cuanto a los medios más tradicionales, presentan tendencias desiguales con una clara preponderancia de la prensa frente a la televisión, la radio y las agencias de información.

Evidentemente, por la estructura de nuestro mercado y por el universo estudiado en esta fase de la investigación, la Comunidad de Madrid absorbe el grueso de la oferta de becas para estudiantes de periodismo articuladas en colaboración con la UCM.

Las condiciones laborales de los periodistas en período de formación rondan los tres meses de duración y en períodos estivales, como ha sido tradicionalmente. Cuentan con una muy baja remuneración, que supera levemente los $200 €$ al mes de media y aun se soportan contrataciones sin remuneración alguna

Tenemos un largo camino por recorrer, pero esta es una primera fase de este objeto de investigación que el Grupo MediaCom UCM tiene como fundamental para el desarrollo de la "musculatura" universitaria de nuestro país (Peinado-Miguel, Fernández-Sande, Rodríguez-Barba \& Ortiz-Sobrino, 2013). 



\section{0 \\ La radio generalista española, ¿pensada para los jóvenes de hoy?}

Nereida López Vidales (Universidad de Valladolid)

http://orcid.org/0000-0002-6960-6129

http://scholar.google.es/citations? $\mathrm{user}=\mathrm{d}-\mathrm{h}-\mathrm{uas} A \mathrm{AAAJ} \& \mathrm{hl}=\mathrm{es}$

Leire Gómez-Rubio (Universidad de Valladolid)

http://scholar.google.es/citations?user=dufyKbUAAAAJ\&hl=es

http://orcid.org/0000-0002-6436-0297

\section{La radio generalista en España y el consumo juvenil en 2014}

T A FALTA DE INTERÉS que muestran las nuevas generaciones Lhacia los medios tradicionales queda de manifiesto en los datos que reflejan los distintos estudios de audiencias. Según se recoge, por ejemplo, en el EGM correspondiente al periodo entre octubre de 2013 y mayo de 2014, el índice de penetración de todos los medios convencionales mantiene una ligera tendencia a la baja mientras aumenta paulatinamente el consumo de Internet.

En este ecosistema mediático, la radio presenta un $61 \%$ de penetración entre la población española lo que significa unas décimas más que la cifra del ejercicio anterior, pero también la cantidad más alta desde la temporada 1996-1997 (55\%), que es cuando se inicia el 
descenso sostenido de la penetración del medio, en general -y de la radio temática musical en particular-, que continúa sin invertirse en el momento actual (Gómez y López, 2014: 197) (Gutiérrez, Ribes y Monclús, 2011: 307). Por segmentos de edad, tanto los jóvenes y adolescentes de 14 a 19 años como los de 20 a 25 años suponen el $6,3 \%$ de la audiencia total de la radio, frente al 22,4\% de los adultos entre 35 y 44 años, quienes representan en todos los medios de comunicación a la franja poblacional más consumidora, incluyendo Internet con un $25 \%$.

En general, la radio se relega a menudo a una elección secundaria frente a otros medios que disponen de pantalla y son los jóvenes de 16 a 24 años los que consumen menos radio de antena convencional, al tiempo que son los que más escuchan contenidos de audio a través de dispositivos móviles (OFCOM, 2010). Los teléfonos móviles, en especial los smartphones, son los dispositivos elegidos en mayor medida por las nuevas generaciones para escuchar radio.

Además, crece el consumo de la radio por Internet. Los mayores consumidores de radio online son adolescentes de 14 a 19 años y adultos de 31 a 40 años. Nuestro sujeto de estudio, los jóvenes, manifiestan que consumen una media de 5 a 8 horas de radio online (42\%) lo que representa un $19 \%$ más que los datos registrados en 2013 (Egostreaming, 2014). El público que escucha la radio por Internet ha crecido en detrimento de la escucha vía antena convencional, AM o FM, hecho que está afectando tanto a la programación informativa y generalista como a la especializada, incluyendo la temática musical, su preferida. ${ }^{8}$

En el estudio La radio de los jóvenes del siglo XXI, planteado por el Observatorio del Ocio y el Entretenimiento Digital, los 956 jóvenes encuestados afirmaron sintonizar la radio principalmente cuando quieren escuchar música $(50,7 \%)$ e informarse (33,4\%). La motivación de estos jóvenes hacia la radio se concentra en dos

\footnotetext{
${ }^{8}$ Sobre la insatisfacción de los jóvenes hacia las propuestas musicales, sobre todo aquellas que se basan en el formato radio fórmula, han hecho hincapié últimamente algunos autores y estudios indicando que se observa una tendencia al consumo de contenidos musicales auto gestionados por estos jóvenes prosumidores (López y Gómez, 2014) en la elaboración de sus playlist particulares (Gutiérrez, Ribes y Monclús, 2011).
} 
aspectos fundamentales: entretenerse, para lo que sintonizan sobre todo emisoras musicales, e informarse puntualmente de noticias, para lo que seleccionan cadenas generalistas. Sin embargo, afirman no seguir una emisora determinada al tiempo que cambian constantemente de opción radiofónica en el dial.

En líneas generales, los jóvenes de hoy definen la radio convencional de antena como un medio de adultos, serio, obsoleto y con escasa innovación en contenidos. Su motivación hacia la escucha de la radio generalista ha ido disminuyendo a la par que aumentaba su preferencia por la radio online y la escucha a través de dispositivos móviles donde pueden gestionar la escucha de audios de cualquier clase, sean música o programas, participar en comentarios e incluso en la distribución de ciertos contenidos para compartir, mediante las redes sociales, aquello que les gusta con los miembros de su "comunidad" (amigos).

\section{La programación de las grandes cadenas generalistas radiofónicas españolas}

La programación radiofónica española muestra, desde hace tiempo, un acusado carácter inmovilista que se plasma en parrillas plagadas de contenidos repetitivos bien conocidos por el público. Al margen de la presencia de los podcast donde se fragmentan los contenidos para su consumo individualizado, la única tendencia de apertura hacia una adaptación al nuevo escenario audiovisual parece centrarse en los programas hechos para su difusión por la Red, aunque estos sean aún muy escasos.

Las nuevas propuestas van de la mano de ofrecer ciertos contenidos online a través de las páginas web de las distintas cadenas, utilizando para ello formatos más o menos híbridos en cuanto a géneros y estilos. En este último punto, con el que se manifiesta un estilo propio por parte de las emisoras, es donde se pueden encontrar los aspectos más diferenciadores. Pero ese estilo de cada cadena continúa unido a los presentadores o conductores principales de los espacios radiofónicos, es decir, a unas pocas voces que contribuyen a la uniformidad de las parrillas. Estos espacios ocupan varias horas de la programación diaria en las cadenas simplificando la oferta radiofónica a la emisión de apenas media docena de programas con sus 
correspondientes cinco o seis voces representativas, de suerte que se podría confirmar que el elemento diferenciador recae aún más, si cabe, en los presentadores?.

Esta situación de acusada personalización de los espacios no es nueva en la radio pero su permanencia en el tiempo incita a pensar que la empresa radiofónica necesita un cambio importante de mentalidad y proyección estratégica que no solo afectaría a la reorganización de sus recursos económicos, sino también a sus recursos humanos para mejorar su posicionamiento en el mercado comunicativo español.

En esta época de crisis económica mundial, la empresa radiofónica ha experimentado un proceso de concentración de la propiedad y profesionalización de la gestión, entrando a formar parte de grandes grupos de comunicación. La línea de actuación general en este escenario de la comunicación 2.0 se ha dirigido hacia la consecución de altos índices de participación de la audiencia mediante la generación de contenidos en los que puede intervenir activamente el usuario-oyente, incluso en su creación (user generated content), a la par que minimizar el coste de producción de los programas (low cost). La radio se mueve hoy en un espacio mediático muy competitivo donde disminuyen los operarios y profesionales del medio mientras aumentan las necesidades de comercialización de todo lo que produce (Fernández y Peinado, 2012: 47).

Desde el punto de vista de la estrategia empresarial y, en consecuencia, de la actuación radiofónica de la emisora, la mayoría de las cadenas de radio despliega una estrategia "multiproducto" planteada sobre la distinción básica de radio generalista y radio especializada (Moreno, 2005: 66). La radio generalista es la radio de información, de comunicación intelectual, de ideas, palabra, expresión, la radio total (Faus, 1995: 182). Es la radio clásica frente a la radio especializada que se caracteriza por la sectorialización de los contenidos y la segmentación de la audiencia (Martí, 1990: 33). La radio especializada centra su relato diario en unos contenidos monotemáticos fundamentales que puede completar con otros de

\footnotetext{
${ }^{9}$ Esta línea de investigación, centrada en la hibridación de los contenidos radiofónicos y la personalización acusada de los mismos, está en fase de finalización por parte de los investigadores de OCENDI.
} 
menor presencia en antena y adapta su narrativa a un tipo de oyente que puede ser o no especializado, pero que sí está segmentado -targetpreviamente por la emisora (Pedrero, 2004: 73). Por su parte, siguiendo a Martí Martí, la radio temática es aquella que se especializa en contenidos. La parrilla se organizaría igual que en una emisora generalista aunque su tiempo de programación responde al concepto de programa como unidad de programación, donde el magazine especializado aparece como el principal exponente.

Desde el punto de vista del público objetivo, las cadenas generalistas dirigen su programación a todo tipo de públicos, mientras que la radio especializada lo hace a segmentos diferenciados, entre los que se encuentran los jóvenes, especialmente en el caso de las radios temáticas musicales. La percepción de esta diferencia en el público es relevante también para entender la falta de relación entre el medio y las nuevas generaciones.

\section{Los formatos programáticos de la radio generalista: descripción y análisis comparativo en 2014}

La continuidad temática en las parrillas radiofónicas generalistas de lunes a viernes gira en torno a la información de actualidad, a su análisis, reflexión o debate. Con el propósito de mantener el interés de la audiencia en su misión informativa y divulgativa, encuentran cabida aquí el entretenimiento, el humor, la música, etc. Los espacios informativos y el magazine son los programas que sustentan las parrillas de radio generalista española con, prácticamente, las tres cuartas partes del tiempo global de emisión diaria $(+70 \%)$, un $11 \%$ se dedica a la programación regional y local y un $7 \%$ a espacios deportivos (Moreno, 2005: 86).

El objetivo de esta aportación es realizar un análisis descriptivo de las parrillas diarias de las cuatro grandes cadenas radiofónicas generalistas españolas con el fin de observar cuál está siendo la respuesta de estas empresas a la actual situación de cambio de hábitos de consumo mediático por parte de las nuevas generaciones en cuanto a contenidos, al tiempo que tratar de mostrar si existen hoy diferencias importantes entre las distintas cadenas. Nuestra hipótesis principal es que el diseño de las parrillas radiofónicas generalistas españolas frustra las expectativas de los jóvenes hacia el medio en su consumo 
tradicional, ya sea por antena convencional o por Internet, favoreciendo el estancamiento de sus índices de audiencia juvenil. Además, se ha procedido a la escucha aleatoria de varios de los programas radiofónicos para recoger datos sobre el carácter de los distintos contenidos, las intervenciones de los periodistas e invitados, los géneros periodísticos presentes y el tipo de formato que representan. En el presente texto mostraremos solo algunos de los resultados a este respecto que componen la investigación completa realizada en el Observatorio ${ }^{10}$.

\section{Radio generalista: una oferta acomodada y sin novedades}

La emisora pública RNE 1 será nuestro punto de partida para iniciar la comparación entre los programas radiofónicos de las cuatro grandes cadenas generalistas españolas. En una primera aproximación, y excluyendo los espacios informativos y los catalogados como "magacín" por la propia cadena, llama la atención la carencia casi absoluta de programas de humor o de ficción, así como la escasez de espacios destinados al público infantil o la práctica desaparición de los concursos de radio.

Lo mismo ocurre en las otras 3 grandes cadenas, SER, COPE y Onda Cero, en cuyas páginas web se especifican programación y programas de cada día de la semana procurando utilizar lo mínimo posible una clasificación de géneros y formatos (o categorías) a los que se corresponden los contenidos. Todas ellas cuentan, en principio y según el index del site corporativo, una menor cantidad de espacios radiofónicos que la cadena pública y la tipología utilizada se resume en: actualidad, deportes, programas, local y podcast, fundamentalmente. Comparando la presentación de sus respectivas webs (portada-index), se observa cómo las tres son muy similares entre ellas al tiempo que no distan mucho de RNE.

En cuanto a la composición de las parrillas generalistas, de forma sucinta y gráfica, podemos exponerlas como sigue:

\footnotetext{
${ }^{10} \mathrm{El}$ proyecto se divide en dos fases: una, el estudio de los hábitos y preferencias juveniles en el consumo de la radio actual (2011-2013) y dos, la relación entre las demandas juveniles y el ecosistema radiofónico en el contexto de cambio del siglo XXI (2013-2014), donde además estudiamos la evolución de los distintos formatos de programas.
} 
I. RNE (Radio 1): La parrilla de RNE, Radio 1, generalista, de ámbito nacional y dirigida a todos los públicos, está diseñada en torno a dos formatos-programa: informativos y magazines. Los géneros ${ }^{11}$ centrales de su programación son el informativo y el entretenimiento, aunque este último englobe muchas veces tanto espacios divulgativos como culturales o formativos, atendiendo a la tipología que señala la propia cadena en su web.

\section{Tabla 1. Programación de RNE 1 de lunes a viernes (2014)}

\begin{tabular}{|c|c|c|c|}
\hline $\begin{array}{c}\text { RNE } \\
\text { (Lunes a viernes) }\end{array}$ & HORARIO & GÉNERO & CARÁCTER \\
\hline las mañanas de rne & $06: 00-12: 00$ & Magazine & Entretenimiento/Informativo \\
\hline España vuelta y vuelta & 12:00-13:00 & Magazine & $\begin{array}{l}\text { Divulgativo, social. Hacia el Info } \\
\text { show }\end{array}$ \\
\hline Diario de las 2 & 13:00-15:00 & Informativo & Informativo \\
\hline $\begin{array}{l}\text { Esto me suena. } \\
\text { Las tardes de Ciudadano } \\
\text { García }\end{array}$ & 15:00-19:00 & Magazine & Hacia Info show \\
\hline El ojo crítico & 19:00-20:00 & Magazine & Cultural \\
\hline 24 horas & 20:00-20:30 & Informativo & Informativo \\
\hline Radiogaceta de los deportes & $20: 30-21: 30$ & Magazine & Deportivo \\
\hline 24 horas & $21: 30-24: 00$ & Informativo & Informativo \\
\hline La noche en vela & 00:00-03:00 & Magazine & Entretenimiento (compañía) \\
\hline Gente despierta & 03:00-06:00 & Magazine & Entretenimiento/Divulgativo \\
\hline
\end{tabular}

En total, la primera cadena de RNE tiene en la temporada 2013-2014, de lunes a viernes, una programación diaria compuesta por 8

\footnotetext{
${ }^{11}$ La mención a los géneros y formatos de todo el texto obedecen a la definición que los propios medios hacen de cada programa.
} 
magazines, uno de ellos de carácter informativo, y dos programas informativos principales.

II. ONDA CERO: La cadena generalista del Grupo Atresmedia presenta una estructura programática similar, donde predominan los grandes formatos radiofónicos: la parrilla está formada por 6 magazines, de los cuales dos son de carácter informativo (de actualidad) y uno deportivo, a los que se suman 3 espacios informativos y un programa de humor.

\section{Tabla 2. Parrilla de Onda Cero de lunes a viernes (2014)}

\begin{tabular}{lcll}
\hline ONDA CERO & HORARIO & GÉNERO & CARÁCTER \\
$\begin{array}{l}\text { (Lunes a viernes) } \\
\text { Herrera en la } \\
\text { Onda }\end{array}$ & $\begin{array}{l}(00: 06-12: 00) \\
\text { L, 07:00-12.30* }\end{array}$ & Magazine & $\begin{array}{l}\text { Informativo/ } \\
\text { divulgativo } \\
\text { (actualidad) }\end{array}$ \\
$\begin{array}{l}\text { Aquí en la } \\
\text { Onda }\end{array}$ & $12.30-14: 00$ & Magazine & $\begin{array}{l}\text { Informativo } \\
\text { (regional) }\end{array}$ \\
$\begin{array}{l}\text { Noticias } \\
\text { mediodía }\end{array}$ & $14: 00-15: 00$ & Informativo & Deportivo \\
$\begin{array}{l}\text { Onda deportiva } \\
\text { Julia en la } \\
\text { Onda }\end{array}$ & $15: 00-16: 00$ & Informativo & $\begin{array}{l}\text { Social/divulgativo/ } \\
\text { participativo }\end{array}$ \\
$\begin{array}{l}\text { Aquí en la onda } \\
\text { La Brújula }\end{array}$ & $16: 00-19: 00$ & $\begin{array}{l}\text { Magazine } \\
\text { (cercano al }\end{array}$ \\
$\begin{array}{l}\text { Al primer toque } \\
\text { La parroquia }\end{array}$ & $\begin{array}{l}\text { Talk show }) \\
\text { No son horas }\end{array}$ & $\begin{array}{l}\text { Informativo } \\
\text { *El lunes de 06:00 a 07:00, Linde y ribera, programa temático sobre caza y pesca. }\end{array}$ \\
\hline
\end{tabular}

III. COPE: La emisora nacional de la Conferencia Episcopal inicia en la temporada 2012-2013 una estrategia de programación marcada por la actualización de su marca, el "rejuvenecimiento" de su audiencia y el aumento de la duración de sus programas radiofónicos, lo que termina por asemejar de forma notable su formato de programación al resto de las cadenas generalistas convencionales. De lunes a viernes, la COPE emite 6 magazines, uno de ellos deportivo, dos informativos (de actualidad) y uno de 
carácter divulgativo/cultural, a los que complementan un espacio religioso y dos informativos, uno de ellos deportivo.

\section{Tabla 3. Parrilla de COPE de lunes a viernes (2014)}

\begin{tabular}{|c|c|c|c|}
\hline $\begin{array}{c}\text { COPE } \\
\text { (Lunes a viernes) }\end{array}$ & HORARIO & GÉNERO & CARÁCTER \\
\hline La mañana & $06: 00-12.00$ & Magazine & $\begin{array}{l}\text { Informativo/divulgativo } \\
\text { (actualidad) }\end{array}$ \\
\hline La Mañana & 12:00-13:30 & Magazine & Informativo (regional) \\
\hline E1 Espejo & $13.30-14: 00$ & Divulgativo & Religioso \\
\hline $\begin{array}{l}\text { Noticias } \\
\text { mediodía }\end{array}$ & 14:00-15:00 & Informativo & \\
\hline $\begin{array}{l}\text { Deportes } \\
\text { COPE }\end{array}$ & $\begin{array}{c}15: 15-16: 00 \\
\text { (viernes, } 20: 30-21: 00 \text { ) }\end{array}$ & Informativo & Deportivo \\
\hline La tarde & 15:00-19:00 & $\begin{array}{l}\text { Magazine } \\
\text { (cercano al Talk } \\
\text { show) }\end{array}$ & Social/divulgativo \\
\hline La Linterna & 19:00-00:00 & Magazine & Informativo \\
\hline $\begin{array}{l}\text { El partido de } \\
\text { las } 12\end{array}$ & 00:00-02:00 & Magazine & Deportivo \\
\hline La Noche & 02:00-06:00 & Magazine & $\begin{array}{l}\text { Divulgativo/cultural/ } \\
\text { entretenimiento }\end{array}$ \\
\hline
\end{tabular}

IV. CADENA SER: La cadena generalista con cobertura nacional del Grupo PRISA es la más escuchada del país, según los datos del EGM, con 4,6 millones de oyentes en 2014.

Tabla 4. Parrilla de SER de lunes a viernes (2014)

\begin{tabular}{lccc}
\hline \multicolumn{1}{c}{ SER } \\
(Lunes a viernes) & HORARIO & GÉNERO & CARÁCTER \\
\hline $\begin{array}{l}\text { Hoy por hoy } \\
\text { Programación } \\
\text { local }\end{array}$ & $06: 00-12.00$ & Magazine & Informativo/divulgativo \\
Hora 14 & $12: 20-14: 00$ & Magazine & Informativo (regional) \\
Ser deportivos & $14: 00-15: 10$ & Informativo & \\
La ventana & $15: 10-16: 00$ & Informativo & Deportivo \\
$\begin{array}{l}\text { Hora 25 } \\
\text { El larguero }\end{array}$ & $16: 00-20: 00$ & $\begin{array}{c}\text { Magazine } \\
\text { (cercano al Talk show) }\end{array}$ & Social/divulgativo \\
$\begin{array}{l}\text { Hablar por } \\
\text { hablar }\end{array}$ & $00: 00-01: 30$ & Informativo & Dagazine \\
$\begin{array}{l}\text { El larguero } \\
\text { (repetición) }\end{array}$ & $01: 30-04: 30$ & $\begin{array}{c}\text { Magazine } \\
\text { (cercano al Talk show) }\end{array}$ & Entretenimiento/social \\
\hline
\end{tabular}


$\mathrm{Su}$ parrilla diaria, de lunes a viernes, está compuesta por 6 magazines, uno de ellos deportivo que se repite en emisión nocturna, uno informativo y otro divulgativo/social, a los que complementan tres espacios informativos, de los cuales uno es deportivo.

La descripción de las parrillas radiofónicas generalistas más importantes del país en sus emisiones diarias de lunes a viernes en 2014 confirma, como vemos, varios aspectos, entre ellos, los siguientes:

a. La homogeneización de las ofertas radiofónicas se plasma en la hegemonía de grandes bloques de programas -géneros informativo y de entretenimiento- con, prácticamente, dos únicos formatos: el servicio informativo general y el magazine. Diferenciar una cadena de otra partiendo de las variables "oferta programática" y "público objetivo" es ineficaz, lo que plantea, además, un problema para la supervivencia de la marca a medio plazo.

b. El aumento de la duración del formato magazine, que llega a sobrepasar las 6 horas de duración, constata una mayor concentración programática. La personalización de los distintos espacios, conducidos en su mayoría por locutores "estrella", se acentúa inevitablemente con el incremento de su duración.

c. La inexistencia de formatos dedicados al humor, concursos, ficción radiofónica o los dirigidos a un target tan específico como el infantil e incluso el juvenil, que se difuminan en el concepto de "todos los públicos".

\section{El magazine: un híbrido convencional para adultos}

El magazine, junto a los informativos nacionales y desconexiones regionales y/o locales, inunda las parrillas radiofónicas generalistas españolas. En ambos casos, se trata de formatos unidos a la actualidad que buscan, sobre todo, informar y entretener, las dos principales funciones-objetivos que los jóvenes otorgan a la radio y a la televisión como medios de comunicación (López y Gómez, 2014: 332). 
El magazine es un formato de programación versátil, flexible y cambiante. En él se pueden encontrar secciones diversas donde tienen cabida la entrevista, el concurso, el debate, la información, la encuesta, el humor y hasta el cotilleo. Es un formato contenedor que mantiene un determinado flujo de contenidos según la franja horaria en que se emite, mañana, tarde o noche.

Estos formatos se suelen clasificar según sean informativos o de entretenimiento, entrando, en este último, estilos tan dispares entre sí que derivan en el nombramiento de "nuevos" espacios que se alejan inicialmente de la marca "magacín": programa despertador, deportivo, musical, cultural, formativo, etc. Los aspectos más destacables que caracterizan los típicos magazines de entretenimiento son: la notoriedad de su conductor/a y la inclusión de espacios cuyos variados temas -salud, cocina, astrología, actualidad, meteorología, música, tradiciones, etc.- se destinan a una audiencia heterogénea (mujeres, hombres, tercera edad, etc.).

En el caso de las cuatro emisoras analizadas, destaca el hecho de que en todas ellas, los magazines programados sean de corte informativo, divulgativo y de actualidad, y que únicamente sean la COPE y la SER las que cuentan con magazines deportivos que, además, en ambos casos cuentan con una presencia notoria, del 17\% y 20\%, respectivamente. Los magazines de actualidad son los que copan el mayor número de horas en las ondas, con porcentajes que oscilan entre el 50\% de RNE y el 33\% de la COPE. También es en RNE donde se concentra el mayor número de magazines divulgativos (38\%), mientras que los magazines informativos tienen su mayor presencia en Onda Cero y la COPE.

Teniendo en cuenta la destacada presencia de este formato en la radio generalista española, cabe preguntarse si estos espacios son realmente para jóvenes, máxime cuando en el estudio realizado por Ocendi solo un $6,8 \%$ de los jóvenes encuestados confesaron escuchar magazines, al tiempo que demandaban una radio con "ideas renovadoras" (34,7\%) y "otro tipo de música alternativa” (24,1\%). 
Gráfico 2: Presencia de los magazines en las parrillas de radio generalista española

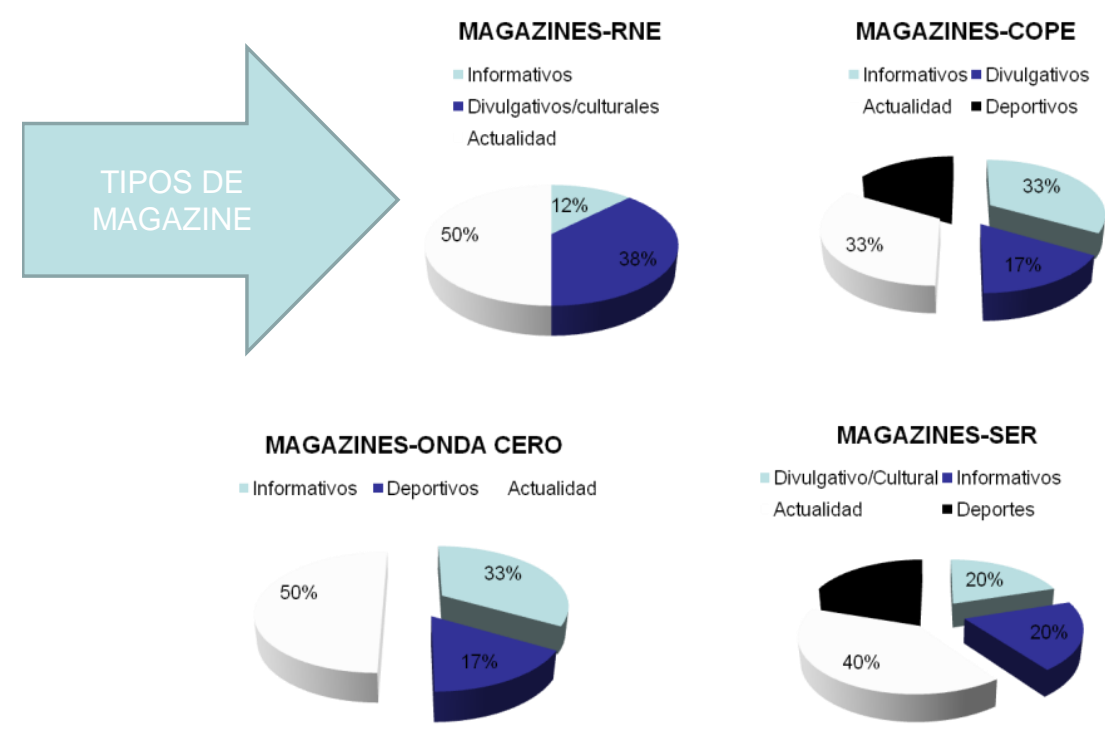

El magazine o magacín surge en los últimos años como un contrato comunicativo nuevo entre oyente y emisor motivado por el desarrollo de un modelo publicitario que responde también a un contexto social diferente donde se hace necesario un programa alternativo que separe información y entretenimiento. Sin embargo, la realidad es que lejos de producirse una separación efectiva entre ambos macro-géneros la tendencia apunta a una consolidación de las sinergias entre ambos modelos con la fusión de elementos de los dos conceptos.

Esta fórmula de éxito en la radio ha tenido que sortear dificultades económicas en su implantación. Un espacio con mayor duración implica mayores gastos en recursos humanos, técnicos y de producción. La apuesta, sin embargo, está avalada por la audiencia y en base a ello se ha ido variando el modelo para abaratar costes de forma que se adoptan producciones low cost y se impone un cambio en la estructura del programa; sin renunciar a la variedad de contenidos ni a la versatilidad implícita en el formato, se incluyen opiniones de expertos, ronda de colaboradores, llamadas telefónicas, bromas telefónicas, micrófonos a pie de calle, etc. 


\section{Ideas para la reflexión: radio generalista y jóvenes, una conexión por establecer}

Los jóvenes se sienten atraídos por la radio y su motivación hacia el consumo mediático de este medio es real. Sin embargo, no les satisfacen sus contenidos actuales, ni en la radio musical ni en la radio generalista, donde representan los índices más bajos de penetración. Teniendo en cuenta que el magazine es el formato con mayor presencia en las parrillas radiofónicas generalistas -ya sea de corte informativo, divulgativo o de actualidad- y el destacado papel que los conductores de dichos espacios juegan a la hora de captar audiencia, sería necesario conocer la aceptación con la que los locutores principales de estos programas cuentan entre los jóvenes de hoy. De este modo, se podría saber si, además de su escaso agrado con muchos de los contenidos ofrecidos por el medio, las empresas radiofónicas deberían plantearse una renovación no tanto de sus estrellas radiofónicas como de abrir sus espacios a nuevos profesionales más cercanos a la población juvenil.

A los jóvenes les gusta la radio, pero demandan un modelo más acorde con su nuevo estilo de vida, más cercano a sus preferencias en contenidos y sobre todo más próximo a su estilo de comunicación y relación actual. La relación que mantienen hoy los jóvenes con la radio ha cambiado. El consumo mediático ha entrado de lleno en una fase de individualización que conduce inevitablemente al establecimiento de una nueva relación con las emisoras: se hace necesario un cambio de estilo en la presentación de los formatos, un diseño más dinámico de las estructuras programáticas y una estrategia estable que asegure la participación juvenil en los contenidos. 



\section{Jóvenes y ficción radiofónica. Terror y adaptaciones como apuesta segura para la ficción en Radio Nacional}

Marta Hernando Lera (Universidad de Valladolid)

ORCID. 0000-0001-5326-4868

http://scholar.google.es/citations?user=uthE9KYAAAAJ\&hl=es

\section{Introducción}

— N LA ACTUALIDAD las cadenas generalistas han apostado 1 por formatos "contenedor" en los que priman los debates y la información, sobre todo política, ya que llenan muchas horas y no requieren mucha inversión. La ficción, los concursos y programas infantiles desaparecen del panorama radiofónico, quedando breves testimonios a principios de los noventa en Radio Nacional de España con el programa Historias que se mantuvo en antena de 1997 a 2003.

Desde el año 2010 Radio Nacional en colaboración con La Casa Encendida de Madrid, desarrollan un nuevo proyecto en el que se apuesta por la ficción sonora de calidad y con una cierta periodicidad (dos o tres ficciones al año). A pesar de todo, y de las facilidades que la página ofrece para la escucha de estos programas, los jóvenes españoles siguen considerando que existe una falta de creatividad en la radio y que la ficción y el entretenimiento que se ofrecen no son suficientes como se recoge en los artículos "Preferencia juvenil en nuevos formatos de televisión. Tendencias de consumo en jóvenes de 14 a 25 años" y "La radio de los jóvenes del siglo XXI" realizados 
entre 2011 y 2013 por el Observatorio del Ocio y el Entretenimiento Digital (Ocendi) y su posterior análisis en el artículo "Nuevos hábitos de los jóvenes españoles y tendencias de futuro en el consumo de radio y televisión" realizado por López Vidales y Gómez Rubio (2014).

\section{Metodología}

El objetivo principal del presente artículo es realizar un análisis comparativo entre las preferencias y deseos de los jóvenes españoles (comprendidos entre los 18 y los 25 años) con respecto a la programación radiofónica ficcional, y de entretenimiento, y la oferta de programas de este tipo en la radio actual. Además analizaremos parámetros relacionados con la estructura narrativa, personajes, narrador, banda sonora y efectos sonoros de las obras de ficción objeto de la investigación, para establecer las principales características de la las ficciones sonoras albergadas en la web de Radio Nacional de España, emisora que utilizaremos como estudio de caso.

La investigación parte de la hipótesis de que la oferta ficcional en la radio española es muy escasa -doce obras en un periodo de cuatro años: 2010 a 2014- y que presenta unas características similares a las ficciones y radioteatros realizados a mediados del siglo pasado, no siendo suficientes para la necesidad de consumo de ficción y entretenimiento de los jóvenes españoles.

La presente aportación parte de la situación reflejada en las investigaciones "Preferencia juvenil en nuevos formatos de televisión. Tendencias de consumo en jóvenes de 14 a 25 años" y "La radio de los jóvenes del siglo XXI" realizados entre 2011 y 2013 por el Observatorio del Ocio y el Entretenimiento Digital (Ocendi) y su posterior análisis en el artículo "Nuevos hábitos de los jóvenes españoles y tendencias de futuro en el consumo de radio y televisión" realizado por López Vidales y Gómez Rubio (2014), centrado en los gustos y preferencias de los jóvenes españoles con respecto al consumo radiofónico y televisivo. En dichas investigaciones también se recogen las demandas que esta nueva generación reclama a los medios audiovisuales y su visión de dichos medios en la actualidad. 
Las investigaciones anteriores se basaron en la realización de 2.536 entrevistas a jóvenes entre 14 y 25 años de todas las Comunidades Autónomas, mediante la selección de una muestra ponderada de cada una de ellas, quedando de esta manera reflejada una muestra significativa del país. Posteriormente se procedió al análisis de los datos obtenidos, lo que dio como resultado la inclinación de los jóvenes por la búsqueda de entretenimiento en los medios audiovisuales, la falta de creatividad en radio y sus propuestas de cambio centradas en la aparición de nuevos géneros radiofónico y más espacios dedicados a la ficción. Así al 46,76\% de los encuestados les gustaría que la que la radio incluyese una mayor variedad de géneros y el 27,1\% reclama más seriales divertidos. En definitiva, entretenimiento.

"Mientras en televisión la ficción, de la mano de series y espacios cinematográficos, y los realities de las cadenas generalistas constituyen sus contenidos favoritos, siendo el entretenimiento la principal función atribuida a este medio, en la radio distinguen entre radio de información y de entretenimiento y radio musical. Esto contribuye a que a la hora de informarse, los jóvenes se decanten por emisoras generalistas, como Ser, Onda Cero o Cope, siendo, sin embargo, las radios temáticas musicales sus favoritas, no sólo para oír música, sino también para entretenerse." (López y Gómez, 2014: 338)

Usaremos los datos reflejados en los anteriores artículos para la realización del contexto en el que se plantea la ficción sonora en la actualidad, comparándolo con sus características principales. Para ello vamos a recurrir a una análisis cualitativo y cuantitativo realizado mediante una ficha en la que se incluyen diferentes variables: 1. Ficha técnica (Título, fecha de emisión, duración, emisora, naturaleza de la emisión, cabecera y argumento) y 2. Análisis del cuerpo de la obra (Originalidad, personajes, narrador, música y efectos sonoros). Nuestra muestra de análisis está centrada en los podcast alojados en el sitio Web de Radio Nacional de España Ficción sonora http://www.rtve.es/radio/ficcion-sonora/, hemos elegido tres de los doce que actualmente se encuentran disponibles. La elección se ha basado en cuestiones de género siendo el terror el que ocupa el 50\% de las emisiones, la comedia 16,66\%, la aventura 16,66\% e históricos 
16,66\%. Eligiendo de todas ellas las más representativas: El exorcista, La vida de Brian, La isla del tesoro y El perro del hortelano.

\section{La ficción radiofónica en España}

La radio de los años de la dictadura franquista era una radio de evasión, de ficciones, concursos y programas deportivos. Era la forma más barata y sencilla de entretenimiento, que llegaba a un amplio espectro social.

La información era escasa y sesgada ofrecida únicamente por Radio Nacional de España (constituida en el año 1937). Por este motivo las cadenas privadas optan por explorar la parcela del terreno radiofónico que les queda libre, la del entretenimiento. Radio Nacional, también apuesta por la retrasmisión de obras de teatro, de conciertos, series, etc. pero la reina va a ser la Sociedad Española de Radiodifusión (SER). Sus seriales y su cuadro de actores fueron los más populares de las ondas en aquellos años, podemos destacar las radionovelas de Guillermo Sautier Casaseca como Ama Rosa, Lo que no muere o series costumbristas para toda la familia como Matilde, Perico y Periquín y ya en los años ochenta La Saga de Los Porretas, a los que daban vida, entre otros, actores radiofónicos como Matilde Conesa, Pedro Pablo Ayuso o Matilde Vilariño.

"Los micrófonos de la radio buscan el entretenimiento. El diseño de la programación radiofónica tiene una estructura principalmente orientada a formatos vinculados con la radio-entretenimiento: galas musicales, galas infantiles, concursos, humor, retransmisiones deportivas y dramáticos. El protagonismo del espectáculo de la radioentretenimiento es únicamente interrumpido por los informativos realizados desde RNE, que también emite la SER y el resto de emisoras, por las retransmisiones de actos oficiales y algunos espacios culturales y de radio-servicio. Esta dimensión espectacular de las emisiones radiofónicas contribuirá a ampliar todavía más su implantación entre las clases populares y constituirá el medio más eficaz y menos caro para la evasión de la realidad de una España hambrienta y sin libertades. La radio será el mejor narcótico para olvidar el horror del inmediato pasado y distraer a la audiencia de la miseria presente." (Balsebre, 2002: 10) 
Las ficciones más populares durante las cuatro décadas de dictadura, fueron las radionovelas y seriales, cuya estructura fragmentada se alarga en el tiempo para mantener enganchado al oyente, asegurándose, de esta manera la inversión publicitaria. El radio teatro o las adaptaciones literarias, se emitían en una entrega con pocos personajes y con una duración de entre sesenta y noventa minutos. Los espacios más populares durante estos años fueron Teatro del aire (SER) y Teatro Invisible (RNE).

Los radioteatros de aquellos años iban dirigidos a una audiencia objetiva muy marcada: clase media alta y público adulto. Las adaptaciones como regla general, dejaban la innovación para el género más popular de todos, la radionovela.

Durante la década de los cincuenta, Radio Madrid emitía unos siete u ocho programas dramáticos al día explotando al máximo los recursos narrativos y publicitarios que les ofrecía el medio. En el año 1969 empezaron a disolverse los principales cuadros de actores y con ello, la búsqueda de otros formatos más rentables para las emisoras, lo que produjo que las emisiones de ficción se fueran espaciando en el tiempo hasta su desaparición.

Con la llegada de la democracia, la información pasa a ser el pilar fundamental de las emisoras de radio. Este modelo, adoptado por las principales emisoras del país, se ha ido consolidando durante tres décadas y parece permanecer inmóvil a pesar de la llegada de las nuevas tecnologías y de que sus "nativos digitales" buscan una nueva radio, más entretenida, con más ficción y con menos carga informativa.

Hoy la ficción es muy escasa y es emitida por la cadena pública, en el caso que nos ocupa Ficción Sonora de RNE. Queremos señalar que también la Cadena SER realizó en el año 2011 una adaptación de la obra de Fernando Fernán Gómez Las bicicletas son para el verano con motivo del 75 aniversario del final de la Guerra Civil Española.

\section{Necesidades y preferencias de los jóvenes españoles}

La radio desde su nacimiento ha sido entretenimiento para toda la familia. Entretenimiento que empezaba con los programas infantiles, y seguía con series de humor y aventura para los adolescentes. La 
revolución llegará con las radiofórmulas y la FM en la que los más jóvenes se sentían identificados, de esta forma se iniciaba el hábito y gusto por escuchar la radio, se creaban oyentes para el futuro.

En la actualidad y según los estudios "Preferencia juvenil en nuevos formatos de televisión. Tendencias de consumo en jóvenes de 14 a 25 años" y "La radio de los jóvenes del siglo XXI" del Observatorio del Ocio y el Entretenimiento Digital (Ocendi) llevados a cabo entre los años 2011 y 2013, los jóvenes españoles consideran Internet como su medio favorito, un 43,3\% de los encuestados, el 12,5\% la televisión y el $11,4 \%$ la radio. Para ellos la radio es entretenida, barata, portátil y ubicua, pero reclaman cambios ya que consideran que existe una crisis de creatividad en la actualidad.

En la actualidad, la información llena las parrillas radiofónicas y deja poco o nada de espacio a la ficción. El 29\% de los participantes en este estudio consideraron que existía demasiada información política en las cadenas generalistas, además un 16\% considera que los temas son aburridos, que el ritmo es rápido $(16 \%)$ y que existen demasiadas noticias (14\%). Del mismo modo, no se sienten identificados con estas informaciones $(17,3 \%)$ ya que creen que van siempre dirigidas al público adulto $(8,5 \%)$.

Los programas de entretenimiento se les presentan como la mejor opción de escucha en la radio generalista, así lo piensa en el 18,8 \% y reclaman nuevas ideas y renovación de la radio actual $(34,7 \%)$, del mismo modo, consideran que la radio se ha quedado estancada en la información olvidándose de dos de sus funciones claves: el entretenimiento y la formación ya que el 23,25 \% reclama más programas culturales y educativos.

Los nuevos contenidos con una mayor variedad de géneros son lo que reflejan el 46,76\% de los encuestados. Así mismo, consideran que debería existir más ficción en la parrilla radiofónica, al 27,1 \% le gustaría que hubiese más seriales divertidos.

Con la aparición de Internet los hábitos y consumo de la sociedad han cambiado y las nuevas generaciones, nativas ya, tienen una nueva concepción de lo que los medios les deben ofrecer para adaptarse a sus necesidades, son usuarios participativos y activos. La radio, a 
pesar de las posibilidades que ofrece la red, no se ha adaptado aún, no hay demasiada interacción en sus páginas web, ya que normalmente sirven como alojamiento para los programas ya emitidos por la radio convencional. Los contenidos que se albergan en las páginas de las diferentes emisoras de nuestro país son el reflejo de la radio convencional en la que la información en el pilar fundamental.

Cada vez son más los oyentes que consumen radio en Internet, a pesar de que siguen principalmente escuchándola de la manera tradicional (se mantiene en cuando a criterios de audiencia casi inmóvil). Según el Estudio General de Medios de 2014, la radio temática es la más escuchada con 14.808 .000 de oyentes frente a la generalista con 11.544.000 de oyentes. Dentro de la radio temática las más escuchadas fueron las dedicadas a la música. El 50,68\% de los encuestados está motivado por la oferta musical de las emisoras y el $33,4 \%$ por la información de actualidad. Tan solo el 6,64\% busca algo divertido. (López y Gómez, 2013)

Según la primera oleada del EGM de 2014 la audiencia con más peso en la radio es la que ocupa el segmento de entre 35 y 44 años, mientras que el sector que va de los 14 a los 24 años representa el $12,6 \%$, cabe destacar que no hay datos sobre menores de 14 años ya que en España no existe programación radiofónica infantil. De todos ellos el 20,1\% escuchan la radio a través de Internet, siendo el grupo más activo el compuesto por los jóvenes de entre 25 y 34 años.

\section{La ficción radiofónica en la actualidad}

En la actualidad, los programas ficcionales han sido sustituidos por magacines en los que el humor está basado únicamente en la actualidad. (¡Anda Ya!, Yu: no te pierdas nada de los 40 principales, Levántate y Cárdenas de Europa FM...)

La ficción ha desaparecido casi por completo de la programación de las principales emisoras de nuestro país. Aunque recientemente la Cadena SER (2011) realiza una adaptación radiofónica de Las bicicletas son para el verano de Fernando Fernán Gómez con motivo del 75 aniversario de la Guerra Civil Española, es Radio Nacional de España la que en los últimos años está realizando ficciones de calidad, grabadas en directo por actores profesionales, emitidas por Radio 3 o 
Radio Nacional y posteriormente alojadas en la página de Ficción Sonora en formato podcast, lo que permite que cualquier usuario pueda descargarlas y oírlas donde y cuando quiera.

Afirmamos que son ficciones radiofónicas de calidad basándonos en las palabras de Guarinos:

"Ficción sonora es el relato de RNE, la radionovela de la SER, de la radio convencional subida a las páginas correspondientes de las cadenas, pero de la misma manera también es ficción el audiolibro, los audiopuzzles, los audiorrelatos hablados de terror, o los podcats que leen a una sola voz capítulos de Crepúsculo o Harry Potter. Todos ellos son tan ficción, tan sonoros y tan online como los anteriores, pero no son radiofónicos, del mismo modo que los anteriores, los de la SER, los de RNE y Onda Cero son radio online únicamente porque se usa Internet como vehículo de transmisión, no como medio original pensado para una transmisión de comunicación.” (Guarinos, 2011: 198)

\subsection{Primeros resultados del análisis comparativo}

Basándonos en la clasificación que establece Merayo podemos dividir los géneros ficcionales en tres grupos: Géneros de monólogo en los que incluye el cuento, el relato radiofónico y la radionovela. Como característica principal y de unión de estos géneros está el narrador que articula la historia. En segundo lugar, tenemos los géneros de diálogo formados por el Sketch, la representación y el radioteatro, en este caso tienen en común la ausencia de narrador; y por último los géneros mixtos en los que se engloban la adaptación literaria y la representación.

Analizando las diferentes características de los distintos géneros nos encontramos con que las obras analizadas pertenecen al género mixto ya que tienen un narrador que no interviene demasiado y utilizan técnicas de los géneros de diálogo. Así mismo, y aludiendo a las características apuntadas por Rodero (10/10/2014), Barea, Montalvillo (1992) y Egil Törnqvist (1991) podemos afirmar que se trata de adaptaciones literarias/cinematográficas en su mayoría, ya que tienen una duración máxima de una hora y media, las transiciones y divisiones de las escenas van marcadas por la música, tienen un 
número de personajes reducido y se prescinde de secundarios para no confundir al oyente, los personajes que están en escena tienen que hablar para que el oyente sepa que siguen presentes, las acotaciones las realiza el narrador o los personajes.

\subsection{Estudio de caso: Ficción Sonora de Radio Nacional de España}

"La ficción en la radio convencional ha venido sufriendo en las tres últimas décadas del siglo XX una importante transformación. De la edad dorada de las radio novelas, teatros y relatos radiofónicos se ha pasado a las apariciones de nuevos formatos, no constituyentes de programas, salvo excepciones (Radio 3, de RNE, por ejemplo, ha apostado siempre por el programa de ficción), sino como parte de programas superiores bien como personajes sueltos, como pequeñas dramatizaciones o microrrelatos." (Guarinos, 1999: 189)

Para el presente trabajo nos vamos a basar en las obras realizadas por el equipo de Radio Nacional, excluyendo aquellas pertenecientes a concursos y centrándonos en las que conforman los géneros más representativos de las ficciones realizadas: El exorcista, La vida de Brian, La isla del tesoro y El perro del hortelano.

A pesar de que la variedad de géneros es evidente (terror, comedia, aventura y obras de teatro clásicas), la proporción en la que aparecen es claramente superada por aquellas obras que tienen como hilo conductor el género de terror, representando un 50\% del total. El resto representan un 16,6\% cada uno. Creemos que el género de terror es uno de los idóneos para realizar ficciones en el medio radiofónico ya que la atmósfera creada por los efectos de sonido y la música genera en el oyente sensaciones, deja volar su imaginación y le hace vivir la historia de una manera muy real.

\subsection{Adaptaciones literarias. Análisis y características}

Hasta el momento (2014) la tónica es la del guion adaptado a las peculiaridades del medio, no la de la creación original. Alfonso Latorre es el encargado de la mayoría de los guiones analizados, imprimiendo uniformidad en cuanto al formato, estructura y carácter de las ficciones. Las obras realizadas son conocidas por el público, podemos decir que se trata de obras que el oyente generalmente 
conoce por lo que se juega con éste reclamo y con el éxito cosechado anteriormente en otros formatos.

Van dirigidas a un público adulto, entre 25 y 54 años (columna vertebral de la radio generalista en España según el EGM). Nos resulta imposible en estos momentos medir el perfil exacto del oyente de los podcast de Radio Nacional, pero podemos afirmar que el público infantil y juvenil no está representado en sus contenidos. Cabe destacar que en momento de la realización de este trabajo (octubre 2014) la página web de Ficción sonora anunciaba la grabación de la obra de Juan Ramón Jiménez Platero y yo dedicada al público infantil.

Centrándonos en la estructura del relato sigue una esquema clásico basado en planteamiento, nudo y desenlace y en la mayoría de las ocasiones van precedidas de una introducción que sitúa al oyente en el tiempo y el espacio. La cabecera aparece tras esta introducción y está formada por música que acompaña el nombre de la obra y su autor original. Es breve y marca a través de la música el tono y el género al que pertenece.

Como hemos dicho anteriormente y atendiendo a las características de las adaptaciones literarias a la radio, las ficciones analizadas no superan los noventa minutos de duración. Se hace necesaria, por tanto, una labor de síntesis de situaciones y diálogos sin perder la esencia del relato original.

El narrador aparece en tres de las cuatro historias analizadas se trata de un narrador ajeno a la historia, observador que narra en tiempo presente y que aporta datos y acotaciones esenciales para que el oyente se sitúe en la escena. Sus intervenciones son muy breves anunciando fechas, horas y lugares.

En La vida de Brian, por ejemplo, el narrador es el propio Brian, el personaje principal de la historia que presenta de primera mano los hechos acaecidos, pero sin caer en el monólogo o en el relato.

El número de personajes que aparecen en la ficción no excede de los dieciséis entre principales y secundarios. Son fácilmente reconocibles por su voz y acciones. En muchas ocasiones nos encontramos con personajes estereotipados lo que ayuda al oyente a seguir la historia. 
En las ficciones de Radio Nacional nos encontramos con un cuadro de actores permanente que participa en todas las obras formado por: Antonio de la Torre, Juan Megías, Juan Suárez, Lourdes Guerras, Carolina Alba, Rodrigo Martín, Miguel Valiente, Julia Fernández, Pedro Muñoz, Javier Gallego, Nacho Hevia, Amaya Prieto, Teresa Vilas, Javier Segade y Fernando Huesca. También cuentan con la participación de otros actores procedentes del teatro o la televisión que participan esporádicamente para dar vida a alguno de los personajes principales de las obras. Así nos encontramos con las voces de Álex Angulo, Pepe Viyuela, Elena Rivera, Miguel Rellán, Fran Perea, Nancho Novo, Lluvia Rojo o Juan Ribó, entre otros.

Las transiciones entre escenas generalmente están marcadas por la música, del mismo modo, la voz del narrador y los efectos de sonido también funcionan como transición entre las distintas escenas y partes de la ficción. Los efectos de sonido y la música juegan un papel fundamental en los relatos ya que no sólo tienen una función cronotópica mediante la cual el oyente se sitúa en un lugar o en una época determinada, sino que realiza una función narrativa que imprime el tono de la historia narrada.

Como venimos diciendo, nos encontramos ante adaptaciones literarias/cinematográficas pues los paralelismos entre ambas se manifiestan no sólo en la estructura, los diálogos o los personajes sino también en la música empleada para la versión radiofónica. Nos encontramos con que las melodías utilizadas son las que previamente han formado parte de las bandas sonoras de las películas (El Exorcista y La vida de Brian). En ambas podemos reconocer los temas principales utilizados en la versión llevada al cine: Tubular Bells de Mike Oldfield en El exorcista o El lado bueno de vivir de los Monty Pyton, en La vida de Brian. Creemos que esto juega un papel importante a la hora de conectar con el oyente que ya conoce estas melodías y hace que lo que se le narra le resulte familiar. En el caso de La isla del tesoro nos encontramos con música con referencias al género de aventura, alegre y dinámica en la que la canción de La botella de Ron de John Silver no puede faltar. 


\section{$5.4 \mathrm{El}$ radioteatro}

Hemos dejado para el final el análisis de la comedia de Lope de Vega El perro del Hortelano, una historia de amor y enredos en el palacio de la condesa Diana. La obra original fue escrita para ser representada en verso con lo que el lenguaje utilizado es el propio del momento de su escritura. Se trata, en definitiva, de radioteatro, pieza que Guarinos define como un:

"Relato ficcional contenido en un único discurso con marcas de principio y final donde bajo el predominio del showing $\mathrm{o}$ mostración, los personajes por sí solos, por sus diálogos y sus actuaciones exponen la situación y hacen avanzar la acción hasta la resolución de los conflictos, ayudados por la técnica del montaje y el poder de otros radiosemas diferentes de la palabra -silencio, efectos y música-, así como por las diversas posibilidades técnicas de diversificación espacial para marcar diversos planos especiales, diversas intensidades expresivas, diversos momento dramáticos o diversos tiempos." (Guarinos, 1999: 32)

Comprobamos que no existe un narrador que sitúe al oyente en la obra, son los propios personajes los que le van a guiar. Evidentemente existe una adaptación para la radio ya que se trata de una obra escrita originalmente para ser representada, pero ésta conserva el formato y las características de la obra original, salvando las acotaciones mediante música, efectos de sonido y los diálogos de los personajes.

\section{Conclusiones}

La radio, y los medios de comunicación en general, siempre han estado relacionados con tres funciones: informar, formar y entretener. En el caso de la radio la primera de ellas está elevada al máximo exponente en las cadenas generalistas, quienes dedican la mayor parte de su programación a la información, dirigida principalmente a un público adulto y centrada en temas políticos. La segunda función está menos representada, pero podemos encontrar reportajes divulgativos sobre temas científicos, literarios, etc. Aunque la función más olvidada es la del entretenimiento que queda relegada a las cadenas 
temáticas (musicales y deportivas) y a los programas de humor centrados en la actualidad. Esta es la radiografía del panorama radiofónico actual, que a pesar de los avances tecnológicos y las posibilidades que ofrece Internet continúa anclado en antiguos modelos que le han proporcionado audiencia durante los últimos treinta años, pero que hoy se encuentran obsoletos debido a que las nuevas generaciones reclaman un cambio en las parrillas radiofónicas: buscan en ella entretenimiento y ficciones que son aún muy escasas.

Las ficciones radiofónicas de calidad las encontramos en Radio Nacional, albergadas en la web de Ficción Sonora y que recoge en formato podcast adaptaciones literarias/cinematográficas desde el año 2010. Aún son escasas en número, doce en total, lo que creemos que no satisface la demanda de ficción planteada por los jóvenes. Del mismo modo, consideramos que las ficciones van dirigidas a un público adulto entre 25 y 54 años, obviando, como ya se hace en el resto de las emisoras al resto de la población. Por tanto, podemos decir que a pesar de que se está realizando ficción de muy buena calidad, con actores profesionales y con periodicidad, no satisface las necesidades de los más jóvenes que no se ven reflejados en la radio actual. Como ya hemos dicho, al término de este artículo, Radio Nacional anunciaba la ficción sonora Platero y Yo de Juan Ramón Jiménez dirigida al público infantil, lo que nos hace pensar en que en el futuro quizá se abra a nuevos públicos y nuevos formatos.

En las ficciones recogidas en la página de Ficción Sonora nos encontramos con que el género que predomina es el de terror ya que creemos que son historias atrayentes y fácilmente adaptables al medio radiofónico. Las representaciones de otros géneros se dan en menor medida aunque creemos que en el futuro irán introduciéndose más representaciones de otros géneros.

A pesar de las posibilidades que las nuevas tecnologías ofrecen al mundo de la radio, los formatos y la manera de realizar ficción es heredera de la que vivió su época dorada en la España de posguerra. Ha cambiado, pero sólo en la forma de realizar el trabajo (medios digitales de grabación, efectos sonoros, podcast...); conserva la esencia de sus predecesores a pesar de que los jóvenes, reclaman más originalidad y géneros nuevos. 



\section{¿Cómo medir la intermetodología? Creación del Cuestionario de Impacto Intermetodológico ${ }^{12}$}

Elisa Hergueta Covacho (UNED and University of Applied

Sciences, Krems, Austria)

http://orcid.org/0000-0002-6230-5403

https://scholar.google.com/citations?user=LWpljUIAAAAJ\&hl=en

\section{Introducción}

T A SOCIEDAD del conocimiento plantea nuevos retos Leducomu-nicativos. Las profundas transformaciones en la creación, gestión y distribución de la información exigen adoptar nuevos modelos comunicativos, alfabetizadores y pedagógicos. La Red se ha convertido en el nuevo escenario en donde los discentes empiezan a desarrollar nuevos procesos en los que se integran como agentes activos, EMIRECs de la sociedad digital, con unas necesidades determinadas en su manera de enfrentarse a la adquisición del saber.

Tribe afirma que "Internet es especialmente propicio para permitir nuevos tipos de producción en colaboración, distribución

\footnotetext{
$12 *$ Este trabajo forma parte de la investigación realizada por el Grupo de Investigación en Comunicación e Información Digital (GICID) del Gobierno de Aragón, con subvención del Fondo Social Europeo.
} 
democrática y experiencia participativa" y "son medios que están libres, al menos hasta cierto punto, de las restricciones tradicionales" (citado por Manovich, 2005: 14). Inmersos en estos escenarios comunicativos y también de narración digital creativa, innovadora y experimental necesitamos nuevos paradigmas discursivos en los que comunicarnos, escribir, expresarnos, organizar y distribuir la información y el conocimiento rompiendo con la linealidad analógica. La conectividad entre nodos y enlaces, el desarrollo de nuevas aplicaciones y herramientas, el uso de plataformas hipermediales, dan lugar a nuevos recorridos narrativos que permiten que los usuarios pasen de ser audiencias pasivas a que participen activamente y se conviertan en co-creadores del conocimiento.

En estos contextos de convergencia mediática, los parámetros de la educación formal son obsoletos en cuanto que hablamos de educación en entornos presenciales, semipresenciales y virtuales. Es necesario plantearse nuevos retos culturales, sociales y educativos que fluyan a favor de introducir nuevas formas de enfrentarse a la creación, a la gestión y a la distribución de los contenidos. La educación actual se ve inmersa en este nuevo escenario sin acabar de encontrar su lugar como mediadora. Necesita adaptarse a este nuevo contexto y desprenderse de su legado tradicional para enfrentarse al reto de cambiar el modelo comunicativo de modo que también pueda cambiar el modelo educativo, de una educación transmisiva, vertical, central y unidireccional, a una educación comunicativa, horizontal, descentralizada, multidireccional e interactiva.

La educomunicación, como elemento que engloba la educación y la comunicación en entornos digitales, no puede olvidar este hecho, de modo que es necesario plantearnos cómo transformarla para posicionarnos, profesores y discentes, dentro del compromiso con la propia realidad social, para analizarla, de manera crítica y ayudar a transformarla y mejorarla.

\section{Intermetodología 2.0}

El concepto de Intermetodología (Marta Lazo y Gabelas Barroso, 2013), desde el punto de vista teórico, es bastante reciente y nace de la creciente necesidad de pasar de la teoría a la práctica educomunicativa y plantearse las implicaciones pedagógicas inherentes a una educación 
para el siglo XXI con el objetivo de potenciar el Factor Relacional en la educación.

Estas prácticas educomunicativas generan relaciones de diversa índole entre los protagonistas del aprendizaje y ayudan a crear y mantener comunidades de aprendizaje y práctica basadas en:

- la colaboración entre nodos

- el intercambio de información

- la conexión e interconexión entre los discentes, la comunidad y el ciberespacio

- la flexibilidad inherente a la ubicuidad y los entornos virtuales

- la diversidad de los discentes, sus mentes, emociones y empatías

- los diferentes procesos de aprendizaje.

Como afirman Marta Lazo y Gabelas Barroso: "La convergencia entre diferentes opciones metodológicas, con el uso de diferentes técnicas activas que permitan el desarrollo participativo de adquisición de competencias de todo tipo, no sólo cognitivas, es lo que bautizamos como intermetodología. El factor relacional en este proceso deriva de la confluencia, intercambio y transferencia de diferentes tipos de actividad o método. La interrelación que se produce entre unas técnicas y otras permite una práctica rica y globalizadora de actividades diversas, sumativas y ampliadoras del propio proceso en el que se dan cita las dimensiones competenciales de análisis-síntesis-reflexión-acción, las cuales se retoman y recuperan una y otra vez, de manera alterna, dependiendo del tipo de técnica que en cada caso se programa y propone al alumnado o que surge del mismo."

Para nosotros ese carácter implica diseñar actividades metodológicas y permitir alcanzar un objetivo concreto y común entre los discentes que comunican, colaboran y negocian para alcanzar una meta común. De modo que generar relaciones, unir nodos, fomentar la aparición de nuevos rizomas y mantener intercambios está en la base de todo el proceso intermetodológico. 


\subsection{El Factor Relacional como eje intermetodológico}

Tratamos de reflejar la importancia del Factor relacional como revisión del discurso TIC en la comunicación y en la educación. Como afirma Aparici "no solo se trata del soporte utilizado en las aulas, sino de las metodologías pedagógicas y estrategias comunicativas que se llevan a cabo en los escenarios educativos formales vinculados a concepciones heredadas de los modelos transmisivos reproductores" (2013: 104).

En este contexto estamos obligados a explicar el fenómeno de la comunicación, y por lo tanto de la educación, desde una nueva perspectiva. Las TIC pasan a denominarse TRIC $^{13}$ (tecnologías + relación + información + comunicación), término que revisa, supera y desmitifica lo meramente tecnológico y cobra particular relevancia en la educomunicación mediática que considera al discente holísticamente como un ecosistema inmerso en entornos sociales y comunicativos horizontales. Educomunicación para alfabetizarse mediáticamente y dialogar con los medios interactuando. Factor Relacional ${ }^{4}$ que engloba a los discentes en sus varias dimensiones para construir un conocimiento común en relación y conexión y desde una reflexión encaminada a la acción que posibilite la confluencia de mentes, empatías, sentidos, sentimientos, procesos y discursos.

Estos procesos no son tecnológicos. La comunicación en la educación existe para entablar "conversaciones", relacionarse entre discentes y con los medios de comunicación, dialogar. En este proceso comunicativo el Factor Relacional (Gabelas, Marta, Hergueta: 2013) en las redes sociales es piedra angular, de manera interpersonal, usando diferentes formatos narrativos (palabras escritas, orales, imágenes, sonidos, videos, gestos,...) a través de los que transmitir sus emociones, sus pensamientos, sus sentimientos, de manera presencial o virtual, cerca o lejos, sincrónica o asincrónicamente.

Virtualmente nos movemos en entornos conversacionales ubicuos que van más allá del espacio/tiempo físico presencial pero que también los incluye. Un entorno vertebrado por lo relacional que trasciende los círculos exógenos del discente (individual, social y

\footnotetext{
${ }^{13}$ http://educarencomunicacion.com/triclab/portfolio/el-baile-de-las-tric/

${ }^{14}$ http://educarencomunicacion.com/triclab/services/historicos-2/
} 
ambiental) y endógenos (cognitivo, afectivo y social) porque produce un lugar permeable y fluido, en el que los procesos de exploración y conocimiento son corales y holísticos. Observamos la necesidad de generar relaciones entre varios niveles, enlazando los diversos ecosistemas conectados que se mueven y conviven en estos escenarios. La red interior (mente, cuerpo, emociones) de cada individuo sumergida en sus conexiones sinápticas conversa, así, con otros individuos de la Sociedad Red (Castells, 2000) en el ciberespacio.

Se hace necesarias prácticas que permitan alcanzar un objetivo concreto entre los interactuantes que comunican, colaboran, negocian para alcanzar una meta común, de modo que generar y mantener relaciones, unir e incrementar los nodos, fomentar la aparición de nuevos rizomas y mantener intercambios e interconexiones en colaboración está en la base de todo el proceso.

\section{Educación 2.0. Elaboración del cuestionario}

La asignatura Educación 2.0, impartida por Roberto Aparici y Elisa Hergueta en el segundo bloque de asignaturas de la segunda edición del Máster en Redes Sociales y Aprendizaje Digital ${ }^{15}$ de la UNED en 2013,.se construyó para implementar y llevar a cabo una educación 2.0 para el siglo XXI, por ello las dinámicas intermetodológicas educomunicativas se estructuraron alrededor de los mismos principios pedagógicos y comunicativos que la propia asignatura ofrecía como contenidos "teóricos". La filosofía era aprovechar el potencial que el entorno tecnológico nos brindaba para generar una metodología pedagógica acompañada de estrategias comunicativas en un entorno de aprendizaje de educación superior que nos permitiese superar la formalidad tradicionalmente imperante en dichos entornos. Como indica Aparici (2013) es necesario basar la educación para el siglo XXI en modelos basados en la participación, la colaboración y la interacción para superar las aulas reproductivas basadas en la competitividad y la división de tareas imperantes en la educación actual.

${ }^{15}$ http://www.masterredesuned.com/ 
Para promover este modelo se crearon prácticas y dinámicas "intermetodológicas" basadas en la complejidad, en el principio de incertidumbre y la teoría del caos que potenciasen un aprendizaje interconectado para establecer y desarrollar las relaciones endógenas y exógenas entre los participantes, discentes y docentes, y los medios, de modo que fueran ellos los protagonistas y gestores de su propio aprendizaje, desarrollado en autonomía. Esto implicaba centrarse en la elaboración personal de los contenidos por parte del alumnado para que fuesen co-autores y co-constructores y los encargados de producir el currículo de la asignatura en un proceso que pretendía desarrollar su análisis crítico y, por lo tanto, su empoderamiento.

La experiencia, como constatan los propios docentes, fue muy positiva y el grupo llegó a formar una comunidad virtual, al interno de la que se desarrollaron otras "microculturas" en el trabajo colaborativo en grupos. Se creó una comunidad de aprendizaje basada en las relaciones que autogestionó su participación y autonomía en una comunicación basada en EMIRECs (Cloutier, 1975) tanto en las dinámicas individuales como grupales.

Siguiendo la filosofía propia de la asignatura y el master uno de los objetivos como docentes era facilitar al alumnado convertirse en coautor y constructor de los contenidos de esta materia junto con el equipo docente. Se determinaron unos contenidos fundamentales propios de la asignatura y englobados en la temática general y paralelamente se promovió el desarrollo de contenidos particulares y concretos en interrelación con el alumnado que se fijaron dependiendo de sus necesidades. Los docentes adoptamos el papel de guías y facilitadores de este proceso.

\subsection{Dinámicas intermetodológicas}

Como ya hemos indicado anteriormente, el programa educativo de la asignatura está basado en los criterios que sustentan una educación 2.0 y pretendíamos potenciar el papel protagonista del propio discente. Tanto los docentes como el propio alumnado aportaron propuestas de conceptos teóricos basados en un modelo de comunicación en el que todos aprendemos de todos con el objetivo de promover la creación de una comunidad de aprendizaje basada en "emirecs" que interacciona y conecta a través de actividades prácticas 
tanto individuales como grupales para el desarrollo de esos contenidos de manera colaborativa. De modo que fue importante la implicación y participación dialógica de los discentes en las actividades comunes de la asignatura así como a través de las herramientas comunicativas de la plataforma educativa o las redes sociales.

Seguimos un modelo de autogestión de la propia participación y de autonomía en la búsqueda y producción de contenidos en base a las necesidades individuales y de la comunidad y se llevaron a cabo debates de reflexión crítica y actividades prácticas. Un aspecto importante fue el desarrollo de proyectos digitales aplicando los conocimientos adquiridos.

La orientación en la planificación general de las prácticas se fundó en permitir a los educandos seguir un proceso de reflexión-acciónreflexión durante toda la asignatura y que, en medida de lo posible, quedase integrado durante cada una de las dinámicas. Cada práctica se presentaba después del chat académico semanal, que se centraba en lanzar diferentes ideas e impulsos de manera no lineal, sin seguir un esquema listado de los contenidos. La filosofía era despertar la curiosidad de los discentes y permitirles retomar y desarrollar posteriormente los contenidos en base a sus intereses y necesidades. La propuesta abierta y flexible podía atender a las diferentes necesidades de aprendizaje de los discentes para que ellos se pudiesen centrar en los temas de más interés personal sin obviar la adecuación al grupo y a los compañeros.

Nuestra posición en la puesta en marcha estaba encaminada a promover la acción del alumnado. Se propuso una comunicación y educación horizontal en la que todos aportasen sus perspectivas al proceso de aprendizaje y que los resultados se generasen a partir de dicha acción conjunta, cambiando así el rol del docente transmisor al de mediador.

En el campo de la metodología nos centramos en una enseñanza y un aprendizaje holístico centrados en los estudiantes, en los entornos virtuales y en las relaciones que se crean entre cada uno de los nodos que participan en la comunicación educativa. 


\subsection{Elaboración del cuestionario}

Para comprender qué aspectos de las prácticas y las dinámicas llevadas a cabo incidieron en mayor medida en el aprendizaje y en el desarrollo de las competencias mediáticas del alumnado y si este modelo puede ser extrapolable, y bajo qué condiciones, a otros entornos de aprendizaje, era necesario analizar y evaluar el impacto de las prácticas intermetodológicas en el aprendizaje y la construcción de conocimiento del grupo de discentes desde el punto de vista de la comunicación digital y de la educación virtual.

Para ello enfocamos el cuestionario planteándonos una pregunta: ¿Cómo medimos el impacto? Queríamos recoger información sobre la incidencia en el alumnado, por ello decidimos que las opiniones fácticas de los discentes acerca de sus propios comportamientos desde una perspectiva emic era la forma idónea de aproximarnos a la visión que tienen ellos de su propia conducta durante el aprendizaje. Optamos por registrar si un determinado comportamiento o influencia se llevó a cabo sin profundizar en las motivaciones. Somos conscientes de que tal declaración puede estar mediada por opiniones subjetivas, sin embargo nos interesaba centrarnos en los propios discentes como protagonistas del proceso de aprendizaje.

Se intentó delimitar las actitudes y creencias de los discentes respecto a su propio comportamiento durante la asignatura, las particularidades de cada práctica y las incidencias de estas en determinados aspectos de su aprendizaje con objeto de hacer una evaluación cuantitativa de los procedimientos de enseñanza/aprendizaje y del proceso de adquisición de conocimientos y competencias asociados a las relaciones endógenas y exógenas (individuo, entorno social, medios) creadas en estos procesos.

Se decidió que las respuestas fueran anónimas para facilitar la participación y garantizar la confidencialidad de las respuestas. Se marcó también al alumnado la ausencia de respuestas o valoraciones correctas o erróneas y la importancia de contestar con sinceridad y desde su punto de vista personal.

El contenido del cuestionario se estructura en tres partes o bloques temáticos. 


\section{Parte 1}

Nos centramos en recopilar información general sobre la propia visión de los discentes acerca de sus comportamientos relacionados con la actividad a lo largo de la asignatura. Partimos de la idea de que la participación es fundamental para que las relaciones al interno de la comunidad de aprendizaje se creen, se afiancen y que indicen directamente en la construcción del conocimiento. El propósito es recopilar información relativa al grado de implicación del alumnado. Por ello las preguntas se refieren a los siguientes aspectos:

- Grado de participación activa en la búsqueda en redes de información.

- Grado de colaboración interpersonal

- Grado de distribución de información

- Grado de análisis crítico de los materiales compartidos

- Grado de intercambio de reflexiones

- Grado de contribución a la organización del grupo

Las preguntas pretenden cubrir el amplio espectro en el que es posible crear y desarrollar relaciones (endógenas y exógenas) básicas de tres tipos:

- Relaciones sinápticas: análisis y reflexión.

- Relaciones nodales: colaboración y organización.

- Relaciones mediales: búsqueda en redes y distribución

\section{Tabla 1. Parte 1: banco de reactivos}

\section{Durante el desarrollo de la asignatura}

1. ¿Has participado activamente en la búsqueda de información?

2. ¿Has colaborado con tus compañeros?

3. ¿Has compartido enlaces e información con tus compañeros?

4. ¿Has analizado los materiales de manera crítica?

5. ¿Has aportado tus reflexiones a tus compañeros durante las discusiones?

6. ¿Has contribuido de manera significativa a la organización del grupo?

Las preguntas cerradas formuladas son de valoración numérica con una escala en la que podían calificar del 1 al 10, siendo el 10 el que 
representaba el valor más alto y positivo y 1 el más bajo y negativo. A continuación se muestran los resultados de la parte 1.

\section{Parte 2}

Damos respuesta a los principales indicadores que definen una tarea intermetodológica refiriéndonos a la incidencia de esta en el proceso de aprendizaje del discente. Para promover una educación innovadora en la que las sinopsis sean la base, las prácticas intermetodológicas deben cumplir unas características mínimas, de modo que cada una de las que enumeramos intenta cubrir una necesidad del aprendizaje.

\section{Tabla 2. Parte 2: banco de reactivos}

Marca tu impresión sobre cada una de las prácticas. Selecciona todos los que correspondan.

1. Clara

2. Colaborativa

3. Colectiva

4. Creativa

5. Supone un desafío

6. Estimulante

7. Facilitadora

8. Centrada en tu proceso

9. Metacognitiva

10. Motivadora

11. Multidireccional

12. Multimedia

13. Multisensorial

14. Transvergente

Nos parece utópico considerar que una dinámica pueda cubrir todas las necesidades del discente en un momento puntual del aprendizaje ya que este se desarrolla a lo largo de un cierto periodo de tiempo. Sin embargo sí queremos destacar que mayor es el número de características que cumple, más relacional será y más posibilitadora de permitir un aprendizaje más completo. En este caso se trata de preguntas cerradas en las que elegir más de una opción: 


\section{Parte 3}

Al igual que en la segunda parte del cuestionario, consideramos que las dinámicas también deben facilitar el desarrollo de un alto espectro de competencias mediáticas y habilidades necesarias para alcanzar el propio empoderamiento educativo. Nuevamente partimos de un núcleo de aspectos que abarcan el Factor Relacional aplicado a la educomunicación en las aulas sin perder de vista el dominio de conocimientos, destrezas y actitudes relacionadas con las ya citadas competencias (Ferrés y Piscitelli, 2012).

\section{Tabla 3. Parte 3: banco de reactivos}

\section{Valora las habilidades que te ha permitido desarrollar cada práctica.}

1. Selección de contenidos en red

2. Análisis de contenidos

3. Comprensión de los contenidos

4. Clasificación de conceptos

5. Personalización de los contenidos

6. Construcción crítica de contenidos

7. Desarrollo de productos multimedia

8. Exploración del ciberespacio

9. Construcción de tu identidad digital

10. Implementación de procedimientos de investigación

11. Creación de ideas

12. Autonomía

13. Pensamiento crítico

14. Reflexión crítica

15. Retroalimentación

16. Libertad de gestión

17. Toma de decisiones

18. Colaboración con el grupo

19. Construcción de relaciones externas

20. Interacción con los compañeros

21. Interacción con los medios

Se les pide a los discentes que estimen cuantitativamente si cada una de las dinámicas les ha permitido adquirir diferentes habilidades directamente vinculadas con su participación e interacción con los medios, la información, las ideas y con otros interactuantes en el proceso de aprendizaje, haciendo énfasis en el incremento de su aptitud analítica y expresiva. 
Las valoraciones numéricas se desarrollan con una escala en la que podían calificar las habilidades en cada práctica del 1 al 10, siendo el 10 el que representaba el valor más alto y positivo y 1 el más bajo y negativo.

\subsection{Aplicación del cuestionario. Resultados}

El siguiente paso fue la aplicación del cuestionario. Constatamos que las prácticas intermetodológicas 2.0 que han servido de dinámicas posibilitan que el alumnado adquiera en general competencias mediáticas fundamentales para promover su aprendizaje a través de su empoderamiento. Los resultados ${ }^{16}$ de las encuestas muestran que la experiencia ha sido estimada por el alumnado como muy positiva ya que las valoraciones medias otorgadas, sea a su propia actividad como a las dinámicas y las habilidades desarrolladas han alcanzado calificaciones altas y demuestran que desde su punto de vista se produjeron procesos beneficiosos para su aprendizaje.

La intermetodología trabajada en esta asignatura les sirvió para potenciar las competencias mediáticas fundamentales necesarias para la construcción de la inteligencia colectiva y les ha ayudado a ser participativos a la hora de crear conocimiento. Asimismo se observa que los procesos sociales horizontales, la colaboración y la interacción han contribuido a aumentar la interacción con los medios hasta permitirles crear nuevos productos multimedia.

A nivel comunicativo podemos concluir que el alumnado ha tenido altas posibilidades de consumir mensajes y contenidos relacionados con la temática gracias a la colaboración entre los compañeros y a la búsqueda, selección y difusión de información. Estas interacciones con los medios por una parte, y con los compañeros por otra, ha posibilitado el desarrollo de su competencia mediática. Verificamos que al potenciar la dimensión participativa de la comunicación, se ha

\footnotetext{
${ }^{16}$ Los resultados y gráficos pueden consultarse en: Hergueta Covacho, E. (2014): Intermetodología 2.0. Prácticas relacionales en la Educación Superior. En Actas del VI Congreso Internacional Latina de Comunicación Social "La democracia no es un editorial. Patrones neoliberales en los medios de comunicación”. Tenerife, Universidad de La Laguna. http://www.revistalatinacs.org/14SLCS/2014 actas/046 Hergueta.pdf
} 
influido de manera muy positiva en las relaciones creadas con los medios y con los pares y que este hecho ha mediado de manera muy positiva en el aprendizaje. Esta participación ha promovido las relaciones tanto endógenas como exógenas de los diferentes actores del proceso y, gracias a las valoraciones de los estudiantes, queda demostrado que la creación y mantenimiento de relaciones sinápticas (análisis y reflexión), relaciones nodales (colaboración y organización) y relaciones mediáticas (búsqueda en redes y distribución) ha tenido un papel esencial en la adquisición de competencias mediáticas y, en consecuencia, al empoderamiento activo del alumnado.

Consideramos que el cuestionario ha dado respuesta a las hipótesis planteadas al inicio de la investigación que se han corroborado en el análisis de las respuestas de los discentes:

- El alumnado ha sido capaz de superar la incertidumbre inherente a la interacción con los medios y de buscar estrategias para desarrollar su pensamiento crítico y la resolución de problemas.

- Las prácticas han estimulado la autonomía y el autoaprendizaje hasta llevar a los estudiantes a la elaboración personal de los contenidos y a ser coautores y co-constructores de información

- Se ha generado conocimiento gracias al alto porcentaje de interacción de cualquier tipo.

- La creatividad, socialización, emociones y en general el desarrollo de habilidades sociales gracias al trabajo en grupo han incidido positivamente en el aprendizaje.

- Estos aspectos relacionales y colaborativos han confluido juntos para facilitar la construcción de conocimiento de manera activa y crítica basado en intereses comunes y la creación de productos multimedia.

\section{Conclusiones}

El objeto del cuestionario empleado era evaluar el impacto de las prácticas intermetodológicas empleadas en los procesos de enseñanza y aprendizaje durante la asignatura. Sin embargo debemos tomar los resultados obtenidos con cierta precaución, ya que la selección de la 
muestra es muy limitada y no es representativa, de modo que sirve como una suerte de "base" desde la que partir para estudios posteriores.

Aunque la información obtenida ha sido relevante y ha contribuido a los objetivos planteados, consideramos necesario hacer una validación por parte de expertos que nos proporcione una visión global del cuestionario, así como ratificar, modificar o sustituir cada uno de los ítems planteados en base a su relevancia y su adecuación a los destinatarios. Los comentarios de los expertos pueden confirmar la validez, o bien, aportar información sobre los motivos de la invalidez y propuestas de mejora para elaborar un nuevo cuestionario.

\section{Bibliografia}

Aguaded, J.I. (2011): “La educación mediática, un movimiento internacional imparable. La ONU, Europa y España apuestan por la educomunicación", en Comunicar, Revista Científica de Comunicación y Educación, N³7.

Aguaded, J.I. y Contreras, P. (2011) (Coords.): La radio universitaria como servicio público para una ciudadanía democrática. A Coruña: Netbiblo.

Aguaded, J.I. y Martín-Pena, D. (2013): “Educomunicación y radios universitarias: panorama internacional y perspectivas futuras", en Revista Latinoamericana de Comunicación Chasqui, 124.

Álvarez, J. (2009): "Perfil del periodista del siglo XXI", en el Blog Nuevos escenarios de la comunicación.

Andretta, S. (2009): "Transliteracy: take a walk on the Wild Side", in the World Library and Information Congress: 75th IFLA General Conference and Council.

Aparici, R. (2013): Educomunicación digital. En VV. AA., Educación, Medios y Cultura de la Participación (Coord., D. Aranda, A. Creus, J. Sánchez Navarro). Barcelona: Editorial UOC.

Araya, C. (2009): "Radio Estudiantil: programas, audiencias y desafíos", en Rev. Reflexiones, 88. 
Arnheim, R. (1980): Estética radiofónica. Barcelona: Gustavo Gili Asuaga, C. (2007): “Gestión de las radios universitarias: definiendo la estrategia”, en Revista RE-Presentaciones, 3.

Azócar, A. (2011): "Diez lecciones sin certeza en la formación de periodistas", en diario El País; recuperado el 2 de abril de 2013.

Bacher, S. (2009): Tatuados por los medios. Buenos Aires. Paidós.

Balandrón, A. (2010): La docencia en Comunicación en el EEES ante los perfiles profesionales emergentes: el caso de los community managers. En Sierra, J. \& Cabezuelo, F. (Coord.). Competencias y perfiles profesionales en los estudios de Ciencias de la Comunicación. Madrid: Fragua.

Balsebre, A. (2002): Historia de la radio en España. Volumen 2, 19391985. Madrid: Cátedra.

Barea, P. (2000): Teatro de los sonidos, sonidos del teatro: teatro-radio-teatro, ida y vuelta. Bilbao: Servicio Editorial de la Universidad del País Vasco.

Bernaola, I., Adrover, M. y Sánchez-Chiquito, J.M. (2011): Programas informativos y de opinión en televisión. Madrid: Síntesis.

Berrocal, S., Campos, E. y Redondo, M. (2014): "Prosumidores mediáticos en la Comunicación política: el «politainment»en YouTube", en Comunicar 43, Vol. 22.

Bustamante Martínez, E. (2011): La enseñanza de la comunicación en América Latina. En: M. López, C. Gutiérrez y C. Camacho. ¿Qué enseñamos las escuelas de comunicación? IV Encuentro Docente. Vocalia V alle de México. CONEICC-Universidad del Claustro de Sor Juana. México.

Cabezuelo Lorenzo, F. y Pérez Serrano, M.J. (2009): "Desafíos en la formación de los periodistas en el nuevo Espacio Europeo de Educación Superior: aspectos éticos y deontológicos", en Temas de Comunicación, no 19 (Venezuela).

Casero Ripollés, A. y Cullel-March, C. (2013): "Periodismo emprendedor. Estrategias para incentivar el autoempleo periodístico como modelo de negocio", en Estudios sobre el Mensaje Periodístico. Vol. 19. 
Castelazo, A. (2014): "Entrevista personal realizada al coordinador de CEM Radio. ITESM campus estado de México. EEES:

Presentación", en Revista Icono 14, no 14.

Castells, M. (2008): La Era de la Información. La Sociedad Red. Vol.1. Madrid: Alianza Editorial.

Ceballos, J. J.; Lemrini, M.; Mateos, R.M.; Vázquez, M. A.; Barrero, J. y Sánchez, J. (2010): "UEMCOM Radio: Refuerzo de competencias mediante streaming y podcasting", en Docencia Universitaria, 8.

Contreras, P. (2012): La voz de los presos en la radio universitaria: puentes con la ciudadanía. La experiencia de UniRadio, Universidad de Huelva. En C. Espino y D. Martín (Coords.) Las radios universitarias, más alla de la radio. Las TIC como recursos de interacción radiofónica. Barcelona: UOC.

Contreras, P.; González-Mairena, M. y Aguaded, J.I. (2014):

"Programar una radio social en la universidad: el Propósito Penélope de UniRadio", en EDMETIC, Revista de Educación Mediática y TIC, 3(1)

Delgado, E. (2012): "Cómo se cocinan los rankings universitarios", en Dendra Médica. Revista de Humanidades. 11(1).

Desztich, R. y McClung, S. (2007): "Why music gets added to college radio playlist", in the Journal of Radio y Audio Media, Victoria, v. 14, n.

2.

Díaz, J. (2002): La Escritura Digital: Hipertexto y Construcción Del Discurso Informativo en el Periodismo Electrónico. Gipuzkoa: U. P. V.

Díaz, L. (1998). Dias de radio. Recuerdos y semblanza de los protagonistas del dial. Temas de Hoy, Madrid.

Diezhandino, P; Aguado, G.; Carrera P.; Fernández, J.; Martín, O. y Muro, I. (2012): El periodista en la encrucijada. Madrid: Fundación Telefónica, Editorial Ariel.

Espino, C. y Martín-Pena, D. (2012): Las radios universitarias, más allá de la radio. Las TIC como recursos de interacción radiofónica. Barcelona.

Editorial UOC. 
Esteban, C. (2012): Las nuevas profesiones del Periodismo. En Cerezo, J. El futuro del periodismo. Madrid: Cuadernos Evoca Comunicación e Imagen.

Farias Batlle, P. (2011): Informe anual de la profesión periodística 2011. Madrid: Asociación de la Prensa de Madrid.

Fernádez-Sande, M. y Peinado-Miguel, F. (2012): La empresa radiofónica actual. En, Gallego, J.I. \& García Leiva, T. (coord.) Sintonizando el futuro: radio y producción sonora en el siglo XXI. Madrid: IRTVE.

Ferrés, J. y Piscitelli, A. (2012): "La competencia mediática: propuesta articulada de dimensiones e indicadores”, en Revista Comunicar, $\mathrm{n}^{\circ} 38$.

Fidalgo Díez, D. (2009): "Las radios universitarias en España: Transformación al mundo digital”, en Telos n 80 .

Font-Mayolas, F. y Masferrer, L. (2010): “Conocimientos y actitudes de estudiantes universitarios respecto al Espacio Europeo de Educación Superior", en Formación e Innovación Educativa Universitaria. Vol. 3, no 2 .

Frau-Meigs, D. (2012): "Transliteracy as the new research horizon for media and information literacy", in Media Studies, 3 (6).

Fuentes, R. (2011): El estudio académico de la comunicación en México: una re-visión sintética actualizada. Lecciones del portal. Portal de la Comunicación InCom-UAB. http://portalcomunicacio.net/uploads/pdf/33 esp.pdf

Gabelas Barroso, J. A., Marta Lazo, C. y Hergueta Covacho, E. (2013): El Factor R-elacional como epicentro de las prácticas culturales digitales. En VV. AA., Educación, Medios y Cultura de la Participación (Coord., D. Aranda, A. Creus, J. Sánchez Navarro). Barcelona: Editorial UOC.

García González, A.; Troyano, Y.; Curral, L. y Chambel, M.J. (2010): "Aplicación de las herramientas de comunicación de la plataforma webct en la tutorización de los estudiantes universitarios dentro del EEES", en Pixel-bit Revista de medios y educación, $\mathrm{n}^{\circ} 37$. 
Gómez Rubio, L. y López Vidales, N. (2014): La dieta mediática de los jóvenes españoles. Nuevos hábitos y tendencias de consumo en radio y televisión. En, Caldevilla, D. (Coord.) Parámetros actuales de evaluación para la comunicación persuasiva. Madrid: Visión Libros.

Gómez-Puertas, L.; Roca-Cuberes, C. y Guerrero-Solé, F. (2014): “Cómo perciben los estudiantes la adquisición de competencias? Análisis comparado: Teorías de la Comunicación en la Universidad Pompeu Fabra", en Historia y Comunicación Social. Vol. 19.

Guallar, J. y Leiva-Aguilera, J. (2013): El Content Curator. Barcelona. Editorial UOC.

Guarinos, V. (2009). Manual de narrativa radiofónica. Síntesis, Madrid Gutiérrez, Ma ; Ribes, X. y Monclús, B. (2011): "La audiencia juvenil y el acceso a la radio musical de antena convencional a través de internet", en Comunicación y Sociedad, Vol. XXIV, no 2. Pamplona: UNAV.

Guzmán Gómez, C. (2011): “Avances y retos en el conocimiento sobre los estudiantes mexicanos de educación superior en la primera década del siglo XXI", en Perfiles educativos, 33.

Hermida, A. y Thurman, N. (2008): "A clash of cultures: The integration of user-generated content in the discourse on weblogs", in the Journalism Studies, 6 (3).

Humanes, M. L. y Roses, S. (2014): "Valoración de los estudiantes sobre la enseñanza del Periodismo en España", en Comunicar, nº 42.

Islas, O.; Gutiérrez, F. y Campo-Garrido, N. (2002): “El espejo indiscreto por el accidentado sendero de la comunicación productiva", en Razón y Palabra, no 24.

Lamuedra, M. (2007): “Estudiantes de Periodismo y prácticas profesionales: el reto del aprendizaje", en Comunicar, $n^{\circ} 28$.

Livingstone, S; Papaioannou, T.; Grancío, M.; Wijmen, C. (2012): "Critical Insights in European Media literacy research and policy". Media Studies, 3 (6)

Livingstone, S; Wijmen, C.; Papaioannou, T.; Costa, C.; Grandío, M.; 
(2014): "Situating Media Literacy in the changing media environment. Critical insights from European research on audiences. In Audience Transformation. Shifting Audience Positions in Late Modernity, New York. Routledge.

López García, X. (2010):"La formación de los periodistas en el siglo XXI en Brasil, España, Portugal y Puerto Rico", en Revista Latina de Comunicación Social, 65.

López García, X. (2001): "Nuevos perfiles de los periodistas en la sociedad de la información", en Ámbitos, No7-8

López Vidales, N. y Gómez Rubio, L. (2014):'Nuevos hábitos de los jóvenes españoles y tendencias de futuro en el consumo de radio y televisión", en Historia y Comunicación Social, no 19

López Vidales, N y Gómez Rubio, L. (2014): "La democratización del modelo comunicativo en radio: Los jóvenes prosumidores", en Revista de Comunicación Vivat Academia, 126.

López Vidales, N. y Ortiz Sobrino, M. A. (2011): Radio 3.0 Una nueva radio para una nueva era. La democratización de los contenidos. Fragua, Madrid

Lorente, J. I. (2010): La formación de comunicadores en el EEES. Hacia una meta-competencia comunicativa. En Sierra, J. \&

Cabezuelo, F. (Coord.): Competencias y perfiles profesionales en los estudios de Ciencias de la Comunicación, Madrid: Fragua

Magaña López, S. (2003): El modelo de radio universitaria en Estados Unidos de Norteamérica: el caso de KTCU. Tesis de Licenciatura Ciencias de la Comunicación. Universidad de las América, Puebla (México).

Manovich, L. (2005): El lenguaje de los nuevos medios de comunicación. La imagen en la era digital. ( $3^{\mathrm{a}}$ ed.). Barcelona: Paidós.

Marhuenda Fluixá, F.; Bernad i García, J. C. y Navas Saurin, A. (2010): "Las prácticas en empresa como estrategia de enseñanza e inserción laboral: las empresas de inserción social”, en Revista de Educación 
Marta Lazo, C. y Vadillo Bengoa, N (coord.) (2013): Evaluación de la implantación del EEES en los estudios de Comunicación, La Laguna:

Cuadernos Artesanos de Latina (34).

Marta Lazo, C. y Grandío, M. (2013):“Análisis de la competencia audiovisual de la ciudadanía española en la dimensión de recepción y audiencia", en Comunicación y Sociedad, Vol. 26, n. 2.

Marta Lazo, C. y Martín-Pena, D. (2014): “Antecedentes, estado de la cuestión y prospectiva de las radios universitarias" en, Revista de Educación Mediática y TIC (EDMETIC), 3(1)

Marta Lazo, C. y Segura, A. (2012): Emisoras universitarias españolas en la Web 3.0: programación y contenidos. En C. Espino y D. Martín (Coords.), Las radios universitarias, más allá de la radio. Las TIC como recursos de interacción radiofónica. Barcelona: UOC

Marta Lazo, C. y Gabelas Barroso, J.A. (2013): “Intermetodología educomunicativa y aprendizaje para la vida", en Comein Revista de los estudios de Ciencias de la Información y Comunicación, 22.

Martí, Josep M. (1990): Modelos de programación radiofónica. Barcelona: Feed-back.

Martínez-Costa, M. P. y Díez Unzueta, J.R. (2005). Lenguaje, géneros y programas de radio. Introducción a la narrativa radiofónica. Pamplona: EUNSA

Martín-Pena, D. \& Aguaded, J.I. (2013). La Asociación de Radios Universitarias como eje dinamizador de intercambios para la divulgación científica. En P. Contreras y M. Parejo (Coords.), Más Ciencia. Cómo trabajar la divulgación cientifica desde las Radios Universitarias. Salamanca: Comunicación Social

Martín-Pena, D. (2013). Las radios universitarias en España: plataformas interactivas y redes de colaboración. Tesis doctoral. Universidad de Huelva. Departamento de Educación.

Masip, P. y Micó, J.L. (2009): "El periodista polivalente en el marco de la convergencia empresarial", en Quaderns del CAC, 31-32

Mellado, C., Simon, J., Barría, S. y Enríquez, J. (2007): “Investigación de perfiles profesionales en periodismo y comunicación para una 
actualización curricular permanente", en revista Zer Revista de Estudios de Comunicación 23.

Merayo, A. (2003).: Para entender la radio. Salamanca: Publicaciones Universidad Pontificia de Salamanca, $3^{\text {a }}$ edición.

Merayo, A. y Pérez, C. (2001): La magia radiofónica de las palabras. Aproximación a la lingüistica en el mensaje de la radio. Salamanca: Cervantes

Meso, K.; Díaz, J.; Larrondo, A.; Salaverría, R.; Sadaba, Mª R. (2010): "Presencia y uso de internet en las redacciones de los diarios vascos y navarros", en Mediatika, 12.

Montoro Sánchez, M. A.; Mora Valentín, E. y Ortiz de Urbina, M. (2012): "Análisis de las competencias adquiridas en los estudios de Dirección de Empresas y su grado de aplicación en las prácticas en empresas", en Revista Complutense de Educación, Vol. 23, n 1.

Moreno, E. (2005): "The "radios" and the models of programming", en Communication \& Society 18(1)

Murciano, M. (2010): "La transformación de los estudios de comunicación en España Nuevo contexto europeo de los estudios universitarios y enseñanzas para favorecer un espacio de cooperación iberoamericano", en Diálogos de la Comunicación, 79.

Murillo, F. M. y Vizuete, J. (2009): “Conocimientos y actitudes de estudiantes universitarios respecto al Espacio Europeo de Educación Superior" en Zer-Revista de Estudios de Comunicación, vol 14, n. 26.

Ortega, F. y Humanes, M. L. (2000): Algo más que periodistas. Sociología de una profesión. Barcelona: Ariel.

Ortiz Sobrino, M. Á. (2012): "Principales señas de identidad de los estudiantes de Comunicación en el EEES de la Comunidad de Madrid en 2012: expectativas, perfil de opción y relaciones mediáticas", en Estudios sobre el mensaje periodístico, vol. 18.

Ortiz Sobrino y Rodríguez-Barba, D. (2011): “El perfil de entrada de los alumnos de grado en las Facultades de Comunicación de las Universidades de Madrid: el caso de la Summer Media School de la fundación FIDES/UFV", en Vivat Academia. 
Ortiz Sobrino, M. A.; Fernández-Sande, M.; Peinado-Miguel, F.; Pérez Serrano, M.J. y Rodríguez-Barba, D. (2011): Perfil de entrada de los alumnos de Comunicación en las Universidades de Madrid, Curso 2010 2011 (Informe técnico), http://eprints.ucm.es/23219/

Ortiz Sobrino, M. A.; Rodríguez-Barba, D. y Pérez Serrano, M. J. (2011): "Perfil de entrada de los futuros alumnos de Comunicación en las universidades de Madrid, en 2010/2012: la reafirmación de los rasgos", en Revista de la SEECI, n 26.

Ortiz, M. A. \& Peña, P. (2010): "Radio Intercontinental -Radio Inter: 60 años de radio", en Revista de Comunicación Vivat Academia. No 113.

Palacios Llanos, L. (2012): Informe Anual de la Profesión Periodística 2012. Madrid: Asociación de la Prensa de Madrid.

Palacios llanos, L. (2013): Informe Anual de la Profesión Periodística 2013. Madrid: Asociación de la Prensa de Madrid.

Paniagua Rojano, FJ.; Gómez Aguilar, M; González Cortés, M. E. (2014): "Incentivar el emprendimiento periodístico desde la Universidad”, en Revista Latina de Comunicación Social, 69.

Parejo, M. y Martín-Pena, D. (2011): OndaCampus Radio: Integradora y formadora. En J.I. Aguaded y P. Contreras (Coords.) La radio universitaria como servicio público para una ciudadanía democrática. A Coruña: Netbiblo

Pedrero Esteban, L. M. (2004):. Las técnicas de programación de la radio temática. En, Martínez-Costa, P y Moreno Moreno, E. (coords.): Programación radiofónica. Arte y técnica del diálogo entre la radio y su audiencia, Ariel, Barcelona: Ariel.

Peinado-Miguel, F. (2011): "Motivación + Innovación + Bolonia = Formación Superior Necesaria", en Anuario de la Comunicación, Madrid, Dircom.

Peinado-Miguel, F. y Fernández-Sande, M. (2011): "Reflexión sobre la motivación de los alumnos de Grado en la elección de estudios de comunicación en las universidades de Madrid", en Estudios Sobre el Mensaje Periodístico, vol. 17, 20. 
Peinado-Miguel, F. y Fernández-Sande, M. (2010): How and Why We Communicate in the EHEA. En Preparing for the Future: Studies in Communication Sciences in the EHEA, Sierra Sanchez, J. (Coord.) Madrid, Editorial Fragua.

Peinado-Miguel, F.; Fernández-Sande, M.; Rodríguez-Barba, D. Y Ortiz Sobrino, M.A. (2013): “Aprendizaje e innovación: una propuesta metodológica desde la Empresa Informativa", en Revista Latina de Comunicación Social n 68.

Peinado Miguel, F.; Marta Lazo, C. y Ortiz Sobrino, M. A. (2015): "Los alumnos de Periodismo de la Universidad de Zaragoza y la Universidad Complutense de Madrid: Impulso vocacional, referencias mediáticas y perspectivas profesionales", en Revista Pangea, 6.

Pérez, J. y Martínez, J. (2011): “Hacia un sistema supranacional de indicadores mediáticos" en Revista Infoamérica, No 5 .

Pérez Serrano, M.J., Marta Lazo, C. y Ortiz Sobrino, M. A. (2014): "Expectativas laborales de los egresados en Comunicación. Análisis de caso de los alumnos de Periodismo de la Universidad de Zaragoza", en Doxa Comunicación.

Pérez Serrano, M. J.; Ortiz Sobrino, M. Á. y Rodríguez-Barba, D. (2013): "Motivaciones para el acceso a los estudios de comunicación en relación a los hábitos de consumo y las referencias mediáticas", en Revista Mediterránea de Comunicación, vol. 4, nº 2.

Pérez Tornero, J. M (2003): Educación en medios: Perspectivas y estrategias. En Aguaded, J.I (Coord). Luces en el laberinto audiovisual. Huelva: Grupo Comunicar.

Piñeiro, M. T. y Ramos, F. (2011): Potencialidades educativas de las webradios universitarias: Una aproximación desde la perspectiva de docentes y discentes. Universidad de A Coruña - CIECID (6)

Rodero E., Vázquez, M. Larrea, O. y Mas, Ll. (2014): "Sonidos que educan entreteniendo. La radio en la educación 2.0" en Rodríguez Terceño, j. (Coord.) Creaciones Audiovisuales Actuales. Madrid. Editorial: ACCI. 
Rodero, E. (2008): “Educar a través de la radio", en Signo y pensamiento 52.

Rodero, E. y Soengas, X. (2010): Ficción Radiofónica. Instituto Radio Televisión Española, Madrid

Rodríguez Gómez, R. (2014):. "Educación superior y transiciones políticas en México", en Revista de la Educación Superior. Vol. XLIII (3); No. 171

Rodríguez, M. I., Herrero, F. J. y Sánchez, F. (2010): Los medios de comunicación en las redes sociales ante el reto de Bolonia. En Sierra, J. \& Cabezuelo, F. (Coord.). (2010): Competencias y perfiles profesionales en los estudios de Ciencias de la Comunicación. Madrid: Fragua.

Rosique, G. (2013): "Los estudios universitarios de periodismo en España: la adaptación al EEES y la formación de periodistas en competencias digitales", en Revista Internacional de Estudios sobre Sistemas Educativos, Vol.1, Núm. 1-2. México: Universidad del Desarrollo Empresarial y Pedagógico.

Sánchez Illán, J. C. (2005): "El perfil profesional del periodista español. Evolución reciente y nuevos desafíos (1990-2005)", en Telos, abril.-junio, $n^{\circ} 63$.

Sánchez, J. y Contreras, P. (2012): "De cara al prosumidor. Producción y consumo empoderando a la ciudadanía 3.0", en Icono 14, 10 (3)

Sierra, J. y Cabezuelo, F. (Coord.) (2010): Competencias y perfiles profesionales en los estudios de Ciencias de la Comunicación. Madrid: Fragua.

Tejada, C. M. (2003): "Perfil, motivaciones y expectativas de los alumnos de primer curso de la escuela de Biblioteconomía y Documentación de la UCM" en Revista General de Información y Documentación, vol. 13, n. 1.

Tejedor, S. (2007): La enseñanza del ciberperiodismo: enseñar y aprender periodismo on-line. En Gómez, B.; Hernández, S. (Eds.): Estudios de Periodística XIII. La Periodística como disciplina universitaria: balance y perspectivas. Pamplona: Universidad de Navarra.

Torregrosa, J.F. (2012): “Un acercamiento didáctico al sonido 
radiofónico. Posibilidades didácticas de la utilización de la radio en las aulas", en Aularia, 2(1)

Vadillo, N.; Marta Lazo, C. y Cabrera, D. H. (2010): "Proceso de adaptación de los estudios de Comunicación al EEES. El caso de Aragón, una comunidad pionera", en Revista Latina de Comunicación Social, n. 65.

Varela, J. (2005): “El asalto de los medios sociales", en Cuadernos de Periodistas (enero de 2005), Asociación de la Prensa de Madrid.

Vázquez Guerrero, M. (2014): Participación estudiantil en la radio universitaria de México: panorama desde las principales instituciones con programas académicos afines a la comunicación. En, Del Valle, M.E. y Padilla, G. Construyendo la nueva enseñanza superior. Madrid. McGraw Hill.

Vázquez, M. (2010). Jóvenes y Radio Universitaria: un cercamiento a las estrategias formativas de dos países. Resultados de la encuesta; La participación juvenil en radiodifusoras universitarias de México y España. II Congreso Internacional de la Asociación Española de Investigadores de la Comunicación (AE-IC), Málaga.

Vázquez, M. (2012): La radio universitaria en México y España. Estudio de la participación y formación de los jóvenes. Tesis doctoral. Universitat Pompeu

Villanueva, G. y Casas, M. (2010): "E-competencias: nuevas habilidades del estudiante en la era de la educación”, en Revista signo y pensamiento $\mathrm{N}^{\circ} 56$.

Williams, R. (1976): Keywords: A Vocabulary of Culture and Society. London: Fontana.

Yuste, B. y Cabrera, M. (2014): Emprender en Periodismo. Nuevas oportunidades para el profesional de la información. Madrid: Editorial UOC. 


\section{Los autores}

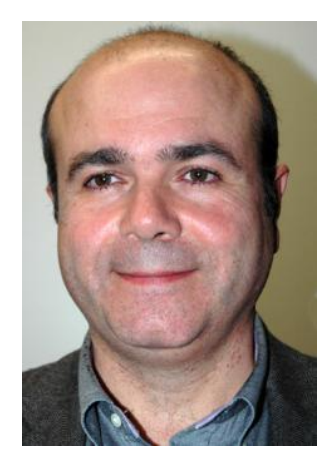

Fernando Peinado-Miguel, Profesor Titular de Universidad y Director del Departamento de Periodismo IV (Empresa Informativa) en la UCM. Imparte docencia en Grado y Posgrado de Periodismo. Investigador Principal del grupo complutense de investigación "Research and Learning of Media and Communications Management" (MediaCom UCM) Ha coordinado los contenidos del proyecto MEDIA Prensa, en el programa de Recursos Educativos en Línea del Ministerio de Educación, Cultura y Deporte.

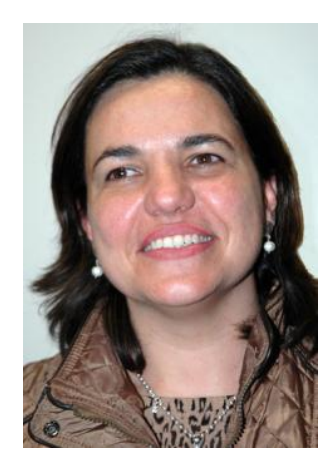

Carmen Marta-Lazo es Profesora Titular de Comunicación Audiovisual y Publicidad y Coordinadora del Grado de Periodismo de la Universidad de Zaragoza. Doctora en Ciencias de la Información por la Universidad Complutense de Madrid. Es Directora de Radio Unizar e Investigadora Principal del Grupo de Investigación en Comunicación e Información Digital (GICID).

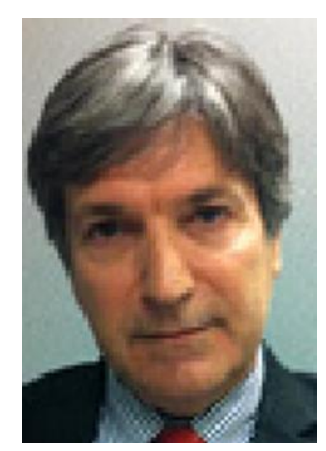

Miguel Ángel Ortiz-Sobrino, Doctor en Ciencias de la Información por la UCM. Licenciado en Periodismo y en Ciencias de la Imagen Visual y Auditiva. Es Máster Oficial en Humanidades por la Universidad Francisco de Vitoria y Diplomado en Investigación de Medios por A.I.M.C. Imparte docencia en el área de Empresa Informativa en la UCM y es Delegado para Medialab/Inforradio de la Facultad de Ciencias de la Información de la misma Universidad. Miembro de MediaCom UCM. Director entre el año 2000 y 2009 del Instituto Oficial de Radio y Televisión. También ha sido director adjunto de Radio Televisión Madrid y jefe de Programas de Onda Madrid. 


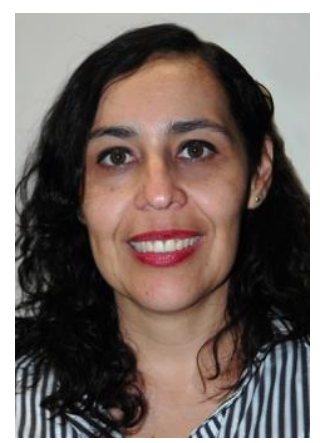

Marina Vázquez-Guerrero es Doctora en Comunicación Pública por la Universitat Pompeu Fabra de Barcelona es actualmente profesora e investigadora de la Escuela Superior de Mercadotecnia y docente del doctorado en Ciencias Sociales de la Universidad de Colima, México. Su tesis doctoral se titula "La radio universitaria en México y España. Estudio de la participación y formación de los jóvenes" y es editora del blog: La radio universitaria. Los múltiples rostros de la radio universitaria iberoamericana disponible en http://radioyuniversidad.wordpress.com/

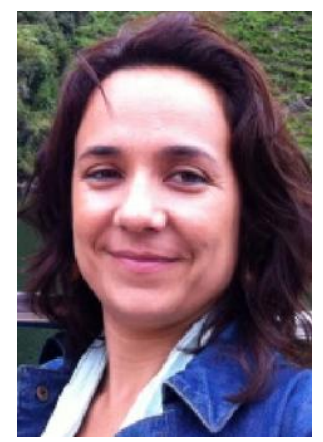

María del Mar Grandío es Profesora en la Facultad de Comunicación y Documentación de la Universidad de Murcia. Autora de "Audiencia, fenómeno fan y ficción televisiva" (2009), co-autora de "Economía de la Participación" (EOI, 2014), "Redes Sociales para estudiantes de Comunicación" (Editorial UOC, 2011) y "Estrategias de comunicación en redes sociales. Usuarios, aplicaciones y contenidos" (Gedisa, 2012). Actualmente es miembro del Comité de Gestión de COST ACTION "New Possibilities for Print Media" (2012-2015). Ha participado en el Proyecto de Investigación financiado por el Ministerio de Ciencia e Innovación "La enseñanza universitaria ante la competencia en comunicación audiovisual en un entorno digital" (2011-2014) y es miembro del equipo español de "The World Hobbit Project" (20142016) financiado por The Bristish Academy.

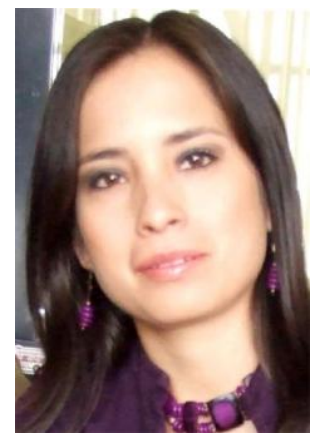

Diana Rivera, Doctora en Comunicación y periodismo por la Universidad Santiago de Compostela, España. Ex Directora del Departamento de Ciencias de la Comunicación de la Universidad Técnica Particular de Loja (UTPL). Actualmente Directora del Área Sociohumanística de la UTPL y coeditora internacional de la revista científica Comunicar. Ha participado en 4 proyectos de investigación 
financiados y es profesora titular de la materia de Medios Impresos en la UTPL. En 2012 fue seleccionada por UNESCO y FELAFACS como profesora para dictar el módulo Periodismo en línea/multimedia para los países de la Región Andina.

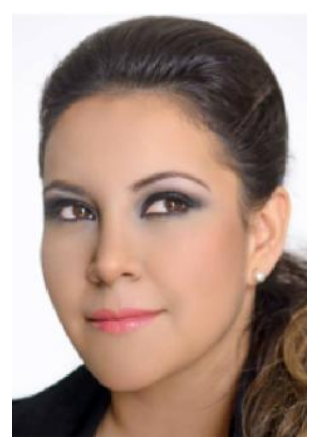

Andrea Velásquez es profesora titular de Marketing y Publicidad de la Universidad Técnica Particular de Loja desde el año 2005. Ingeniera en Marketing por la Universidad Internacional del Ecuador. Magíster en Comunicación e Industrias Creativas por la Universidad de Santiago de Compostela-España. Doctoranda en Comunicación en la Universidad de Santiago de Compostela -España. Fue Directora del Área de Marketing de la Universidad Técnica Particular de Loja, miembro del equipo de calidad de las titulaciones de Relaciones Públicas y Comunicación Social de la Universidad Técnica Particular de LojaEcuador. Actualmente investiga temas relacionados con consumo de Medios, marca digital, recepción y audiencias.

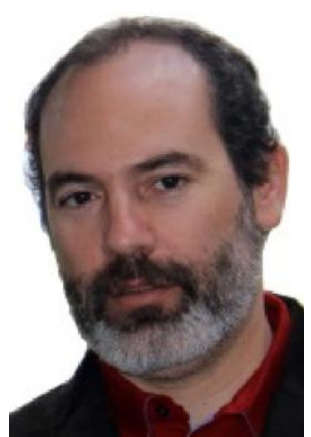

Isidro Marín, profesor Asociado del Departamento de Sociología y Trabajo Social en la Universidad de Huelva (España). Profesor Tutor con Venia Docendi en el Centro Asociado de la UNED de Huelva. Docente investigador del Departamento de Ciencias de la Comunicación de la Universidad Técnica Particular de Loja (UTPL). Es profesor en el Máster Internacional de Comunicación y Educación Audiovisual (UNIA/UHU). Miembro del Consejo Técnico del Grupo Comunicar, colectivo veterano en España en «Media Literacy», y corrector de la revista científica iberoamericana de comunicación y educación «Comunicar». Es colaborador del Grupo de Investigación «Agora» dentro del Plan Andaluz de Investigación (HUM-648) y miembro del Grupo de Investigación E6 (SEJ-216). 


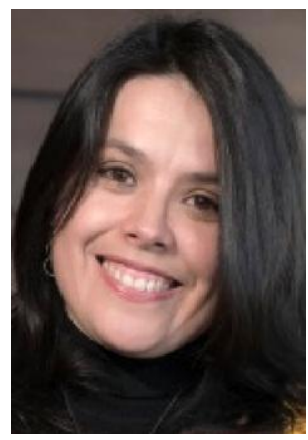

Catalina Mier es Comunicadora Social, Candidata a doctora en la Universidad Santiago de Compostela (España). Actualmente Secretaria General de CIESPAL. Ex Responsable de la Sección Departamental Narrativas Audiovisuales del Departamento de Ciencias de la Comunicación de la Universidad Técnica Particular de Loja (UTPL). Docente titular de la materia de Investigación de proyectos de la Titulación de Relaciones Públicas de la UTPL.

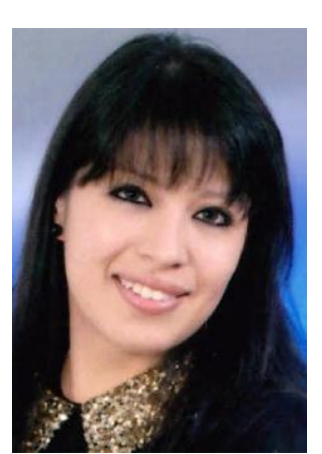

Stephany Celly, egresada de la carrera de Comunicación Social y Becaria de investigación en la Universidad Técnica Particular de Loja. Experiencia en codirección de radiodifusión en Radio Ondas de Esperanza de la ciudad de Loja-Ecuador. Ha realizado pasantías en video, reporterismo y edición; tiene experiencia en relaciones públicas. Además de ha desempeñado como asistente de elaboración de planes empresariales y de comunicación. Co-organizadora del "Taller binacional de diplomacia ciudadana: Migración, comunicación y resolución de conflictos" en la Universidad Técnica Particular de Loja. Ha participado en dos proyectos de investigación: Mapeo de medios de comunicación-Ecuador, 2013. Y Competencias mediáticas Loja, Zamora -Ecuador, 2013-2014. Ponente en el IV Congreso Iberoamericano de Narrativas Audiovisuales 2014, desarrollado en Loja-Ecuador.

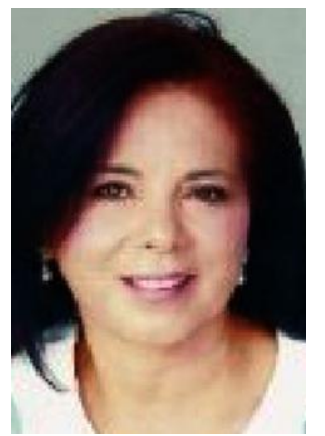

Lelia Fabiola Zapata Palacios, Profesora Asociada en el Departamento Periodismo IV, Empresa Informativa, en la UCM. Doctora en Ciencias de la Información por la Universidad Complutense de Madrid (1994). Egresada del I Máster de Comunicación realizado en España (1991), Técnica en Comunicación y RRPP por la DGM y la Unión Europea (2003) y Formadora Ocupacional por el IFES (2007). Profesora invitada por la Universidad Nacional de Piura (Perú) y la 
Universidad Particular Técnica de Loja (Ecuador). Socia Fundadora de la Agencia de Comunicación Interna Talentos Reunidos.

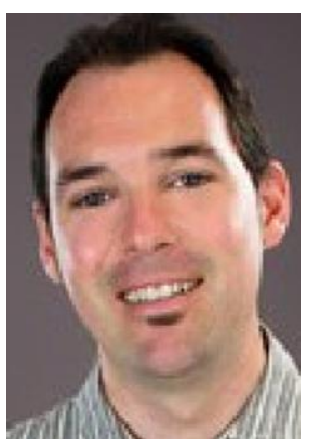

Daniel Martín Pena, Doctor en Educomunicación por la Universidad de Huelva. Máster en Comunicación y Educación Audiovisual por la Universidad de Huelva y Licenciado en Comunicación Audiovisual por la Universidad de Extremadura. Director desde 2004 de OndaCampus, la RadioTv de la Universidad de Extremadura y Personal Científico Investigador de esa misma institución. Miembro del Grupo de Investigación "ARDOPA" de la UEx, en el cual está desarrollando una investigación sobre radios universitarias. Participó en la creación de la Asociación de Radios Universitarias de España, de la que es miembro de la Comisión Gestora desde su creación en 2011, en la categoría de Secretario General. Ha coordinado un número especial de la Revista EdMETIC sobre radios universitarias.

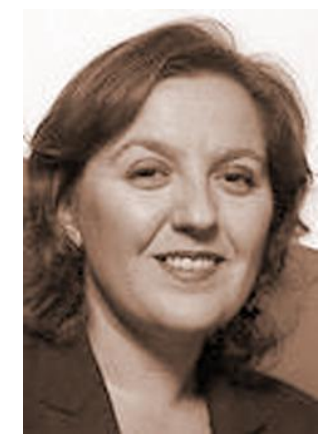

Ana Segura Anaya, Coordinadora de Programas en Aragón Radio, la Radio Autonómica de Aragón y profesora asociada en el Grado de Periodismo de la Universidad de Zaragoza. Licenciada en Ciencias de la Información y Diplomada en Comunicación e Información por la Universidad Pontificia de Salamanca y Master en Radio por la Universidad Complutense de Madrid y RNE, ha desarrollado su carrera profesional en las grandes cadenas de radio nacionales españolas (RNE, SER y COPE), hasta que el 2005 de incorporó al equipo fundacional de la Radio Autonómica de Aragón, como coordinadora de programas. Es también coordinadora de contenidos en radio.unizar.es, la radio on line de la Universidad de Zaragoza. Entre sus líneas de investigación destacan los contenidos digitales y la radio como medio educativo. 


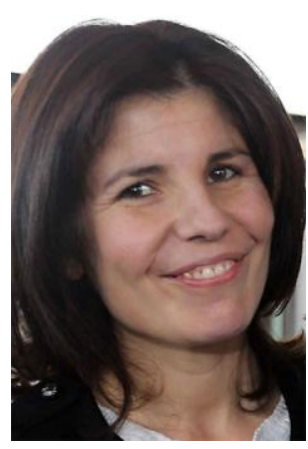

Pilar Sánchez-García, Doctora por la Universidad de Valladolid. Licenciada en Ciencias de la Información por la Universidad Pontificia de Salamanca. Actualmente es profesora en la Universidad de Valladolid y miembro del Grupo de Investigación Reconocido Nuevas Tendencias en Comunicación (NUTECO). Sus líneas de investigación actuales se centran, principalmente, en el análisis de la formación de los periodistas en el entorno multimedia con especial atención a los efectos del EEES en los Grados de Periodismo, así como de los nuevos perfiles profesionales y retos formativos ante la actual convergencia comunicativa. Ha impartido docencia en la Universidad europea Miguel de Cervantes y ha ejercido el Periodismo durante 15 años.

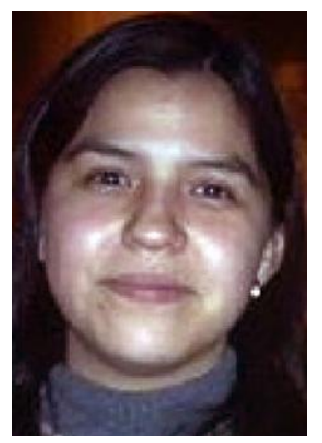

Laura Lizeth Campos Guido, profesora y Coordinadora de Informática y Sistemas en la Facultad de Ciencias de la Comunicación de la Universidad Autónoma de Nuevo León, en Monterrey, México. Imparte docencia en Formación de Emprendedores, Mercadotécnia y Comercio Internacional. Doctora por la UCM, ha trabajado para diferentes empresas como CYSMA, BBVA y Wanadoo España entre otras y ha dado clases de Bachillerato en Unitec.

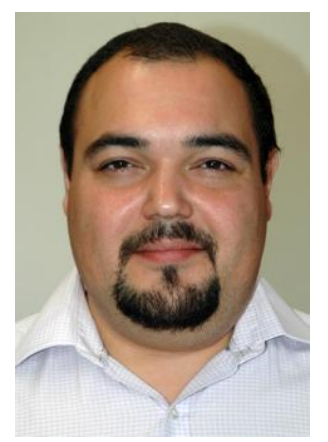

Juan Antonio Garza Sánchez, profesor en la Facultad de Ciencias de la Comunicación de la Universidad Autónoma de Nuevo León, en Monterrey, México. Imparte docencia en Comunicación Masiva, Teorías de la Comunicación y Cultura de Masas, Formación de Emprendedores, entre otras. Secretario Técnico de la Dirección de la Facultad de Ciencias de la Comunicación de la UANL, 2011 a 2014. Coordinador de Relaciones Internacionales en la Facultad de Ciencias de la Comunicación de la UANL. Organizador General del XVI Encuentro Nacional CONEICC 2013 en el marco 
del 80 Aniversario de la UANL. Ha trabajado en TV, organizado eventos, promotor de productos. Responsable de Educación en el Municipio de Guadalupe y productor en Televisa Radio.

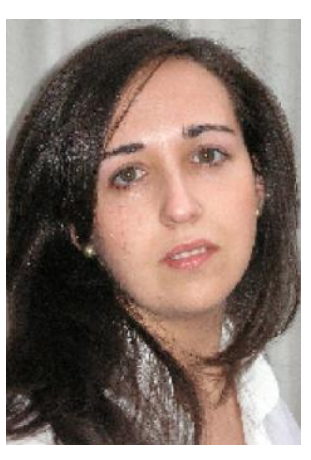

María José Pérez-Serrano, Profesora en Periodismo IV, Empresa Informativa, en la UCM. Licenciada en Periodismo, doctora en Ciencias de la Información por la UCM. Miembro del grupo de investigación MediaCom UCM. Su trayectoria y producción científica se vincula al estudio de la Empresa Informativa $y$, específicamente, a la concentración de medios de comunicación y su influencia en el pluralismo. Entre sus publicaciones destacan el libro La concentración de medios en España. Análisis de casos relevantes en radio prensa y televisión, así como artículos de investigación en revistas nacionales e internacionales, tales como Estudios del Mensaje Periodístico y Global Media Journal, capítulos y comunicaciones en los ámbitos científicos antes citados.

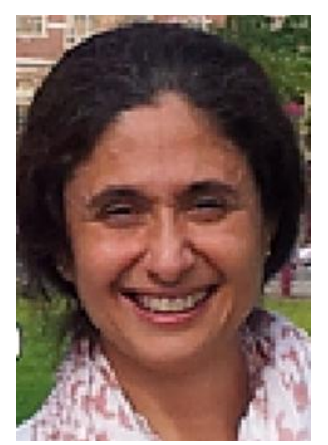

María Dolores Rodríguez-Barba, Profesora en Periodismo IV, Empresa Informativa, en la UCM. Licenciada en Comunicación Audiovisual, doctora en Ciencias de la Información por la UCM. Miembro del grupo de investigación MediaCom UCM. Especializada en Dirección de Empresas de Comunicación. Ha publicado en revistas de impacto como El Profesional de la Información, Revista Latina de Comunicación Social o Icono 14; Dirigido varias tesis doctorales sobre al desempeño profesional con enfoques sobre la perspectiva de género, las situaciones de crisis o la gestión de contenidos en radio. Ha participado en diferentes publicaciones: Radio 3.0, una nueva radio para una nueva era; Guia de Publicaciones gratuitas en Madrid; el Informe Anual de la Profesión Periodística; o La Radio y la Televisión en la Europa digital. Profesionalmente, ha trabajado en TVE y en diferentes cadenas radiofónicas ejerciendo labores de programación y dirección técnica. 


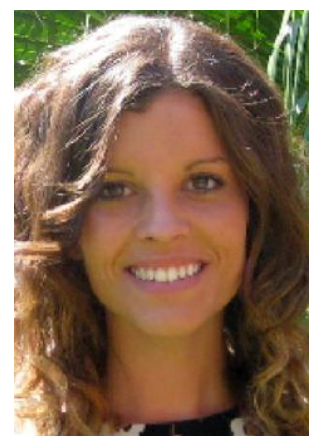

Miriam Rodríguez Pallarés, Doctora en Periodismo por la Universidad Complutense de Madrid, Máster en Periodismo por la UCM y Diplomada en Biblioteconomía y Documentación por la USAL. Miembro del grupo de investigación MediaCom UCM y, desde 2010, Colaboradora Honorífica del Departamento de Periodismo IV, Empresa Informativa (UCM). Actualmente, su producción científica se desarrolla en el ámbito de la gestión de activos intangibles (contenidos y conocimiento) en el entorno de los medios de comunicación de masas, además, está involucrada en proyectos de investigación vinculados al estudio del contexto metodológico, didáctico y profesional en el campo de las Ciencias de la Comunicación. Ha publicado en revistas de impacto como El Profesional de la Información y Revista Latina de Comunicación Social.

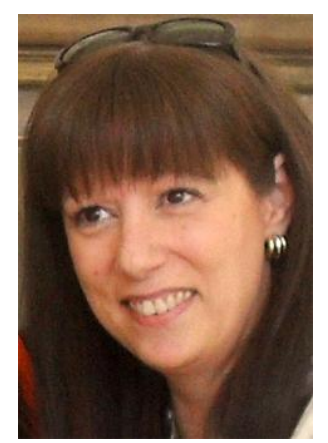

Nereida López Vidales. Profesora Titular del Grado en Periodismo de la Universidad de Valladolid con dos tramos de investigación reconocidos por la CNEAI. Licenciada en Periodismo, Doctora en Ciencias Políticas y Sociología por la UPV y Magister en Producción Radiofónica. Desde 1997 compagina el periodismo profesional con la docencia universitaria. Ha publicado diversos artículos científicos y diez libros. Sus líneas de investigación académica se centran en la tecnología de los medios audiovisuales, la evolución de los perfiles profesionales, las tendencias de consumo mediático, la cultura digital y la creación de nuevos contenidos de entretenimiento para el ocio digital. Directora y fundadora del Observatorio del ocio y el entretenimiento digital (Ocendi). 


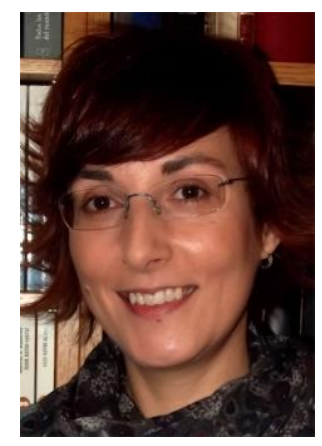

Leire Gómez Rubio. Profesora del Grado en Periodismo y del Máster en Investigación de la Comunicación como Agente Histórico-Social en la Universidad de Valladolid. Licenciada en Periodismo y en Publicidad y Relaciones Públicas por la UPV/EHU, durante varios años ha trabajado en prensa escrita, televisión y gabinetes de comunicación. Sus líneas de investigación se centran especialmente en contenidos, formatos y audiencias en radio y televisión, así como en nuevas tendencias en consumo audiovisual y medios de comunicación locales. Es autora de varios artículos científicos y coautora del libro Radio Informativa. Guía didáctica de iniciación al medio.

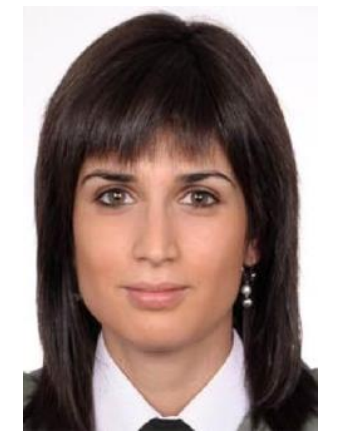

Marta Hernando Lera, Licenciada en Periodismo y Máster en Investigación de la comunicación como Agente Histórico-Social por la Universidad de Valladolid. En este momento, realiza su tesis doctoral sobre la ficción radiofónica en España en la actualidad dirigida por la profesora Nereida López Vidales.

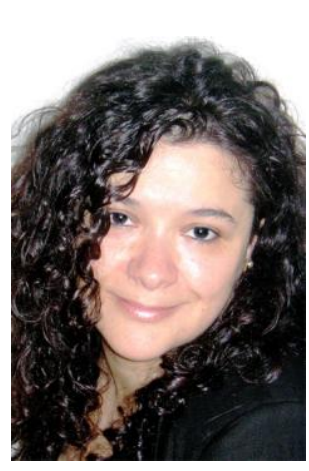

Elisa Hergueta Covacho, Docente de español en la University of Applied Sciences, en Krems, Austria, además de profesora colaboradora del Master Redes Sociales y Aprendizaje Digital de la UNED. Doctoranda en el programa Comunicación y Educación en Entornos Virtuales de la UNED. Colaboradora del Ministerio de Educación de Austria como formadora de profesores en temas de didáctica. Participante como ponente en congresos y simposium relacionados con la educación mediática, la educomunicación y las nuevas tecnologías en el aula. Miembro del Grupo de Investigación en Comunicación e Información Digital (GICID). 